Aus der Klinik für Allgemein-, Viszeral- und Kinderchirurgie

(Prof. Dr. med. M. Ghadimi)

der Medizinischen Fakultät der Universität Göttingen

\title{
Die Rolle von CBP bei der Strahlenresistenzentwicklung im kolorektalen Karzinom
}

\author{
INAUGURAL - DISSERTATION \\ zur Erlangung des Doktorgrades \\ der Medizinischen Fakultät der \\ Georg-August-Universität zu Göttingen
}

vorgelegt von

Cornelius Franz Menze

aus

Lindau (Bodensee)

Göttingen 2019 
Dekan:

Referent/in:

Ko-Referent/in:

Drittreferent/in:
Prof. Dr. rer. nat. H. K. Kroemer

Prof. Dr. med. M. Ghadimi

Prof. Dr. med. B. Chapuy

Prof. Dr. med. M. Dobbelstein

Datum der mündlichen Prüfung: 15.08.2019 
Hiermit erkläre ich, die Dissertation mit dem Titel „Die Rolle von CBP bei der Strahlenresistenzentwicklung im kolorektalen Karzinom" eigenständig angefertigt und keine anderen als die von mir angegebenen Quellen und Hilfsmittel verwendet zu haben.

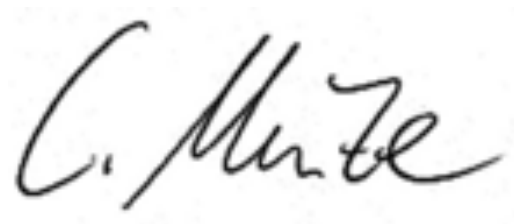

Göttigen, den 29.08.2018 


\section{Inhaltsverzeichnis}

I. Abkürzungsverzeichnis..............................................IV

II. Abbildungsverzeichnis............................................. VI

III. Tabellenverzeichnis...................................................

$1 \quad$ Einleitung und Fragestellung ........................................................ 1

1.1 Klinische Bedeutung des kolorektalen Karzinoms .................................. 1

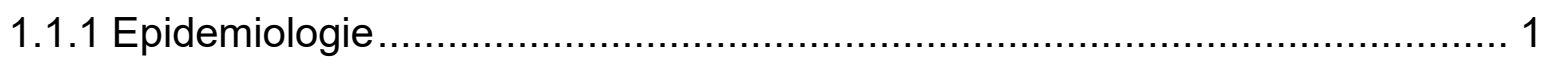

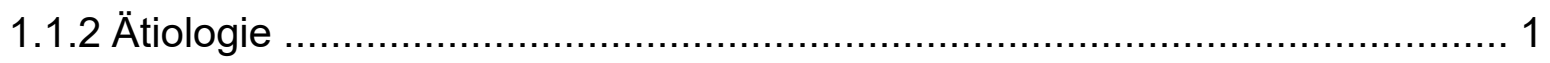

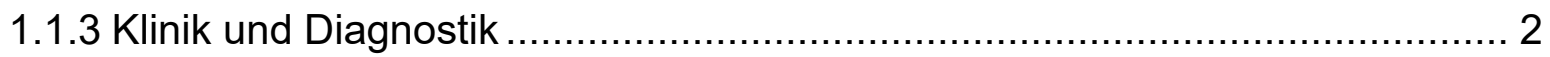

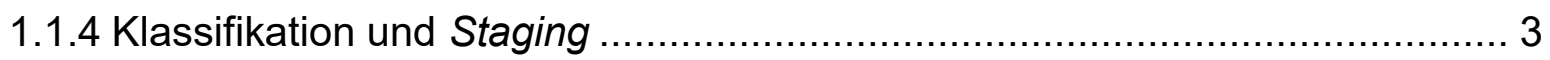

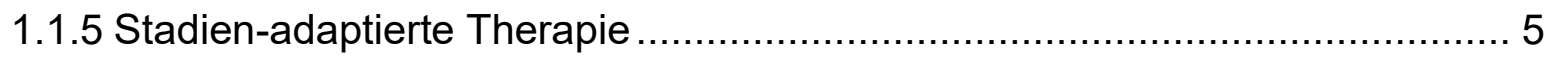

1.2 Molekularbiologie des kolorektalen Karzinoms .................................... 6

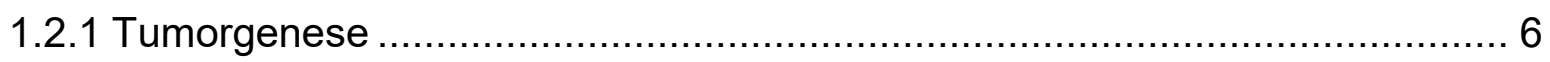

1.2.2 Posttranslationale Modifikationen von Histonen ........................................ 9

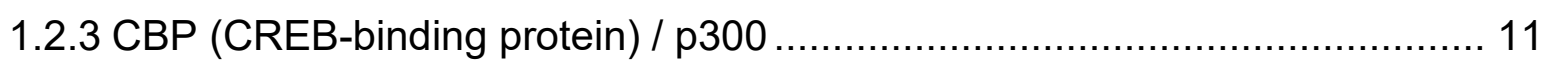

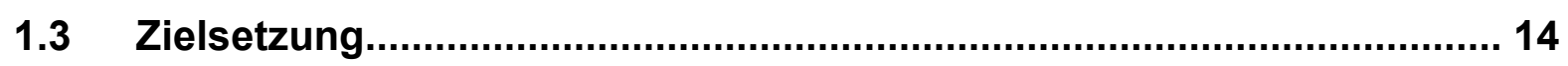

2 Methoden und Patientenkollektiv ................................................ 15

2.1 Immunhistochemische Methoden ....................................................... 15

2.1.1 Herstellen von Paraffinschnitten ........................................................ 15

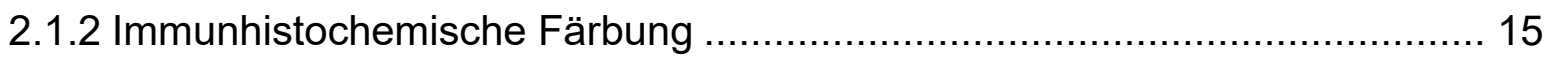

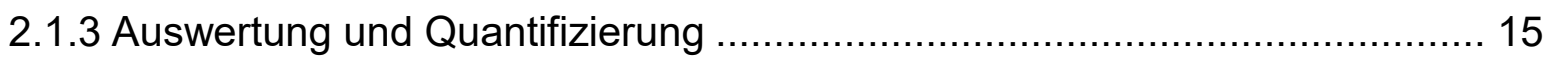

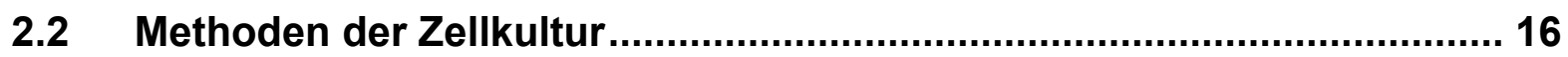

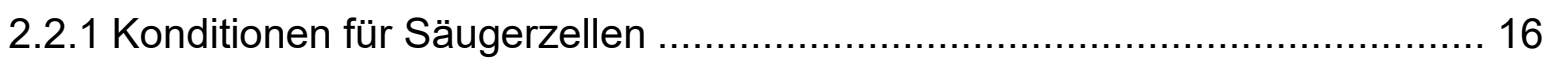

2.2.2 Allgemeine Arbeiten mit der Zellkultur ................................................... 17

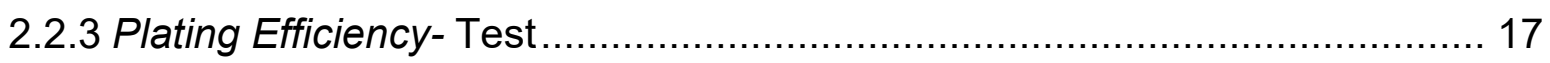




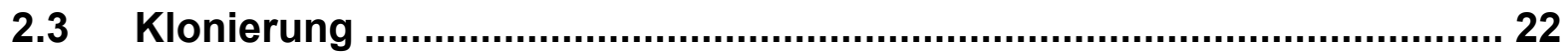

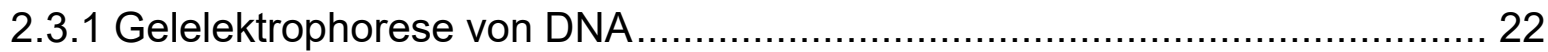

2.3.2 Transformation von chemisch kompetenten Bakterien mittels heat shock ... 22

2.3.3 Gewinnung von Plasmid-DNA aus Bakterien ........................................ 23

2.3.4 Gewinnung von chromosomaler DNA aus Zellkulturen .............................. 23

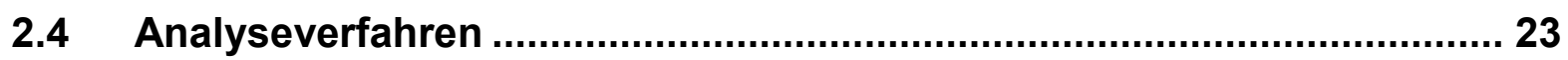

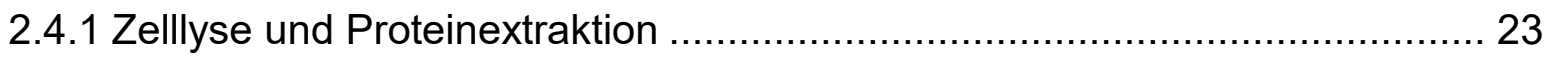

2.4.2 Proteinauftrennung mittels Gelelektrophorese ..................................... 24

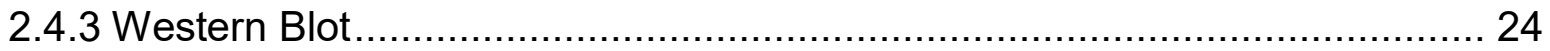

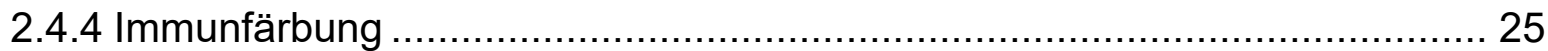

2.4.5 Visueller Letalitätstest nach shRNA-knockdown ...................................... 26

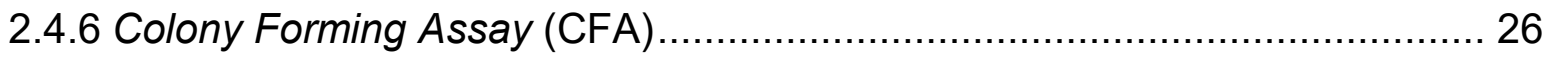

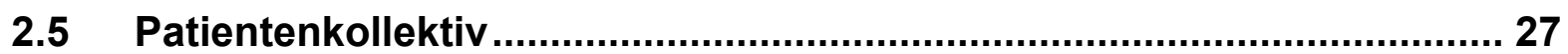

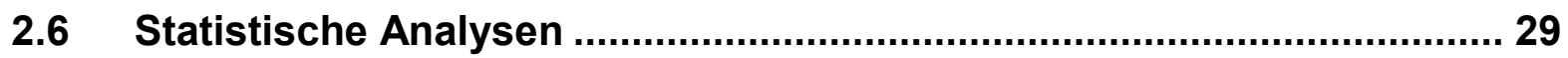

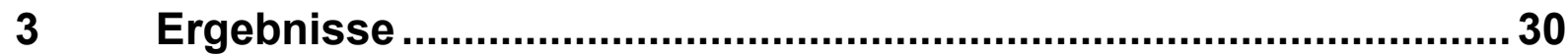

3.1 Immunhistochemische Auswertung …….......................................... 30

3.1.1 Korrelation zwischen CBP-Expression und Tumorregion ........................ 30

3.1.2 Korrelationen zwischen CBP-Expression und pathologischen Parametern . 31

3.1.3 Korrelation zwischen CBP-Expression und Tumorrezidivrate .................... 33

3.1.4 Korrelation zwischen CBP-Expression und tumorspezifischem Überleben .. 33

3.2 Molekularbiologische Auswertung ……............................................ 35

3.2.1 Einfluss von CBP-knockdown auf die Letalität ...................................... 35

3.2.2 Der knockdown von CBP induziert eine erhöhte Strahlensensibilität ........... 37

3.2.3 Der CBP-knockdown wirkt sich direkt auf Interaktionspartner aus ............... 38

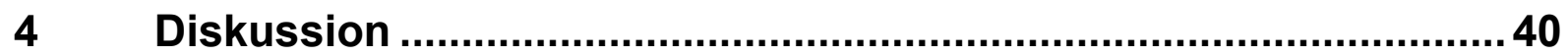

4.1 Auswirkung von CBP auf Tumorwachstum und Morphologie ............... 40

4.2 Korrelation von CBP Expression des Tumors und Überleben .............. 40 
4.3 CBP ist ein stark regulatorisches Protein ........................................ 41

4.4 Der Resistenzverlust ist multifaktoriell bedingt ................................ 42

4.5 Diskrepanz zwischen klinischen und molekularbiologischen Ergebnissen? .............................................................................................. 43

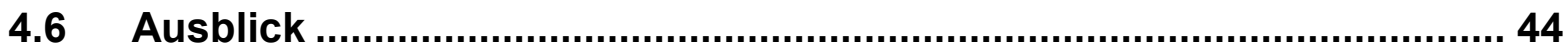

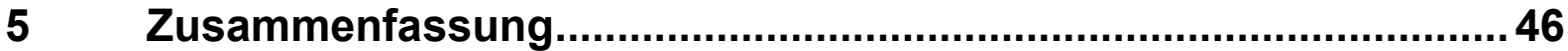

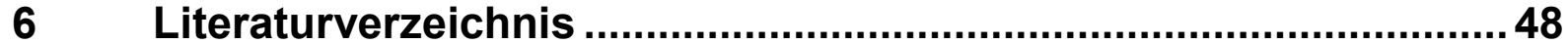

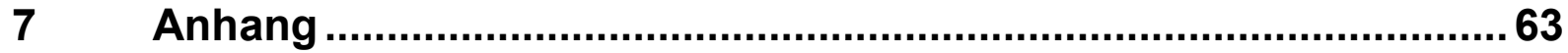

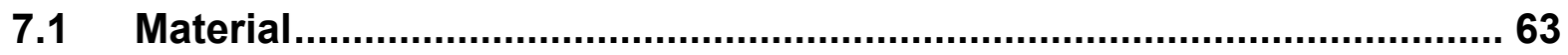

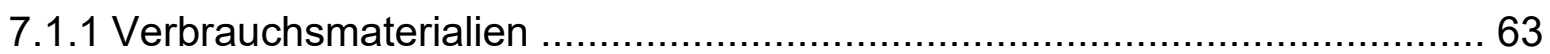

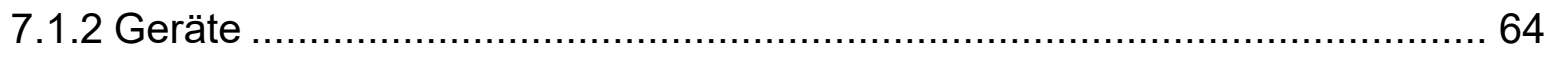

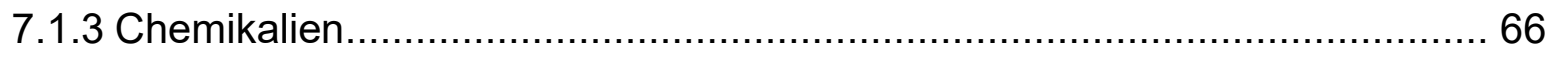

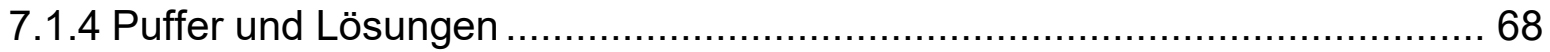

7.1.5 Zellkultur und Bakterienkultur ........................................................ 68

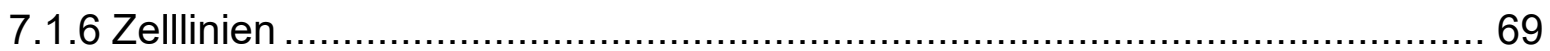

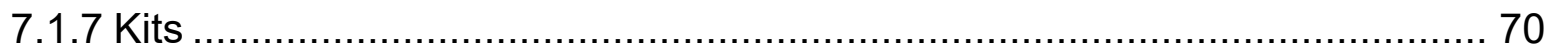

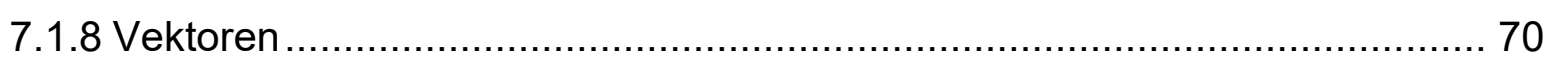

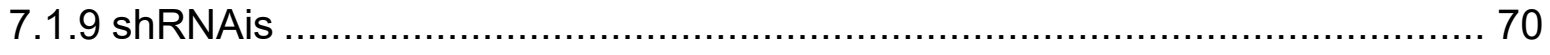

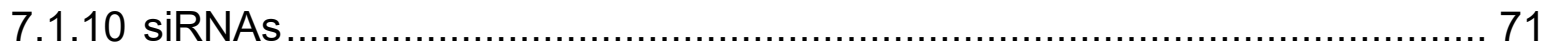

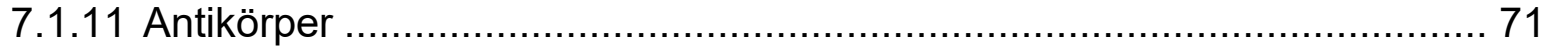

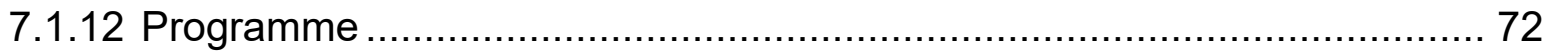




\section{Abkürzungsverzeichnis}

APC adenomatöse Polyposis Coli (Tumorsuppressorgen)

ARR anteriore Rektumresektion

ATCC American Type Culture Collection

CBP CREB-binding protein

CFA colony forming assay

CpG Cytosin - Phosphat - Guanin

CREB CAMP-response-elemente-binding-protein binding protein

CSS cancer specific survival

DNA deoxyribonucleic acid

DRF dose reduction factor

dsRNA double stranded ribonucleic acid

EDTA Ethylendiamintetraacetat

FAP familiäre adenomatöse Polyposis

FBS fetal bovine serum

GTF general transcription factor

HAT Histonacetyltransferase

HDAC Histondeacetylase

HNPCC hereditäres nicht-polypöses kolorektales Karzinom

KD knockdown

LD letale Dosis

MLH1 mutL homolog 1

mRNA messenger ribonucleic acid

MSI Mikrosatelliteninstabilität

MUTYH mutY Homolog (E. coli)

PBS phosphate buffered saline

PME partielle mesorektale Exzision

RCT Radiochemotherapie 


$\begin{array}{ll}\text { RISC } & \text { RNA-induced silencing complex } \\ \text { RNA } & \text { ribonucleic acid } \\ \text { rpm } & \text { rounds per minute } \\ \text { RT } & \text { Radiotherapie } \\ \text { SDS } & \text { Sodiumdodecylsulfat } \\ \text { shRNA } & \text { small hairpin ribonucleic acid } \\ \text { siRNA } & \text { small interfering ribonucleic acid } \\ \text { TAD } & \text { transactivation domain } \\ \text { TARR } & \text { tiefe anteriore Rektumresektion } \\ \text { TAZ } & \text { transcriptional adapter zinc finger } \\ \text { TGF- } \$ & \text { tumor growth factor } B \\ \text { TME } & \text { totale mesorektale Exzision } \\ \text { TNM } & \text { Klassifikation maligner Tumoren } \\ \text { TTLR } & \text { time to local recurrence } \\ \text { TTR } & \text { time to recurrence } \\ \text { UICC } & \text { Union internationale contre le cancer } \\ \text { Wnt } & \text { wingless Int-1 }\end{array}$




\section{Abbildungsverzeichnis}

Abbildung 1: Beispiel H-Score - Drei Präparate unterschiedlicher

Expressionsstärke

Abbildung 2: Übersicht über den pLKO.1 Puromycin-resistenten shRNAi-Vektor

(modifiziert nach OpenBiosystems) ................................................... 19

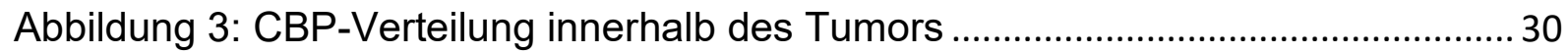

Abbildung 4: Korrelation der CBP-Verteilung innerhalb des Tumors............................ 31

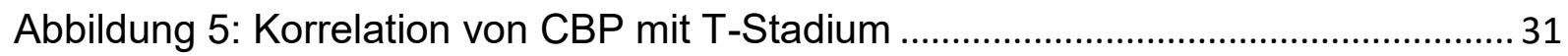

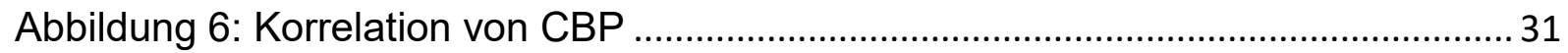

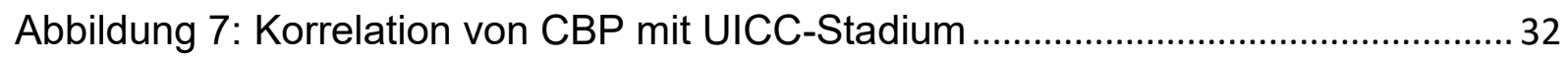

Abbildung 8:Korrelation von CBP mit Lymphgefäßinfiltration...................................... 32

Abbildung 9: Korrelation von CBP mit Veneninfiltration .............................................. 32

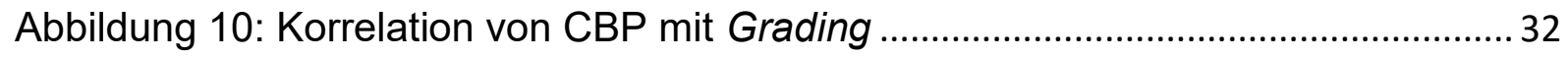

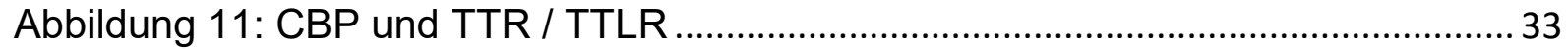

Abbildung 12: Korrelation von CBP-Expression und CSS ........................................... 34

Abbildung 13: Western Blot sh-knockdown-Überstand (HEK-293T)............................ 35

Abbildung 14: Zelluntergang nach CBP-knockdown mit shRNAi ................................ 36

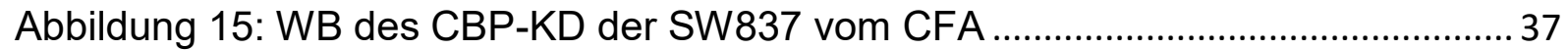

Abbildung 16: CFA mit RT (Radiotherapie) und RCT (Radiochemotherapie) von

SW837 mit si-knockdown von CBP (3 Versuchsreihen)..................... 37

Abbildung 17: WB von Interaktionspartnern bei CBP-KD in HEK-293T ...................... 38 


\section{Tabellenverzeichnis}

Tabelle 1: TNM-Klassifikation nach UICC 2010 (Wittekind und Meyer 2010) 4

Tabelle 2: TNM-Klassifikation und UICC-Stadien (Storch 2016) ................................... 5

Tabelle 3: Verwendete Zelllinien und Kultivierungskonditionen .................................. 17

Tabelle 4: Abkürzungen der Vektorelemente des pLKO.1 Puromycin-resistenten shRNAi-Vektors 19

Tabelle 5: Benutzte Antikörper und verwendete Konditionen 26

Tabelle 6: Einzusetzende Zellzahlen bei CFA 27

Tabelle 7: Patientenkollektiv 28

Tabelle 8: Zusammenfassung: Korrelation CBP-Expression und pathologische Parameter. .35

Tabelle 9: DRF der SW837 mit CBP-KD bei LD25/50/75 38 


\section{Einleitung und Fragestellung}

\subsection{Klinische Bedeutung des kolorektalen Karzinoms}

\subsubsection{Epidemiologie}

Das kolorektale Karzinom ist eines der häufigsten Malignome weltweit. Die höchste Inzidenz findet sich in den westlichen industrialisierten Ländern, die niedrigste Inzidenz für kolorektale Tumoren ist in den ärmeren afrikanischen und asiatischen Ländern. In Deutschland erkranken jährlich ca. 64000/Jahr (2013).(Fuchs et al. 2011; Kaatsch et al. 2012; Robert-Koch-Institut 2016).

Das mittlere Erkrankungsalter ist bei Frauen respektive Männern 68,3 Jahre und 69,3 Jahre (2013). Im Jahr 2013 war das kolorektale Karzinom nach dem Mammakarzinom die zweithäufigste Tumorentität in Deutschland (Robert-Koch-Institut 2016). Die Inzidenz von kolorektalen Tumoren ist seit den 1980er Jahren bis zur Jahrtausendwende bei Frauen um 25 \% und bei Männern um 45 \% gestiegen. Der stärkste Anstieg bei Frauen ist in einem Alter über 80 Jahren, bei den Männern in einem Alter von 60 bis 79 Jahren zu verzeichnen. Das relative 5-Jahres-Überleben hat sich durch die besseren Therapiemöglichkeiten und die eingeführten Vorsorgeuntersuchungen in demselben Zeitraum von $45 \%$ auf $60 \%$ verbessert (Fuchs et al. 2011). Die Angaben bezüglich der Verteilung der Malignome auf Colon und Rektum variieren. Nach den Angaben des Robert Koch-Institutes sind etwa zwei Drittel im Colon, 30 \% im Rektum und die übrigen Karzinome im rektosigmoidalen Übergang sowie im Analkanal lokalisiert (Kaatsch et al. 2012; Robert-Koch-Institut 2015).

\subsection{2 Ätiologie}

Die Entstehung eines kolorektalen Karzinoms ist multifaktoriell, spezifische Risikofaktoren können in endogene und exogene Faktoren unterteilt werden. Zu den relevanten exogenen Risikofaktoren zählen der übermäßige Konsum von dunklem Fleisch, fettreiche Kost und Alkohol. Eine verminderte Aufnahme von Vitaminen und Spurenelemente wie beispielsweise Selen wird ebenfalls diskutiert. Auch die Zubereitungsart von Speisen kann sich negativ auswirken, wie beispielsweise 
scharfes Anbraten oder Grillen. Adipositas, Rauchen, Asbestbelastung und körperliche Inaktivität gelten ebenfalls als exogene Risikofaktoren (Friedenreich 2001; Fuchs et al. 2011; Kaatsch et al. 2012; Liersch et al. 2007).

Ätiologisch relevante endogene Ursachen für die Entstehung eines kolorektalen Karzinoms sind genetische Prädispositionen wie die familiäre adenomatöse Polyposis (FAP), MUTYH-assoziierte Polypose (MAP), das hereditär nicht-polypöse kolorektale Karzinom (HNPCC), adenomatöse Polypen, Colitis ulcerosa oder die Verwandschaft ersten Grades zu einem Betroffenen. Insgesamt treten in $5 \%$ der Fälle hereditäre Karzinome auf. Die Mikrosatelliteninstabilität (MSI), bedingt durch DNA-Mismatch-Reparatur-Gen-Defekte, spielt hier ebenfalls eine Rolle (Fuchs et al. 2011; Kaatsch et al. 2012; Liersch et al. 2007).

Die Entstehung erworbener kolorektaler Karzinome basiert auf der Annahme der sogenannten „Adenom-Karzinom-Sequenz“ nach Fearon und Vogelstein (Kinzler und Vogelstein 2002). Diese Sequenz beschreibt die Entwicklung vom Adenom über die Dysplasie hin zur Neoplasie. Das Karzinom entsteht aus einer epithelialen Proliferation, einer damit einhergehenden Hyperplasie und konsekutivem Differenzierungsverlust eines benignen Adenoms, welches in den meisten Fällen exophytisch in das Darmlumen wächst. Wird das Adenom nicht im Rahmen einer Vorsorgekoloskopie entfernt, besteht ein nicht unerhebliches Risiko, dass das Adenom weitere zellzyklische Kontrollmechanismen verliert und sich zu einem Karzinom weiterentwickelt. Ein Adenom $>1 \mathrm{~cm}$ wird innerhalb von 20 Jahren mit einer Wahrscheinlichkeit von 35\% ein kolorektales Karzinom (Fuchs et al. 2011; Kinzler und Vogelstein 2002).

Neben der Entstehung gemäß der Adenom-Karzinom-Sequenz können sich Karzinome auch über den sogenannten serrated pathway aus hyperplastischen Polypen entwickeln. Hierbei führen ebenfalls mehrere Mutationen gemeinsam über sogenannte sessile serratierte Adenome (SSA) und traditionell serratierte Adenome (TSA) zu dem serratierten Adenokarzinom (Makinen 2007; Pox et al. 2014).

\subsubsection{Klinik und Diagnostik}

Die Symptome sind in der Regel unspezifisch; meist treten veränderte Stuhlgewohnheiten wie Frequenz und Konsistenz, Blutauflagerungen auf dem Stuhl oder Schmerzen bei der Defäkation auf. Auch ein positiver fäkaler okkulter Bluttest 
(FOBT) kann Hinweis auf einen gastrointestinalen Tumor geben. Die Zeichen einer B-Symptomatik wie Gewichtsverlust (mehr als $10 \%$ des Körpergewichts in 6 Monaten), Nachtschweiß und Fieber können bei Vorhandensein eines kolorektalen Karzinoms auftreten, ebenso Tenesmus und Pruritus. In einem fortgeschrittenen Stadium ist auch das Auftreten eines mechanischen lleus oder einer rektalen oder abdominellen tastbaren Raumforderung möglich (Hamilton und Sharp 2004).

Das klinische Staging umfasst eine ausführliche Anamnese mit besonderer Berücksichtigung der Familienanamnese, die klinische und rektal-digitale Untersuchung sowie die Durchführung einer starren Rektoskopie mit rektaler Endosonographie. Die Diagnose des kolorektalen Karzinoms wird durch die Endoskopie mit histologischer Sicherung gestellt(Ghadimi und Becker 2006). Zur Bestimmung der Tiefeninfiltration sowie zur Einschätzung des Nodalstatus bei lokal begrenzten Tumoren sollte die Diagnostik um eine rektale Endosonographie ergänzt werden. Bei ausgedehnteren Tumoren ist zur Beurteilung des kleinen Beckens und der Tiefeninfiltration ein MRT notwendig. Als wichtiger laborchemischer Verlaufsparameter sollte schon präoperativ das CEA (carcinoembryonales Antigen) bestimmt werden (Pox et al. 2014).

\subsubsection{Klassifikation und Staging}

Die Klassifikation richtet sich nach der anatomischen Ausbreitung, im Speziellen nach der Ausbreitung des Primärtumors (T), nach dem Befall von Lymphknoten (N) und nach dem Vorhandensein von Fernmetastasen (M) (Wittekind und Meyer 2010). Diese TNM-Klassifikation wird ergänzt durch eine klinische Klassifikation (cTNM), welche prätherapeutisch anhand von klinischer Untersuchung, Bildgebung, Endoskopie und Biopsie erstellt wird. Die postoperative pathologische Klassifikation (pTNM), die anhand von exzidiertem Tumor und Proben durch den Pathologen bestimmt wird, wird nach stattgehabter neoadjuvanter System- oder Strahlentherapie und nach adäquatem Re-Staging mit yTN(M) vervollständigt. Einen weiteren wichtigen Parameter stellt das Grading $(G)$ dar, welches den Differenzierungsstatus des Tumors angibt (Wittekind und Meyer 2010). Eine Übersicht bietet Tabelle 1: 


\begin{tabular}{|c|c|}
\hline \multicolumn{2}{|c|}{ T - Primärtumor: } \\
\hline Tx & Primärtumor kann nicht beurteilt werden \\
\hline T0 & Kein Anhalt für Primärtumor \\
\hline Tis & Carcinoma in situ \\
\hline T1 & Tumor infiltriert Submukosa \\
\hline T2 & Tumor infiltriert Muscolaris propria \\
\hline T3 & $\begin{array}{l}\text { Tumor infiltriert durch die Muscularis propria in die Subserosa oder in nicht } \\
\text { peritonealisiertes perikolisches oder perirektalisches Gewebe }\end{array}$ \\
\hline T4 & $\begin{array}{l}\text { Tumor Tumor infiltriert direkt in andere Organe oder Strukturen und/oder } \\
\text { perforiert das viszerale Peritoneum }\end{array}$ \\
\hline T4a & Tumor perforiert viszerales Peritoneum \\
\hline T4b & Tumor infiltriert direkt in andere Organe oder Strukturen \\
\hline \multicolumn{2}{|c|}{$\mathrm{N}$ - regionäre Lymphknoten: } \\
\hline $\mathrm{Nx}$ & Regionäre Lymphknoten können nicht beurteilt werden \\
\hline N0 & Keine regionären Lymphknotenmeteastasen \\
\hline N1 & Metastase(n) in 1 bis 3 Lymphknoten \\
\hline N1a & Metastase in 1 regionärem Lymphknoten \\
\hline $\mathrm{N} 1 \mathrm{~b}$ & Metastasen in 2 bis 3 regionäre Lymphknoten \\
\hline N1c & $\begin{array}{l}\text { Tumorknötchen bzw. Satellit(en) im Fettgewebe der Subserosa oder im nicht- } \\
\text { peritonealisierten perikolischen/ perirektalen Fettgewebe ohne regionäre } \\
\text { Lymphknotenmetastasen }\end{array}$ \\
\hline N2 & Metastasen in 4 oder mehr Regionären Lymphknoten \\
\hline $\mathrm{N} 2 \mathrm{a}$ & Metastasen in 4 bis 6 Lymphknoten \\
\hline N2b & Metastasen in 7 oder mehr regionären Lymphknoten \\
\hline \multicolumn{2}{|c|}{ M - Fernmetastasen: } \\
\hline M0 & Keine Fernmetastasen \\
\hline M1 & Fernmetastasen \\
\hline M1a & $\begin{array}{l}\text { Metastase(n) auf ein Organ beschränkt (Leber, Lunge, Ovar, nicht-regionäre } \\
\text { Lymphknoten) }\end{array}$ \\
\hline M1b & Metastasen in mehr als einem Organ oder im Peritoneum \\
\hline
\end{tabular}

Tabelle 1: TNM-Klassifikation nach UICC 2010 (Wittekind und Meyer 2010) 
Tumoren unterschiedlicher TNM-Stadien, die dasselbe Therapieschema erfahren, werden im selben Stadium nach der Union internationale contre le cancer (UICC) eingeteilt. Dieses dient als Grundlage für die Therapieentscheidung und Prognose (Tabelle 2).

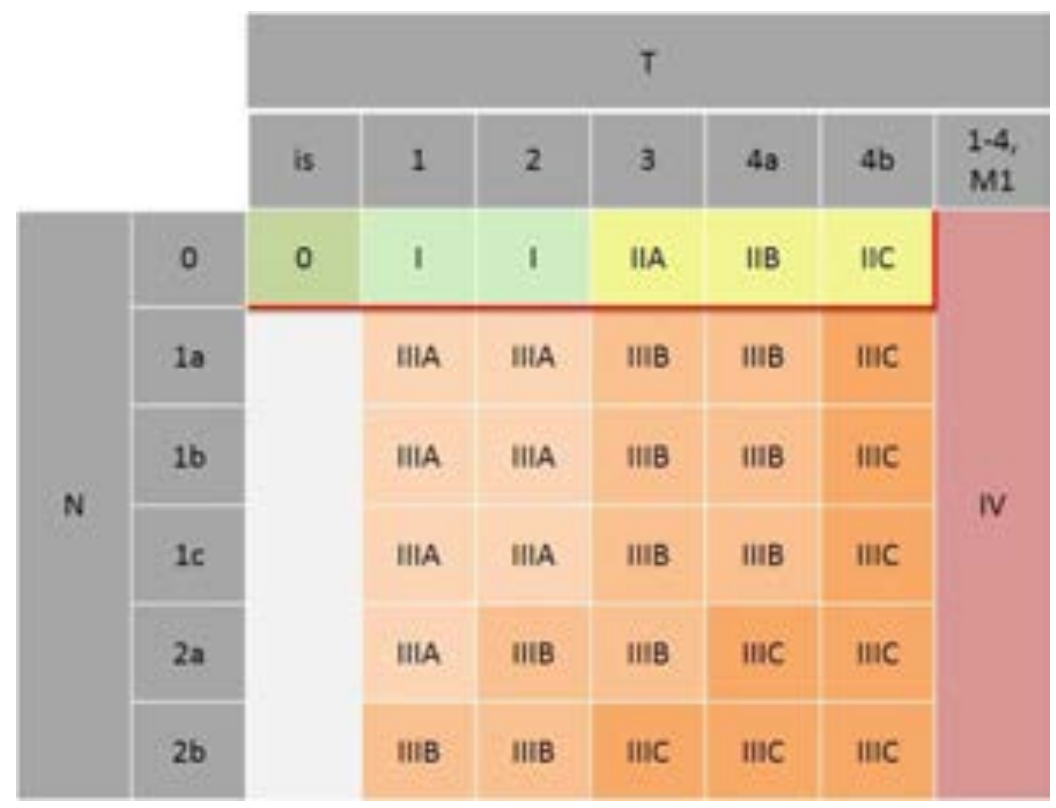

Tabelle 2: TNM-Klassifikation und UICC-Stadien (Storch 2016)

\subsubsection{Stadien-adaptierte Therapie}

Die Therapie des kolorektalen Karzinoms erfolgt multimodal und adaptiert an das Erkrankungsstadium. Die Präparation umfasst eine no-touch-Technik sowie eine Enbloc-Resektion. Liegen bei einem Kolonkarzinom Tumorkonglomerate vor, welche in Nachbarorgane infiltieren (in ca.10 \% der Fälle), so kann eine multiviszerale En-blocResektion mit dem Ziel einer R0-Resektion und der dazugehörigen Lymphadenektomie angestrebt werden (Fuchs et al. 2011).

Patienten, bei denen ein Kolonkarzinom mit dem UICC-Stadium I onkochirurgisch R0 reseziert wurde, sollten keiner adjuvanten Chemotherapie zugeführt werden. Eine klare Indikation zur adjuvanten Chemotherapie liegt bei Patienten mit einem Tumor im Stadium III vor. In diesem Fall wird eine Kombinationstherapie mit Oxaliplatin und 5-Fluroruracil empfohlen. Liegt ein Tumorstadium II vor, ist eine adjuvante Chemotherapie möglich, aussagekräftige Daten hierzu fehlen jedoch. Hier ist eine individuelle Nutzen-Risiko-Abwägung notwendig, da der absolute Nutzen bei lediglich 2-5 \% liegt (Fuchs et al. 2011). Ist das Tumorstadium II von Risikofaktoren (z. B. Tumorperforation, Tumoreinriss, Operation unter Notfallbedingungen, Anzahl 
untersuchter Lymphknoten zu gering) vorhanden, so steht die Indikation für eine adjuvante Chemotherapie. Bei Patienten mit Stadium-II-Tumoren wird eine 5Fluroruracil-Monotherapie empfohlen (Fuchs et al. 2011).

Liegt ein kolorektales Karzinom im Tumorstadium IV vor, so kann eine präoperative Radio- oder Radiochemotherapie zum Downsizing in kurativer Intention durchgeführt werden (Pox et al. 2014).

Bei der Therapie des Rektumkarzinoms muss generell zwischen Tumoren des unteren bzw. mittleren Rektumdrittels ( $0-12 \mathrm{~cm}$ ab Anokutanlinie) und Tumoren des oberen Rektumdrittels (12-16 cm ab Anokutanlinie) unterschieden werden. Liegt ein Rektumkarzinom im UICC-Stadium I vor, so wird eine alleinige operative Therapie im Sinne einer Resektion des Primärtumors im Gesunden und einer radikalen En-BlocLymphknotendissektion empfohlen, im unteren und mittleren Rektumrittel kombiniert mit einer totalen mesorektalen Exzision (TME), im oberen Rektumdrittel kombiniert mit einer partiellen mesorektalen Exzision (PME) (Fuchs et al. 2011).

Bei einem Karzinom der UICC-Stadien II/III der unteren beiden Rektumdrittel sollte eine neoadjuvante Radio- oder kombinierte Radio-/Chemotherapie durchgeführt werden. Ist der Tumor im oberen Rektumdrittel lokalisiert, kann eine adjuvante Therapie ähnlich dem des Kolonkarzinoms oder eine perioperative Radio/Chemotherapie durchgeführt werden. Im Rahmen der neoadjuvanten Radio/Chemotherapie sollte eine 5-Fluorouracil-Monotherapie mit oder ohne Folinsäure angewandt werden (Fuchs et al. 2011).

\subsection{Molekularbiologie des kolorektalen Karzinoms}

\subsubsection{Tumorgenese}

Die intrazellulären Ursachen der Tumorentstehung sind zahlreich und auf vielen Ebenen der Zellbiologie zu finden. In der Regel führt die Akkumulation von Veränderungen gemeinsam zu einer Dedifferenzierung und einer unkontrollierten Zellteilung. Dies betrifft sowohl die Tumorgenetik als auch Störungen der enzymatischen Funktionen.

Die Mechanismen, die hierbei zur Dysregulation führen, reichen von chromosomaler Instabilität (Lengauer et al. 1997) über Defekte von DNA-Reparaturmechanismen (Bronner et al. 1994), aberranter DNA-Methylierung (Issa 2004) und mutationsbedingter Inaktivierung von Tumorsupressorgenen (Goss und Groden 
2000) bis hin zur Aktivierung von onkogenen Signaltransduktionskaskaden (Bos et al. 1987).

Die häufigsten Formen der chromosomalen Instabilität beim kolorektalen Karzinom sind Instabilitäten, mit denen mehrere Veränderungen bezüglich Kopienzahl der Chromosomen und Chromosomenstruktur einhergehen (Barber et al. 2008; Lengauer et al. 1997). Chromosomale Instabilität geht mit einem Verlust von Tumorsupressorgenen wie APC, P53 oder SMAD4 einher. Tumorsupressorgene können den malignen Phänotyp unterdrücken (Fearon und Bommer 2008; Grady 2008; Kinzler und Vogelstein 2002). In kolorektalen Karzinomen gibt es eine Vielzahl von inaktivierenden Mutationen in Genen, die in ihrer physiologischen Funktion eine chromosomale Stabilität während der Replikation gewährleisten und durch Mutation die Tumorgenese durch Instabilität begünstigen (Barber et al. 2008). Im Gegensatz zu vielen anderen Karzinomen stellt beim kolorektalen Karzinom die Amplifikation von Genkopien eine eher untergeordnete Rolle bei der Entstehung der chromosomalen Instabilität (Leary et al. 2008) dar. Insgesamt sind bei $85 \%$ der sporadischen und bei allen FAP-assoziierten kolorektalen Karzinomen chromosomale Instabilitäten zu finden (Schulmann und Schmiegel 2002).

Welchen Stellenwert die Defekte von DNA-Reparaturmechanismen in der Tumorgenese spielen, lässt sich an dem hereditärem non-polypösen kolorektalen Karzinom (HNPCC) erkennen. HNPCC-Patienten mit einer Keimbahnmutation in den mismatch-repair-Genen MLH1 (MutL homolog 1) und MSH2 (MutS homolog 2) haben ein Lebenszeitrisiko von $80 \%$ bis zu ihrem 45. Lebensjahr ein kolorektales Karzinom zu entwickeln (Boland et al. 2008; Bronner et al. 1994; Fishel et al. 1993; Leach et al. 1993; Lynch et al. 2008; Papadopoulos et al. 1994). Sind die Mutationen der mismatch-repair-Gene vergesellschaftet mit genomischer Instabilität, so steigt das Risiko einer Karzinomentstehung bei HNPCC-Patienten dramatisch. Einige Tumoren entstehen innerhalb von 36 Monaten nach unauffälliger Koloskopie (Jarvinen et al. 2000). Hieraus resultiert auch die Empfehlung der jährlichen Koloskopie bei HNPCC-Patienten (Lynch et al. 2008). Eine somatische Inaktivierung von mismatch-repair-Genen ist bei ca. $15 \%$ der Patienten mit nicht-familiärem kolorektalen Karzinom zu finden. Bei diesen Patienten liegt in der Regel ein biallelisches Silencing der Promotor-Region des MLH1-Gens durch DNAMethylierung vor (Herman et al. 1998; Kane et al. 1997; Veigl et al. 1998) Durch den Verlust der mismatch-Reparaturmechanismen kommt es außerdem als 
Begleiterscheinung zur Mikrosatelliteninstabilität, welche in $15 \%$ der sporadischen und in allen hereditären kolorektalen Karzinomen nachweisbar ist (Lynch und de la Chapelle 2003; Thibodeau et al. 1993; Yamamoto et al. 2002). Tumoren, deren Genese durch Defekte in den mismatch-repair-Genen charakterisiert sind, finden sich primär als nicht-hereditäre Tumoren im proximalen Kolon und sind mit höherem Lebensalter und weiblichem Geschlecht assoziiert (Lynch et al. 2008). Besonders anfällig für mismatch-repair-Defekte sind Tumorsupressorgene, deren funktionelle Domänen mono- und dinucleotide repeats in ihren kodierenden Sequenzen enthalten. Beispiele hierfür sind TGFBR2 (transforming growth factor $ß$ receptor type II) und BAX (BCL2-associated X protein) (Fearon und Bommer 2008; Grady 2008; Kinzler und Vogelstein 2002).

Neben den mismatch-repair-Genen spielen unter den DNA-Reparaturmechanismen auch die base-excision-repair-Gene eine wichtige Rolle in der Tumorgenese und sind Gegenstand der aktuellen Forschung. Als Beispiel für eine Keimzellbahnmutation ist das Gen MYH (mutY homologue, MUTYH) zu nennen (Al-Tassan et al. 2002; Kastrinos und Syngal 2007).

Intakte Genstrukturen können auch epigenetisch durch die Methylierungs- oder Histonstruktur inaktiviert werden. Hier ist das epigenetische Silencing zu nennen, welches in den meisten Fällen aus aberranter DNA-Methylierung besteht. Diese Art des gene silencing kann auch bei kolorektalen Karzinomen beobachtet werden (Issa 2004; Kondo und Issa 2004). Bei der DNA-Methylierung wird in CpG-Dinukleotiden das Cytosin am $\mathrm{C}_{5}$-Atom durch DNAmethylasen mit einer Methyl-Gruppe versehen. In nicht pathologisch verändertem Genom werden Cytosine vor allem in repetitiven DNA-Sequenzen außerhalb von Exonen methyliert. Werden Cytosine in CpG-rich repeats methyliert, die oft in Promotorregionen lokalisiert sind, kann es zu Dysregulationen kommen. Eben diese Methylierungen von Promotor-assoziierten CpG-rich repeats werden in kolorektalen Karzinomen gefunden (Issa 2004).

Durch diese genetischen Veränderungen sind die nachgeschalteten Signaltransduktionskaskaden, in die Tumorsupressor-Proteine eingebunden sind, mitunter gestört. Die Aktivierung des Wnt signaling pathways ist als einer dieser Signalwege etabliert und sein Stellenwert in der Tumorgenese und dem Progress belegt (Moon 2005). Bestandteile des Wnt signalling pathways sind unter anderem bereits aus der Tumorgenese bekannte Proteine wie ß-Catenin, TCF (T-Cell factor) und APC (adenomatous polyposis coli) (Pez et al. 2013). Der Wnt signaling pathway 
wird aktiv, wenn das Onkoprotein ß-Catenin an seine nukleären Partner bindet und der Transkriptionskomplex aktiviert ist (Fearon und Bommer 2008; Goss und Groden 2000; Kinzler und Vogelstein 2002). Ein wichtiger Gegenspieler des Protoonkogens ß-Catenin ist das APC-Tumosupressorgen, welches neben der Degradation des $ß$-Catenins auch dessen Translokation in den Kern inhibiert. Wird das APC mutationsbedingt funktionslos, entfällt ein wichtiger Regulator und der Wnt signaling pathway wird konstitutiv aktiv. Liegt eine Keimbahnmutation im APC-Gen vor, ensteht die FAP (familiäre adenomatöse Polyposis). Träger dieser Keimbahnmutation entwickeln bis zum 40. Lebensjahr mit einer Wahrscheinlichkeit von nahezu 100\% ein kolorektales Karzinom (Goss und Groden 2000; Kinzler und Vogelstein 2002; Lynch et al. 2008). Der aktivierte Tumorsupressor p53 geht mit einem Zellzyklusarrest einher (Zelltod-Checkpoint), der durch zellulären Stress aktiviert werden kann (Vazquez et al. 2008). In den meisten Tumoren liegt eine biallelische Inaktivierung des Gens vor. Für gewöhnlich liegt eine Kombination aus einer missence-Mutation und einer chromosomalen 17p-Deletion vor (Baker et al. 1989; Fearon und Bommer 2008; Grady 2008; Kinzler und Vogelstein 2002). Eine dritte wichtige Tumorsupressor-Signaltransduktionskaskade im kolorektalen Karzinom ist der TGF-ß-Pathway (Transforming growth factor ß). Die Inaktivierung des TGF-ß-Pathways koinzidiert mit der Transformation von Adenomen zu highgrade-Dysplasien oder Karzinomen (Grady et al. 1998).

Weitere Protoonkogene sind RAS (rat sarcoma) und BRAF (rapidly accelerated fibrosarcoma homolog B1), welche die mitogen-aktivierende Proteinkinase (MAPK) aktivieren (Bos et al. 1987; Davies et al. 2002). Ein weiteres Protoonkogen stellt das PI3KCA-Gen dar. Dieses kodiert die katalytische Untereinheit der Phosphatidylinositol-3-kinase (PI3K) (Samuels et al. 2004). Die PI3K beeinflusst Proliferation, Überleben, Zellmigration und Zellmorphologie (Bader et al. 2006; Miled et al. 2007).

\subsubsection{Posttranslationale Modifikationen von Histonen}

Histone sind Proteine, welche DNA organisieren, das Chromatin definieren und aus 5 Hauptgruppen ( $\mathrm{H} 1, \mathrm{H} 2 \mathrm{~A}, \mathrm{H} 2 \mathrm{~B}, \mathrm{H} 3$ und $\mathrm{H} 4)$ bestehen. Acht Histone bilden ein Oktamer, bestehend aus 4 Paaren zwei gleicher Histone, das Nucleosom. Die DNA ist um eben diese Nucleosomen gewunden (Luger 2003). 
Histone können an vielen Stellen dynamisch modifiziert werden, welche die Chromatinfunktion bedingen. Insgesamt sind über 60 verschiedene Aminosäurereste bekannt, an denen bislang Modifikationen nachgewiesen werden konnten. Folgende Modifikationen an Histonen sind bekannt: (De-)Acetylierung (Sterner und Berger 2000; Vaquero et al. 2006), Phosphorylierung(Macdonald et al. 2005), Lysin-(De-)Methylierung (Bannister und Kouzarides 2005; Shi et al. 2006), ArgininMethylierung (Lee et al. 2005), Deimination (Cuthbert et al. 2004), (De-)Ubiquitylierung (Emre et al. 2005; Wang et al. 2006), Sumoylierung (Nathan et al. 2006), ADP-Ribosylierung (Hassa et al. 2006) und Prolinisomerisierung (Nelson et al. 2006).

Bezogen auf ihre Auswirkung auf die Transkription können die Modifikationen in Kategorien eingeteilt werden. Acetylierung und Phosphorylierung wirken transkriptionsfördernd, wohingegen Deacetylierung, Sumoylierung und Prolinisomerisierung transkriptionsinhibierend wirken. Ubiquitinierungen können sowohl transkriptionsfördernd als auch transkriptionsinhibierend wirken und sind somit bifunktional. (Kouzarides 2007; Vakoc et al. 2005). Methylierungen sind meist an Lysinresten zu finden und wirken meist bifunktional.

Die Acetylierung von Histonen ist mit der Aktivierung der Transkription assoziiert. Acetyltransferasen können in drei Hauptgruppen unterteilt werden (Selvi et al. 2010): GNAT (GCN5-Related-N-acetyltransferase), MYST (MOZ, Ybf2/Sas3, Sas2, Tip60) und CBP/p300 (CREB-binding protein). Generell modifizieren diese Enzyme mehr als einen Lysinrest, einige sind jedoch hochspezifisch und auf einzelne Lysine beschränkt. Die meisten Acetylierungsstellen finden sich an den $\mathrm{N}$-terminalen Enden der Histone, welche auch morphologisch am zugänglichsten sind (Sterner und Berger 2000). Durch die Acetylierung der Histone wird die positive Ladung der Proteine neutralisiert und die verminderte Wechselwirkung führt $\mathrm{zu}$ einer Auflockerung der Chromatinstruktur mit leichterem Zugang zur DNA für die Transkriptionsmaschinerie (Kouzarides 2007; Ruthenburg et al. 2007; Siomi und Siomi 2009).

Im Gegensatz zur Acetylierung führt die Deacetylierung zur transkriptionellen Repression. Auch hier sind drei Familien von Histondeacetylasen (HDAC) bekannt. Sie sind in viele Signaltransduktionskaskaden eingebunden und Bestandteil in zahlreichen repressiven Chromatinkomplexen. Deacetyltransferasen zeigen im 
Gegensatz zu den Acetylasen eine wesentlich geringere Spezifität bezüglich ihrer Zielstrukturen (Kouzarides 2007; Vaquero et al. 2006).

\subsubsection{CBP (CREB-binding protein) / p300}

Transkriptionsaktivatoren binden an spezifische Sequenzen an Promotoren sowie Enhancern des Zielgens und initiieren die Transkription, indem sie die Transkriptionsmaschinerie, bestehend aus den General Transcription Factors (GTFs) (TFIIA, TFIIB, TFIID, TFIIE, TFIIF, TFIIH) und der RNA-Polymerase II, an die Transkriptionsinitiationsstelle bringen (Ptashne und Gann 1997; Thomas und Chiang 2006). Co-Faktoren der Transkription ermöglichen das ChromatinRemodeling und modifizieren enzymatisch die Chromatinstruktur, wodurch sich diese auflockert und die Gentranskription ermöglicht wird (Naar et al. 2001; Wang et al. 2013).

CBP (CREB-protein [CAMP-response-elemente-binding-protein binding protein] binding protein) und dessen Homolog p300 sind beides transkriptionelle Coaktivatoren. Sie verbinden DNA mit den GTFs und bedingen eine Auflockerung des Chromatins durch ihre intrinsische Histonacetyltransferase(HAT)-Aktivität (Bannister und Kouzarides 1996; Ogryzko et al. 1996; Shiama 1997). Neben der HAT-Funktion können CBP/p300 auch einige Transkriptionsfaktoren acetylieren und dadurch deren Aktivität modulieren. CBP und p300 erfüllen teils unterschiedliche Funktionen; aufgrund ihrer sowohl strukturellen als auch funktionellen Ähnlichkeit werden beide Proteine oft zusammengefasst (Kalkhoven 2004; Wang et al. 2013).

Bei CBP sind vier Transactivation domains (TAD) bekannt: die Cysteine-Histidinerich region 1 (CH1), welche einen transcriptional adapter zinc finger 1 (TAZ1) beinhaltet (Bhattacharya et al. 1999; De Guzman et al. 2000), eine CREBinteragierende KIX-Domäne unbekannter Funktion (Parker et al. 1996), eine Cysteine-Histidine-rich region $3(\mathrm{CH})$ in der ein weiterer transcriptional adapter zinc finger 2 (TAZ2) und eine ZZ-type zinc finger domain enthalten sind (Albanese et al. 1999; De Guzman et al. 2000) sowie eine nuclear receptor co-activator binding domain (NCBD), welche auch interferon-binding domain (IBiD) genannt wird (Lin et al. 2001; Parker et al. 1996). Diese TADs vermitteln Protein-Protein-Interaktionen mit DNA-bindenden Transkriptionsfaktoren und helfen der Transkriptionsmaschinerie. Darüber hinaus beinhaltet CBP noch eine Histonacetyltransferase-Aktivität, um 
Histone und andere Proteine zu acetylieren und eine daran anschließende Bromodomäne, welche modifizierte Histone erkennt (Ragvin et al. 2004).

Die mit CBP assoziierten Faktoren beinhalten folgende pro-proliferative und onkogene Proteine (Wang et al. 2013): c-Myc (Vervoorts et al. 2003), c-Myb (Dai et al. 1996), CREB (Chrivia et al. 1993), c-Jun (Bannister et al. 1995) und c-Fos (Bannister und Kouzarides 1995). Darüber hinaus werden auch pro-apoptotische und Tumorsupressorproteine reguliert (Wang et al. 2013): p53 (Avantaggiati et al. 1997; Lill et al. 1997), Forkhead box class $O$ (FOXO) transcription factor 1/3a/4 (Nasrin et al. 2000; So und Cleary 2002, 2003), signal transducer and activator of transcription (STAT) 1/2 (Bhattacharya et al. 1996; Zhang et al. 1996), Hypoxia-

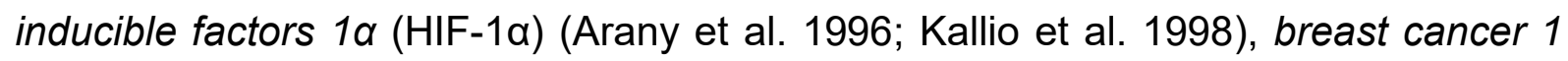
(BRCA1) (Pao et al. 2000), SMA/MAD homology (Smad) proteins (Feng et al. 1998; Janknecht und Nordheim 1996), Runt-related transcription factor (RUNX) (Kitabayashi et al. 1998), E2 Transcription Factor (E2F) (Ait-Si-Ali et al. 2000) und EProteine (Denis et al. 2012; Wang et al. 2013).

CBP hat durch seine vier TADs eine große Fülle von Interaktionspartnern, von denen wiederum eine Vielzahl mehrere TADs beinhalten. Diese Kombination führt zu einer enormen kombinatorischen Möglichkeit der Komplexbildung (Teufel et al. 2007; Wang et al. 2012).

Neben den vier TADs und der HAT-Domäne fungiert CBP zusätzlich noch als Coaktivator für nukleäre Rezeptoren. Diese Interaktionen sind durch kurze Peptidmotive vermittelt, welche durch die activation function-2 (AF-2) region der ligand-bindenden Domänen (LBDs) von nukleären Rezeptoren erkannt wird (Wang et al. 2013). Zu den Rezeptoren gehören der Retinoid-X-Rezeptor (RXR) (Chakravarti et al. 1996), der Androgen-Rezeptor (AR) (Fronsdal et al. 1998) und der EstrogenRezeptor (ER) (Hanstein et al. 1996; Wang et al. 2013).

Die vielen schon genannten Histonmodifikationen werden kombiniert miteinander als histone code bezeichnet und regulieren das Expressionslevel von Genen (Jenuwein und Allis 2001). Die von CPB enthaltene Histonacetyltransferase-Domäne acetyliert nucleosomale Histone in der Nähe der Promotorregionen. Diese HAT-Funktion oder die Adapterfunktion von CBP spielt eine entscheidende Rolle in der PromotorAktivator-spezifischen Transkription. Diese Histonacetylierung bewirkt eine Auflockerung des Chromatins und erleichtert den Zugriff auf chromosomale DNA (Bannister und Kouzarides 1996; Gorisch et al. 2005; Ogryzko et al. 1996; Wang et 
al. 2013). Zu den von CBP/p300 acetylierten Lysinresten an Histonen gehören unter anderem H3K14, H3K18, H3K23, H3K27, H4K5, H4K8, H4K12 und diverse Lokalisationen an den Histonen H2A und H2B (Ding et al. 2014; Schiltz et al. 1999). Die Struktur der HAT-Domäne des CBP lässt einen katalytischen Mechanismus vermuten, bei dem Acetyl-CoA gebunden wird und der Lysinrest des Histons im „CBP-Tunnel“ acetyliert wird. Dieser Mechanismus unterscheidet sich von dem anderer Histonacetyltransferasen, was die Spezifität und Selektivität der HATDomäne des CBP erklärt (Liu et al. 2008; Wang et al. 2008). Die beiden Paraloge CBP und p300 unterscheiden sich insbesondere hinsichtlich der Spezifität einzelner Lysinreste. Mit Hilfe massenspektrometrischer Verfahren konnte gezeigt werden, dass p300 bei der Acetylierung der Lysinreste H3K14, H3K18 und H3K23 eine um den Faktor $10^{10}$ erhöhte Spezifität besitzt (Henry et al. 2013). Auch konnte gezeigt werden, dass CBP und das Tumorsupressorgen PTEN miteinander interagieren und deren Expressionsmuster in Prostatakarzinomen korrelieren. Im Mausmodell (CBPpc${ }^{\text {I-PTEN }}{ }^{\mathrm{pc}+/}$ ) konnten erhöhte Proliferationsraten und die Entstehung von early onset high-grade-Prostatakarzinomen nachgewiesen werden (Ding et al. 2014). Bei bestehendem CBP-Verlust und PTEN-Defizienz findet an dem Lysinrest H3K27 ein Wechsel von einer Acetylierung zur Trimethylierung statt, was mit einer reduzierten Expression des Tumorsupressorgens DAB2IP einhergeht (Ding et al. 2014). Jedoch acetyliert CBP mit seiner HAT-Domäne nicht ausschließlich Histone. Beispielsweise wird auch das Tumorsupressorprotein p53 modifiziert. Am c-terminalen Ende des p53 befindet sich eine unspezifische DNA-bindende Domäne, welche mit der sequenzspezifischen DNA-bindenden Domäne desselben Proteins interferiert. Wird die unspezifische DNA-Bindungsstelle durch das CBP acetyliert, führt dies zur Inaktivierung und zur Trennung von der sequenzspezifischen DNA-Bindungsstelle. Diese wird nun frei, erhöht dessen Aktivität und die Spezifität des p53 (Gu et al. 1997) 


\section{$1.3 \quad$ Zielsetzung}

CBP ist als Histonacetyltransferase ein Coaktivator der Transkription. Es ermöglicht durch enzymatische Modifizierung am Chromatin und anderen Proteinen eine Umstrukturierung des Chromatins, wodurch eine Vielzahl regulativer Prozesse inklusive Mechanismen der Zellreparatur beeinflusst werden können. CBP ist in vielen pro-apoptotischen und pro-proliferativen Prozessen involviert, und ein Zusammenhang mit malignen Erkrankungen konnte bereits gezeigt werden.

Ziel der Arbeit war es, eine vermutete CBP-vermittelte Modulation der Tumorproliferation und den etwaigen Einfluss auf die Resistenzentwicklung am Beispiel des Rektumkarzinoms zu untersuchen. Hierzu wurde drei wesentliche experimentelle Schritte geplant.

Zunächst sollte mit Hilfe immunhistochemischer Methoden untersucht werden, ob und inwieweit Zusammenhänge zwischen der CBP-Expression in Tumoren und den klinischen Parametern von Patienten mit rektalen Karzinomen existieren.

In einem zweiten Schritt wurden molekularbiologische Aspekte eines CBPknockdowns auf die Tumorproliferation anhand CBP-relevanter Signalkaskaden überprüft.

Zuletzt wollten wir mit Hilfe genetischer Repression in Karzinomzelllinien eine etwaige Relevanz von CBP in der Resistenzbildung bei Strahlen- und Chemotherapien analysieren. 


\section{Methoden und Patientenkollektiv}

\section{$2.1 \quad$ Immunhistochemische Methoden}

\subsubsection{Herstellen von Paraffinschnitten}

Bevor mit der immunhistochemischen Färbung begonnen werden kann, müssen Gewebeschnitte von den in Paraffin eingebetteten Präparaten hergestellt werden. Hierzu werden die Paraffinblöcke mit einem Schlittenmikrotom in $2 \mu \mathrm{m}$ starke mikroskopische Präparate geschnitten. Diese Schnitte werden mit Hilfe eines Wasserbades auf einen Glasobjektträger gebracht, auf einer Heizplatte gestreckt und über Nacht in einem Wärmeschrank bei $40^{\circ} \mathrm{C}$ getrocknet.

\subsubsection{Immunhistochemische Färbung}

Die immunhistochemische Färbung erfolgt automatisiert mit dem Färbeautomaten BenchMark XT von Roche. Das Präparat wird zunächst mit einer wässrigen Entparaffinierungslösung (EZ Prep) behandelt. Anschließend erfolgt eine AntigenDemaskierung durch eine Hitzevorbehandlung bei $100{ }^{\circ} \mathrm{C}$ über 90 Minuten. Das Präparat wird für diesen Schritt mit einem Tris-Borat-EDTA ( $\mathrm{pH}$ 7,6)-Puffer bedeckt. Die folgende Antikörper-Inkubation (CBP-Antikörper 1:50-Verdünnung) dauert 88 Minuten bei Raumtemperatur. Der für die Färbung verwendete Zweitantikörper ist mit Meerrettichperoxidase konjugiert und wird mit einem Färbekit (Fast Red Kit) angewendet. Die Gegenfärbung des Gewebes erfolgt im letzten Schritt mit Hämatoxilin.

\subsubsection{Auswertung und Quantifizierung}

Um ein möglichst reproduzierbares Ergebnis in der immunhistochemischen Analyse zu erlangen, wurde ein standardisiertes Vorgehen angewandt. Zunächst werden in jedem Präparat drei Areale ausgewählt, welche an der Basis des Tumors, also an der Grenzschicht zum gesunden Gewebe, im Zentrum des Tumors und am Apex, also zum Lumen des Darmes, liegen. Jedes dieser Areale umfasst etwa $7500 \mu \mathrm{m}^{2}$. Zur Quantifizierung der Expressionsstärke wurde der H-Score verwendet (Goulding 
et al. 1995). Hierzu werden alle Zellen in den Arealen ausgezählt und nach ihrem Färbegrad eingeteilt.

$0=$ Nicht gefärbt

1 = Leicht gefärbt

$2=$ Mittel gefärbt

3 = Stark gefärbt

Nach der folgenden Formel wird der $\mathrm{H}$-Score ermittelt:

$\%$ (schwach gefärbt) $\times 1+\%$ (moderat gefärbt) $\times 2+\%$ (stark gefärbt) $\times 3=0-300$

Beispiel für $H$-Score: $19,59 * 1+70,74 * 2+5,85^{*} 3=178,6$

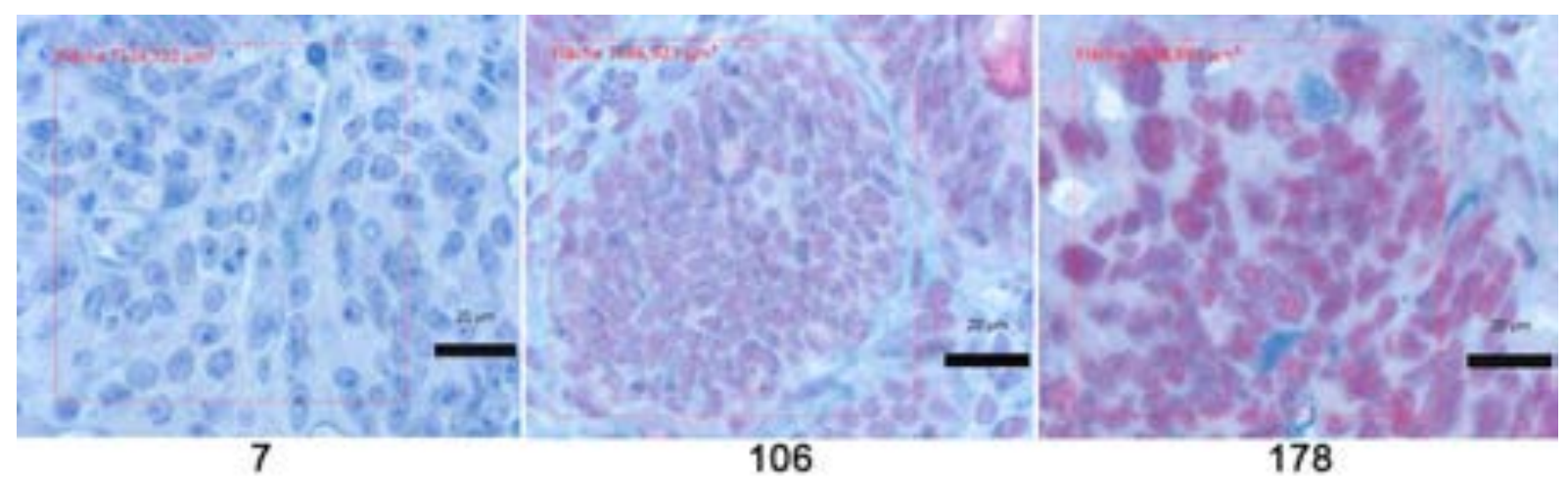

Abbildung 1: Beispiel H-Score - Drei Präparate unterschiedlicher Expressionsstärke

\subsection{Methoden der Zellkultur}

\subsubsection{Konditionen für Säugerzellen}

Alle für die Versuche verwendeten Zelllinien sind humanen Ursprungs und können bei der American Type Culture Collection (ATCC) kommerziell erworben werden. Die Zellen werden bei $37{ }^{\circ} \mathrm{C}$ sowohl bei Raumluft als auch bei $5 \%$ igem $\mathrm{CO}_{2}$-Gehalt kultiviert. Es werden die von ATCC empfohlenen Medien verwendet. Alle Medien werden zusätzlich mit 10\% FBS (fetal bovine serum), 1\% L-Glutamin und 1\% Penicillin/Streptomycin versetzt. Alle verwendeten Zelllinien weisen ein adhärentes Wachstum auf.

\begin{tabular}{|c|c|c|c|}
\hline Zelllinie & Herkunft & Medium & Atmosphäre \\
\hline HEK-293T & Embryonale Nierenzellen & DMEM & $5 \% \mathrm{CO}_{2}$ \\
\hline PC-3 & Adenokarzinom der Prostata & DMEM & $5 \% \mathrm{CO}_{2}$ \\
\hline
\end{tabular}




\begin{tabular}{|c|c|c|c|}
\hline SW480 & Adenokarzinom des Colons & L15 & Raumluft \\
\hline SW837 & Adenokarzinom des Rektums & L15 & Raumluft \\
\hline SW620 & LK-Metastase Colonadenokarzinom & L15 & Raumluft \\
\hline HT29 & Adenokarzinom des Colons & McCoy's 5A & $5 \% \mathrm{CO}_{2}$ \\
\hline
\end{tabular}

Tabelle 3: Verwendete Zelllinien und Kultivierungskonditionen

\subsubsection{Allgemeine Arbeiten mit der Zellkultur}

Alle Zellen werden zur Langzeitlagerung bei $-150{ }^{\circ} \mathrm{C}$ in Flüssigstickstoff aufbewahrt. Zum Auftauen werden die Zellen in ein $37^{\circ} \mathrm{C}$ warmes Wasserbad gestellt. Sobald die Zellen aufgetaut sind, werden sie in $10 \mathrm{ml}$ vorgewärmtes Medium überführt und bei 800 rpm für 5 Minuten zentrifugiert. Das Zellpellet wird in frischem Medium resuspendiert. Die Zellen können ausplattiert werden.

Bei der weiteren Kultivierung der Zellen wird angestrebt, die Zellen in der logarithmischen Wachstumsphase zu halten. Daher ist darauf zu achten, dass die Zellen eine Konfluenz von 80 \% nicht überschreiten. Ein Wechsel des Mediums sollte alle 2-3 Tage erfolgen.

Haben die Zellen eine Konfluenz von 50-80 \% erreicht, können diese gesplittet, d. h. in mehrere Petrischalen aufgeteilt werden. Hierzu wird zunächst das Medium verworfen und mit PBS gewaschen. Anschließend erfolgt ein Ablösen der Zellen mit einer 0,25 \%igen Trypsin-EDTA-Lösung. Der Lysevorgang wird durch die Zugabe von Medium gestoppt. Es folgt eine Zentrifugation, Resuspendierung und das Ausplattieren in neue Kultivierungsschalen.

Zur Ermittlung der genauen Zellkonzentration der Zellsuspension wird eine Neubauerzählkammer verwendet. Um abgestorbene Zellen bei der Zählung identifizieren zu können wird die Suspension in dem Verhältnis 1:10 mit Trypanblau versetzt.

\subsubsection{Plating Efficiency-Test}

Bei dem Plating Efficiency Test soll die optimale Zellzahl für eine Zelllinie, in diesem Fall PC-3, bestimmt werden, die für einen CFA (Colony Forming Assay) eingesetzt wird. Hierzu werden die Zellen in bestimmter Zahl (200, 400, 600, 800, 1000 und 1200 Zellen je well) in Duplikaten in 6-well-plates ausplattiert. Ziel ist es, die Zellzahl zu finden, bei der nach einer bestimmten Zeit ungefähr 200 Kolonien je well mit mindestens 50 Zellen wachsen. 


\subsubsection{Gen-Silencing mit RNA-Interferenz (RNAi)}

Bei der RNA-Interferenz handelt es sich um einen bei allen eukaryoten Lebewesen vorkommenden Mechanismus, der u.a. dazu dient, die Genexpression auf mRNAEbene zu regulieren. Der Organismus hat mit dieser Methode die Möglichkeit, auch posttranskriptionell auf die Expression einzuwirken und ein Gen-Silencing, also die Verminderung der Expressionsstärke eines Gens, zu ermöglichen (Kurreck 2009).

Bei dem Mechanismus der RNA-Interferenz sind mehrere Strukturen beteiligt. Das zentrale Biomolekül stellt eine doppelsträngige RNA (dsRNA) mit einer Länge von ca. 20-30 Basenpaaren dar. Außerdem sind die Proteine Dicer und RISC (RNA-induced silencing complex) beteiligt. Die dsRNA wird durch die Endoribonuklease Dicer geschnitten und anschließend an den RISC angelagert, welcher die dsRNA in Einzelstränge teilt. (Bagasra und Prilliman 2004; Siomi und Siomi 2009) Der Komplex aus ssRNA (single-stranded RNA) und RISC bindet die komplementäre mRNA, welche darauf hin abgebaut wird (Liu et al. 2004).

Dieses Phänomen des posttranskriptionellen Gen-Silencing kann experimentell genutzt werden.

\subsubsection{Gen-Silencing mit siRNA}

Eine Möglichkeit, diesen Mechanismus zu nutzen, bieten die siRNAs (small interfering RNA). Diese stellen kleine dsRNA Moleküle dar, welche die Kodierung der Komplementärsequenz der mRNA des Gens enthalten, das supprimiert werden soll. Über verschiedene Wege wie Elektroporation oder Lipofektion können die siRNAs in das Zellinnere eingebracht werden und dort durch den oben beschriebenen Mechanismus das Gen-Silencing bewirken. Jedoch ist dieser knockdown nur von passagerer Dauer, da die siRNAs degradiert werden.

\subsubsection{Lentivirale Integration von shRNAi in Säugerzellen}

Eine weitere Möglichkeit, RNA-Interferenz experimentell einzusetzen, ist die Verwendung von shRNA (small hairpin RNA) durch lentivirale Integration. Hierzu werden lentivirale Partikel hergestellt, welche einen Expressionsvektor in die Wirtszelle einbringen. Der Vektor enthält die Kodierungen der shRNA für das 
Zielmolekül, welches herunterreguliert werden soll, von Promotoren und eines Resistenzgens.

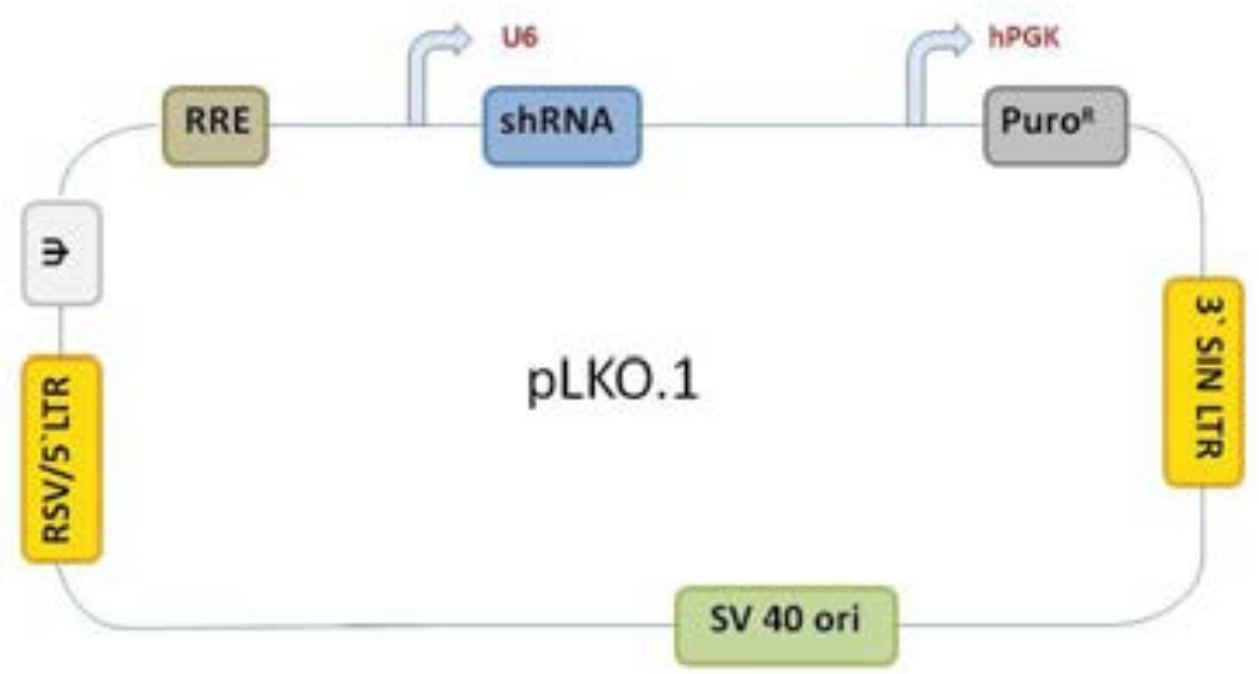

\begin{abstract}
Abbildung 2: Übersicht über den pLKO.1 Puromycin-resistenten shRNAi-Vektor (modifiziert nach OpenBiosystems); Abkürzungen siehe unten
\end{abstract}

\begin{tabular}{l|l} 
Vektorelement & Funktion \\
\hline U6 & Promotor; sorgt für Expression des Zielgens in den Zielzellen \\
\hline shRNA & knockdown des entsprechenden Zielmoleküls \\
\hline hPGK & $\begin{array}{l}\text { Humaner Phosphoglyceratekinase-Promotor für die Expression des Puromycin- } \\
\text { Resistenzgens }\end{array}$ \\
\hline PuroR & Puromycin-Resistenzgen \\
\hline 3'SIN LTR & 3'self-inactivating long terminal repeat für mehr lentivirale Sicherheit \\
\hline SV 40 ori & Promotor für stetige Expression \\
\hline RSV/5'LTR & RSV Promotor/5'long terminal repeat für eine starke lentivirale Transkription \\
\hline$\Psi$ & Psi packing sequence für lentivirales "Genompacking" \\
\hline RRE & Rev response element für effizienteres Packing“
\end{tabular}

Tabelle 4: Abkürzungen der Vektorelemente des pLKO.1 Puromycin-resistenten shRNAi-Vektors

Ist der Vektor durch das Viruspartikel in die Wirtszelle eingeschleust, werden die Gene über lentivirale Mechanismen in das Genom der Zelle integriert. Die shRNA wird nun von der Wirtszelle selbst synthetisiert und ist dauerhaft auch nach weiteren Zellteilungen vorhanden. Wie die siRNA wird auch die shRNA durch Dicer und den RISC weiterverarbeitet. 


\subsubsection{Amplifikation von shRNAi-Vektoren}

Die für diese Arbeit verwendeten Vektoren wurden in bereits transformierten E.coliStämmen (Escherichia coli) bereitgestellt. Mit den E.coli-Stämmen, welche mit einer Carbenicillinresistenz ausgestattet sind, werden jeweils $250 \mathrm{ml}$ LB-Medium angeimpft. Das Medium ist carbenicillinhaltig $(100 \mu \mathrm{g} / \mathrm{ml})$. Am Folgetag werden die Bakteriensuspensionen entsprechend dem Versuchsprotokoll (HiPure Plasmid Filter Midiprep Kit) bearbeitet. Mit den aufgereinigten Plasmiden können nun Transfektionen durchgeführt werden.

\subsubsection{Transfektion und Herstellung lentiviraler Überstände}

Um Viruspartikel herzustellen, welche den shRNAi-Vektor tragen und übermitteln können, müssen zunächst diese shRNAi-Vektoren zusammen mit sogenannten Helfervektoren, die unter anderem für lentivirale Hüllproteine kodieren, in eine Zelle eingebracht werden. Hierzu wird die Modellzelllinie HEK-293T verwendet.

Für die Transfektion sollten die Zellen eine Konfluenz von 60-70 \% in einer P10Petrischale erreicht haben. In einem Eppendorfgefäß werden $30 \mu \mathrm{l}$ TransIT $\AA-293$ vorsichtig mit $900 \mu \mathrm{l}$ Opti-MEM vermischt. In einem weiteren Gefäß werden $2 \mu \mathrm{g}$ Helfervektor-Mix $(0,8 \mu \mathrm{g}$ pHDM-VSVG, 0,4 $\mu \mathrm{g}$ pHDM-tat1b, 0,4 $\mu \mathrm{g}$ pHDM-HgPM2 und $0,4 \mu \mathrm{g}$ pRC-CMV-Rall) und $8 \mu \mathrm{g}$ shRNAi-Vektor zu $100 \mu \mathrm{l}$ Opti-MEM hinzugegeben und vermengt. Beide Lösungen werden nun miteinander vermischt und für 20 Minuten bei Raumtemperatur inkubiert.

Anschließend werden $10 \mathrm{ml}$ frisches Medium auf die Zellen gegeben und die VektorMixtur darauf geträufelt. Die Zellen werden dann unter entsprechenden zellspezifischen Konditionen circa. 48 Stunden inkubiert. In diesem Zeitraum produzieren die Zellen Viruspartikel, welche in das Medium abgegeben werden. Das Medium wird entnommen, durch einen Filter (Porengröße 0,45 $\mu \mathrm{m}$ ) gepresst und anschließend frisch verwendet oder bei $-80^{\circ} \mathrm{C}$ eingefroren.

\subsubsection{Lentivirale Infektion von Zellen}

Mit den zuvor hergestellten Viruspartikeln können nun diverse Zelllinien infiziert und somit der shRNAi-Vektor integriert werden. Hierzu werden die Zellen in einer bestimmten Zellzahl in 6-well-Platten ausplattiert. Die Zellzahl ist abhängig von 
Zellreihe und Versuchsaufbau und variiert zwischen $1 * 10^{5}$ bis $5^{\star} 10^{5}$ Zellen je well. Am Folgetag wird das alte Medium verworfen und $1 \mathrm{ml}$ frisches Medium auf die Zellen gegeben. Hinzu kommt ein $1 \mathrm{ml}$ lentiviraler Überstand. Das Medium wird mit Polybrene $(10 \mu \mathrm{g} / \mathrm{ml}$ Endkonzentration) versetzt. Dieses kationische Polymer reduziert die ladungsbedingten Wechselwirkungen zwischen Viruspartikel und Zelloberfläche und soll so das Eindringen in die Zelle erleichtern. Das mit Viruspartikeln angereicherte Medium wird nach ca. 12 Stunden durch frisches Medium ersetzt.

Nach weiteren 24 Stunden können die Zellen in eine P10-Schale überführt werden. Da jene Zellen, bei denen die Integration der shRNA erfolgreich war, auch ein Resistenzgen gegen Puromycin integriert haben, kann nun eine Selektion mit Puromycin begonnen werden.

\subsubsection{Puromycintitration}

Da jede Zelllinie unterschiedlich sensibel auf Puromycin reagieren kann, wird für die verwendeten Zelllinien eine Puromycintitration durchgeführt. Hierfür müssen die Zellen wie in den vorherigen Schritten mit einem Leervektor (shEmpty) versehen werden, welcher keine Kodierung für eine Suppression enthält. Anschließend werden verschiedene Puromycinkonzentrationen getestet. Die höchste nicht letal wirkende Puromycinkonzentration ist zu wählen. In den Versuchen zeigten sich folgende optimale Puromycinkonzentrationen:

- HEK-293T 2,0 $\mu \mathrm{g} / \mathrm{ml}$

- SW480 2,5 $\mu \mathrm{g} / \mathrm{ml}$

- SW620 2,5 $\mu \mathrm{g} / \mathrm{ml}$

- SW837 $\quad 5,0 \mu \mathrm{g} / \mathrm{ml}$

- PC-3 $\quad 1,5 \mu \mathrm{g} / \mathrm{ml}$

\subsubsection{Elektroporation}

Eine weitere Methode, siRNA in das Zellinnere zu befördern, ist die Elektroporation. Das Prinzip dieses Verfahrens besteht darin, mit Hilfe eines elektrischen Feldes eine permeable Zellmembran zu erhalten. In der Phase der erhöhten Permeabilität kann die siRNA die Zellmembran passieren. Für diese Arbeiten wurde das Lonza Amaxa 
Cell Line Nucleofector Kit $V$ verwendet. Die Versuche wurden nach dem Versuchsprotokoll durchgeführt.

Der stärkste knockdown von CBP kann 24-48 h nach der Elektroporation erreicht werden. Dies ist der optimale Zeitpunkt, um die Zellen weiter zu analysieren oder einem Colony Forming Assay zuzuführen.

\subsection{Klonierung}

\subsubsection{Gelelektrophorese von DNA}

Mit der Gelelektrophorese werden DNA-Fragmente der Größe nach aufgetrennt. Die DNA-Proben und ein Größenmarker werden auf ein Agarosegel aufgetragen, das in einer Elektrophoresekammer liegt und mit 1xTAE-Puffer überschichtet. Die Proben werden zuvor mit 6x LoadingDye versetzt, welches durch den Glycerolgehalt das Absinken der DNA in die Taschen des Gels bewirkt.

Anschließend wird Spannung an die Kammer angelegt. Da die DNA negativ geladen ist, wandert diese zum Pluspol. Die Wanderungsgeschwindigkeit ist umgekehrt proportional zu der Größe der DNA-Fragmente. Die Elektrophorese läuft bei 80-120 V. Die Agarosekonzentration des Gels ist abhängig von der Größe der aufzutrennenden DNA-Fragmente. Bei kleinen Fragmenten wird eine höhere Konzentration verwendet als bei großen. Um die DNA sichtbar zu machen, wird das Gel mit einer DNA-interkalierenden Substanz (Biotium GelRed) versetzt. Die Banden werden danach unter UV-Licht deutlich erkennbar.

Für ein $1 \%$ iges Agarosegel werden $100 \mathrm{ml}$ 1xTAE-Puffer und $1 \mathrm{~g}$ Agarose vermischt. Zusätzlich werden $10 \mu \mathrm{l}$ GelRed hinzugefügt. Diese Lösung wird in der Mikrowelle mehrfach aufgekocht, bis sich die gesamte Agarose gelöst hat. Anschließend lässt man die Agarose leicht abkühlen. Nun können die Gelkammern befüllt werden.

\subsubsection{Transformation von chemisch kompetenten Bakterien mittels heat shock}

Bei einer Transformation wird ein verändertes Plasmid wieder in ein Bakterium eingebracht. Möchte man ein unverändertes Plasmid wieder in ein Bakterium einfügen, spricht man von einer Retransformation. Für eine Transformation werden 
10 - 500 ng Plasmid-DNA und $50 \mu$ l kompetente Bakterien vermischt und 30 min auf Eis inkubiert. Anschließend werden die Bakterien für $30 \mathrm{sec}$ dem Heat shock in einem $42{ }^{\circ} \mathrm{C}$ warmen Wasserbad ausgesetzt und direkt darauf für weitere 2 min auf Eis gelegt. Nun wird das SOC-Medium hinzugegeben. Die Bakterien werden $1 \mathrm{~h}$ bei $37{ }^{\circ} \mathrm{C}$ auf dem Schüttler inkubiert. Anschließend werden die Bakterien auf Agarplatten ausplattiert. In der Regel wird je eine Platte mit $10 \%$ und eine mit $90 \%$ der Bakterien ausplattiert. Die Platten werden über Nacht bei $37^{\circ} \mathrm{C}$ inkubiert.

\subsubsection{Gewinnung von Plasmid-DNA aus Bakterien}

Für die Gewinnung von Plasmid-DNA macht man sich die klonale Vermehrung von Bakterien zunutze. Von den am Vortag präparierten Agarplatten der Transformation wird jeweils eine Kolonie mit einem Zahnstocher gepickt und 200 ml LB-Medium, das mit Ampicillin oder Kanamycin versetzt ist (1:1000), angeimpft. Die Kultur wird über Nacht bei $37^{\circ} \mathrm{C}$ auf einem Schüttler inkubiert.

Die nächsten Arbeitsschritte bis zum isolierten Plasmid sind in dem von Invitrogen mitgeliefertem Versuchsprotokoll (HiPure Plasmid Filter Midiprep Kit) nachzulesen.

\subsubsection{Gewinnung von chromosomaler DNA aus Zellkulturen}

Um chromosomale DNA aus Zellkulturen zu gewinnen, muss eine ausreichende Menge Zellen ( $5 \times 10^{6}$ Zellen) zentrifugiert werden. Das Zellpellet wird anschließend mit PBS gewaschen und nochmals zentrifugiert.

Die folgende Präparation wird nach dem von QIAGEN mitgelieferten Versuchsprotokoll (QIAGEN DNeasy Blood and Tissue Kit) durchgeführt.

\section{$2.4 \quad$ Analyseverfahren}

\subsubsection{Zelllyse und Proteinextraktion}

Um die Proteine der Zellen untersuchen zu können, müssen die Zellen zunächst lysiert und die Proteine extrahiert werden. Zunächst werden die Zellen mit PBS gewaschen, mit Trypsin aus der Petrischale gelöst und anschließend ein weiteres Mal mit PBS gewaschen. Nun wird der Lysepuffer hinzugegeben. Der Lysepuffer (Nonidet P40) wird mit Proteaseinhibitor (1:100), Phospho-Stopp (1:10) und DTT 
(1:10) versetzt, um Dephosphorylierung und Proteinabbau zu verhindern und die Tertiärstruktur der Proteine aufrecht zu erhalten.

Mit dem Lysepuffer erfolgt eine Inkubation auf Eis (45-60 Minuten). Die Suspension wird anschließend zentrifugiert. Der Überstand enthält die Proteine und kann bei $-80{ }^{\circ} \mathrm{C}$ gelagert werden.

Zur Bestimmung der Proteinkonzentration wird das Verfahren nach Bradford verwendet. Hierzu werden in einer 96-well-Plate in Triplikaten $50 \mu$ ler Proteinlösung vorgelegt. Als Standard wird eine Verdünnungsreihe einer Lösung mit fest definierter Konzentration von bovinem Serumalbumin (BSA) verwendet. Anschließend wird je well $200 \mu \mathrm{l}$ Roti Quant-Reagenz hinzugegeben, ein kommerziell erhältliches Reagenz, bei dem eine Umwandlung des Coomassie-Blau-Farbstoffes durch die Interaktion mit den Proteinen zustande kommt. Dieser Farbumschlag kann nach 5 Minuten Inkubation photometrisch bei $595 \mathrm{~nm}$ gemessen werden.

\subsubsection{Proteinauftrennung mittels Gelelektrophorese}

Um die zuvor isolierten Proteine weiter analysieren zu können, werden diese mit Hilfe einer Gelelektrophorese ihrer Größe nach aufgetrennt. Hierzu wird ein Bis-TrisGradientengel (4-12 \%) der Firma Invitrogen verwendet. Die Verwendung eines Gradientengel ermöglicht die Auftrennung eines besonders großen Spektrums von Proteinen. Für die Elektrophorese wird ein MES-SDS-Laufpuffer verwendet. Es werden etwa 8-15 $\mu$ Protein je Probe aufgetragen. Anschließend wird eine Spannungsquelle an die Gelkammer angeschlossen. Die negativ geladenen Proteine wandern nun in Richtung Anode. Um die Proben zu sammeln und später scharf begrenzte Banden zu bekommen, läuft das Gel die ersten Minuten mit 100 Volt, anschließend wird die Spannung auf 150 Volt erhöht.

\subsubsection{Western Blot}

Um die aufgetrennten Proteine sichtbar zu machen, müssen diese von dem Gel auf eine Membran übertragen werden. Für diese Arbeit wird ein Wet-Blot mit einer MiniTrans-Blot-Cell von Bio-Rad verwendet. Es wird eine Polyvinylidendifluorid-Membran (PVDF) verwendet, welche vor dem Transfer in Methanol getränkt wird um diese für die Proteine aufnahmefähig zu machen. 
Das Gel wird auf die PVDF-Membran gelegt. Auf beiden Seiten werden drei Lagen Filterpapier aufgelegt. Dieses Paket wird wiederum zwischen zwei Schwämmen in den Einspannrahmen der Blot-Kammer eingespannt und in die Blot-Kammer gestellt. Es ist darauf zu achten, dass die Membran zur Kathode und das Gel zur Anode gerichtet ist, damit die Proteine korrekt übertragen werden: Anschließend wird die Kammer mit Transferpuffer aufgefüllt. Der Transferpuffer besteht aus $100 \mathrm{ml}$ Transferpuffer (10x), $700 \mathrm{ml} \mathrm{H} \mathrm{H}_{2} \mathrm{O}$ und $200 \mathrm{ml}$ Methanol. Das Blotten erfolgt über $3 \mathrm{~h}$ bei $260 \mathrm{~mA}$.

\subsubsection{Immunfärbung}

Im Anschluss sind die Proteine auf die Membran zu übertragen, und es kann mit der Immunfärbung begonnen werden. Zunächst müssen auf der Membran unspezifische Proteinbindestellen geblockt werden. Hierdurch erhöht sich die Sensitivität des Western-Blots. Dies geschieht bei einer 30-minütigen Inkubation bei Raumtemperatur mit einer 5 \%igen Milchpulver-Lösung auf der Basis eines PBSPuffers. Nach dem Blocken wird die Membran für 5 Minuten mit PBST (PBS mit 0,05\% Tween versetzt) gewaschen.

Die spezifische Detektion von Proteinen erfolgt durch die sog. Primärantikörper. Inkubationszeit, Konzentration und Lösungsmittel (5\% Milchpulver oder $5 \%$ BSA) variieren bei den unterschiedlichen Antikörpern und sind der unten aufgeführten Tabelle (siehe Tabelle 5) zu entnehmen. Nach der Inkubation mit dem Primärantikörper wird die Membran wieder dreimal für 5 Minuten mit PBST gewaschen. Es folgt die zweistündige Inkubation mit dem Sekundärantikörper, welcher gegen die jeweilige Spezies des Primärantikörpers (Kaninchen oder Maus) gerichtet ist. Nach der Inkubation wird die Membran wieder dreimal für 5 Minuten gewaschen. Die Sekundärantikörper sind mit dem Enzym Meerrettichperoxidase konjugiert, welches nun zur Visualisierung der Proteinbanden auf der Membran benötigt wird. Hierfür wird ein Substrat für die Meerrettichperoxidase, das Luminata forte, auf die Membran gegeben, welches nun über mehrere Schritte zu Luminol oxidiert wird, welches wiederum luminesziert. Diese Lumineszenz kann nun durch eine sensitive Kamera aufgenommen werden.

In allen Immunfärbungen wurde das Histon H3 als Proteinladekontrolle gefärbt. 


\begin{tabular}{|c|c|c|c|c|c|}
\hline Antikörper & $\begin{array}{c}\text { Größe } \\
\text { Zielprotein }\end{array}$ & Verdünnung & $\begin{array}{c}\text { Lösungs- } \\
\text { mittel }\end{array}$ & $\begin{array}{c}\text { Inkubations- } \\
\text { zeit }\end{array}$ & $\begin{array}{c}\text { Sekundär- } \\
\text { antikörper }\end{array}$ \\
\hline CBP & $265 \mathrm{kDa}$ & $1: 2000$ & Milchpulver & $2 \mathrm{~h}$ & Kaninchen \\
\hline ß-cat & $92 \mathrm{kDa}$ & $1: 1000$ & $\mathrm{BSA}$ & Über Nacht & Kaninchen \\
\hline act-ß-cat & $92 \mathrm{kDa}$ & $1: 4000$ & Milchpulver & Über Nacht & Maus \\
\hline c-myc & $57-65 \mathrm{kDa}$ & $1: 1000$ & $\mathrm{BSA}$ & Über Nacht & Kaninchen \\
\hline c-jun & $43-48 \mathrm{kDa}$ & $1: 1000$ & $\mathrm{BSA}$ & Über Nacht & Kaninchen \\
\hline p53 & $53 \mathrm{kDa}$ & $1: 2000$ & Milchpulver & Über Nacht & konjugiert \\
\hline $\mathrm{p} 21$ & $21 \mathrm{kDa}$ & $1: 500$ & Milchpulver & Über Nacht & Maus \\
\hline $\mathrm{H} 3$ & $17 \mathrm{kDa}$ & $1: 3333$ & Milchpulver & 30 min & Kaninchen \\
\hline
\end{tabular}

Tabelle 5: Benutzte Antikörper und verwendete Konditionen

\subsubsection{Visueller Letalitätstest nach shRNA-knockdown}

Um den Einfluss eines knockdowns auf die Vitalität zu überprüfen wurde dieser Test durchgeführt. Zur Veranschaulichung werden in einer Versuchsanordnung nach festen Zeitpunkten Fotoaufnahmen gemacht um den Zelluntergang zu dokumentieren. Hierzu wird die Zelllinie HEK-293T verwendet. Es werden erstens Wildtypzellen wachsen gelassen, zweitens Zellen mit einem Leervektor und drittens Zellen, die mit einer gegen CBP gerichteten shRNA infiziert sind.

Zur Überprüfung des knockdowns wird mit den Proteinen der toten Zellen ein Western Blot durchgeführt.

\subsubsection{Colony Forming Assay (CFA)}

Der Colony Forming Assay misst, wie stark die Resistenz der Zellen zu einem bestimmten Zeitpunkt gegenüber einer Radio- oder Radiochemotherapie sind. Dazu wird eine bestimmte Zellzahl, die je nach Zellinie variiert, in Triplikaten in einer 6well-Plate ausgesät. Nach einer Adhärenzzeit von $24 \mathrm{~h}$ kann mit der Bestrahlung begonnen werden. Die Zellen werden mit 1, 2, 4, 6 und 8 Gray (Gy) bestrahlt (Geräteeinstellung: 200 kV, 15 mA, Filter: 0,5 mm Kupfer, Tischhöhe: $351 \mathrm{~mm}$ ). Die Behandlung mit 5-FU $(100 \mu \mathrm{M} / \mathrm{ml})$ beginnt $12 \mathrm{~h}$ nach dem Setzen der Zellen und hält $24 \mathrm{~h}$ an; danach wird das Medium gegen ein Frisches ausgetauscht.

Werden für den Versuch Zellen mit einem knockdown eingesetzt, so wird ein Teil der Zellen weiter kultiviert, um zum Zeitpunkt der Bestrahlung eine Proteinextraktion 
vorzunehmen. Damit kann sichergestellt werden, dass während der Schadenssetzung (Bestrahlung) auch tatsächlich ein knockdown vorgelegen hat.

Sobald die Zellen die Bestrahlung und Chemotherapie erfahren haben, werden sie $\mathrm{zu}$ den üblichen Konditionen weiter kultiviert, bis sie Kolonien von mindestens 50 Zellen gebildet haben. Dies entspricht in etwa 5-6 Teilungszyklen. Daraus kann man schlussfolgern, dass Zellen, die eine ebensolche Kolonie bilden, den gesetzten Schaden adäquat kompensieren konnten.

Um die Zellen zu fixieren und zu färben wird zunächst das Medium verworfen, der Boden mit 70 \%igem Ethanol bedeckt und für 20 Minuten bei Raumtemperatur inkubiert. Anschließend wird das Ethanol verworfen und für 5 Minuten Hämalaunblau (bei SW480 Kristallviolett) auf die Zellen gegeben. Nach dem Spülen mit Wasser können die Platten getrocknet werden.

\begin{tabular}{|c|c|c|c|c|}
\hline & & \multicolumn{3}{|c|}{ Zellzahl je well } \\
\hline \multirow{4}{*}{$\begin{array}{c}\text { Dosis } \\
\text { (Gy) }\end{array}$} & 0 & HEK-283T & SW480 & SW837 \\
\cline { 2 - 5 } & 1 & 400 & 250 & 750 \\
\cline { 2 - 5 } & 2 & 400 & 250 & 750 \\
\cline { 2 - 5 } & 4 & 800 & 250 & 750 \\
\cline { 2 - 5 } & 6 & 1200 & 750 & 1500 \\
\hline
\end{tabular}

Tabelle 6: Einzusetzende Zellzahlen bei CFA

\subsection{Patientenkollektiv}

Bei dem Patientenkollektiv handelt es sich um Teilnehmer einer prospektiv randomisierten und multizentrischen Phase II-Studie (GAST-05-Studie | ISRCTN 35198481), in der die Therapie des lokal fortgeschrittenen Rektumkarzinoms im oberen Rektumdrittel untersucht wurde. Die beiden randomisierten Versuchsarme unterscheiden sich in der gewählten Operationsart. Patienten in Versuchsarm A erhielten begleitend zu der TARR/ARR eine TME, Patienten in Versuchsarm $B$ eine PME. Vor dem operativen Eingriff erhielten alle Patienten dieselben diagnostischen Voruntersuchungen. Da keine neoadjuvante Chemotherapie vorgesehen war, unterlag der Tumor keinen Selektionseinflüssen. 4-5 Wochen nach der Operation 
erhielten die Patienten ggf. die adjuvante Chemotherapie. Die Nachsorge fand gemäß den Leitlinien der Deutschen Krebsgesellschaft statt. Das für die immmunhistochemische Untersuchung verwendete Patientenkollektiv bestand aus 30 Frauen und 63 Männern. Der jüngste Patient des Kollektivs war 38 Jahre alt, der älteste Patient war 88 Jahre alt. Im Median betrug das Patientenalter 70 Jahre.

\begin{tabular}{|c|c|}
\hline Parameter & Patientenanzahl absolut (Prozent) \\
\hline Frauen & $30(32,3 \%)$ \\
\hline Männer & $63(67,7 \%)$ \\
\hline Altersmedian & 70 \\
\hline ARR & $37(39,8 \%)$ \\
\hline TARR & $53(57 \%)$ \\
\hline TME & $38(40,9 \%)$ \\
\hline PME & $52(55,9 \%)$ \\
\hline Adjuvante Therapie & $61(65,6 \%)$ \\
\hline $\mathrm{pT} 1$ & $3(3,2 \%)$ \\
\hline pT2 & $18(19,4 \%)$ \\
\hline pT3 & $61(65,6 \%)$ \\
\hline pT4 & $11(11,8 \%)$ \\
\hline pNO & $53(57 \%)$ \\
\hline $\mathrm{pN} 1$ & $22(23,7 \%)$ \\
\hline pN2 & $18(19,4 \%)$ \\
\hline LO & $68(73,1 \%)$ \\
\hline L1 & $23(24,7 \%)$ \\
\hline V0 & $80(86 \%)$ \\
\hline V1 & $12(12,9 \%)$ \\
\hline G1 & $0(0 \%)$ \\
\hline G2 & $67(72 \%)$ \\
\hline G3 & $25(26,9 \%)$ \\
\hline pUICC I & $13(14 \%)$ \\
\hline pUICC II & $39(41,9 \%)$ \\
\hline pUICC III & $38(40,9 \%)$ \\
\hline pUICC IV & $2(2,2 \%)$ \\
\hline
\end{tabular}




\subsection{Statistische Analysen}

Die statistischen Auswertungen erfolgten in Zusammenarbeit mit Herrn Prof. Dr. Tim Beißbarth vom Institut für Medizinische Statistik Göttingen.

Bei der Berechnung der Verteilung der CBP-Expression in basalen, apikalen und zentralen Bereichen wurde der Pearson-Korrelationskoeffizient verwendet. Der Pearson-Korrelationskoeffizient lässt Aussagen über statistische Zusammenhänge zu, sofern die Daten dichotom und intervallskaliert sind. Es ist notwendig, dass die Variablen normalverteilt sind.

Die Korrelation des CBP-Status mit den klinischen Parametern ( $p T, p N, L, V$, grade, pUICC) wurde nach Kendall's Tau berechnet und die Signifikanz bestimmt.

Bei den Analysen bezüglich des TTR (time to any recurrence), TTLR (time to local recurrence) und CSS (cancer specific survival) wurden Kaplan-Meier Kurven erstellt. Hier sind der p-Wert und die Hazard Ratio aus dem Cox Proportional Hazards Model bestimmt worden. Bei sämtlichen Analysen wurde das Signifikanznivau auf $\alpha=5 \%$ $(p<0.05)$ festgelegt. Für die statistischen Berechnungen wurde das Programm $R(R$ Core Team 2013) verwendet. In ähnlicher Weise wurden die statistischen Analysen in der Arbeit von L.-C. Conradi verwendet (Conradi et al. 2011).

Um die Daten über die Expressionsstärke in den immunhistochemischen Schnitten zu erhalten, wurde der H-Score verwendet (Goulding et al. 1995).

Dieser wurde wie folgt berechnet:

$\%$ (schwach gefärbt) $\times 1+\%$ (moderat gefärbt) $\times 2+\%$ (stark gefärbt) $\times 3=0-300$ 


\section{Ergebnisse}

\subsection{Immunhistochemische Auswertung}

\subsubsection{Korrelation zwischen CBP-Expression und Tumorregion}

Bei den Analysen der CBP-Expression bezogen auf die Lokalisierung innerhalb des Tumors, nämlich die basalen, zentralen und apikalen Bereiche, lässt sich ein Trend erkennen.

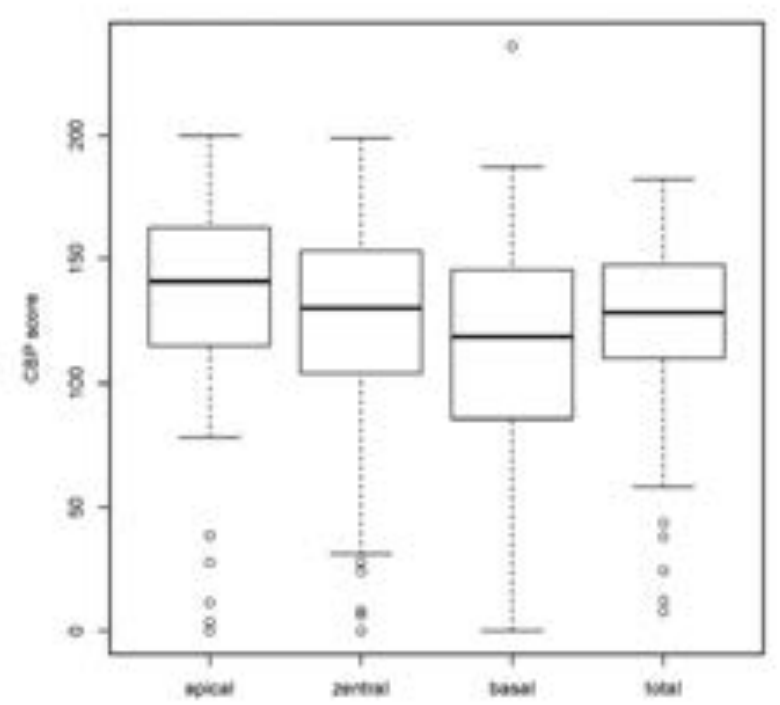

\section{Abbildung 3: CBP-Verteilung innerhalb des Tumors}

Es zeigt sich, dass in den basalen Bereichen des Tumors die geringste CBPExpression vorliegt. In den apikalen Bereichen ist die höchste Konzentration von CBP zu finden (Abbildung 3). Setzt man die CBP-Expressionen zueinander in Beziehung, ist dieser Trend ebenfalls klar erkennbar (Abbildung 4).

Nach statistischer Auswertung zeigt sich dieser Trend zwar bestätigt, ist jedoch nicht signifikant ( $p-W e r t>0,05)$. 

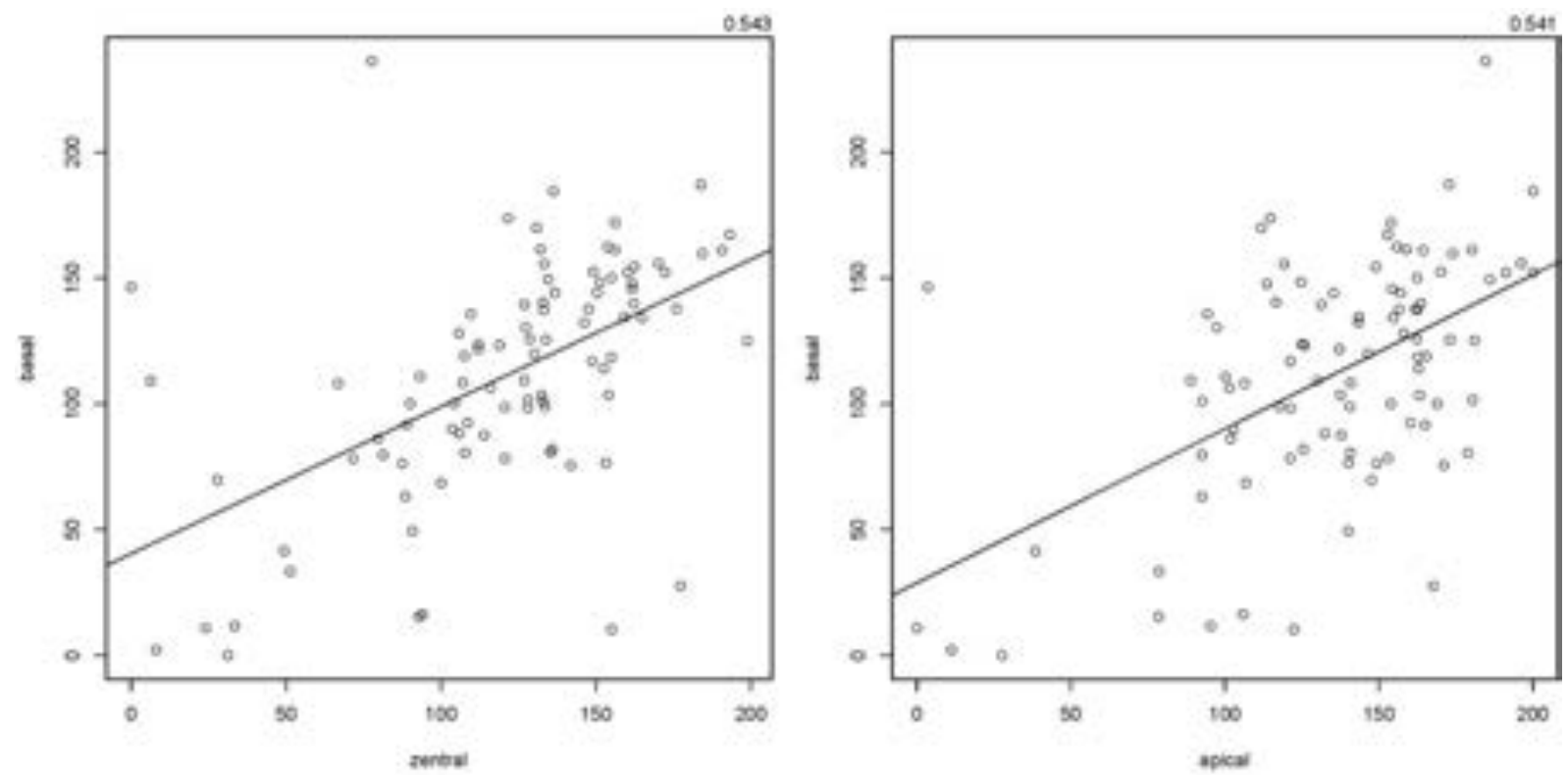

Abbildung 4: Korrelation der CBP-Verteilung innerhalb des Tumors

\subsubsection{Korrelationen zwischen CBP-Expression und pathologischen} Parametern

Neben der Verteilung des CBP innerhalb des Tumors wurden die Präparate auch auf einen Zusammenhang zwischen der Expressionsstärke von CBP und pathologischen Parametern hin untersucht. $\mathrm{Zu}$ den untersuchten Parametern gehörten die Tumorausdehnung $(T)$, der Lymphknotenstatus $(\mathrm{N})$, Lymphgefäßstatus (L), Tumoreinbruch in Venen (V), das UICC-Stadium und das Grading (G). Bei keinem dieser Parameter konnte eine signifikante Korrelation festgestellt werden (Abb.5-10).

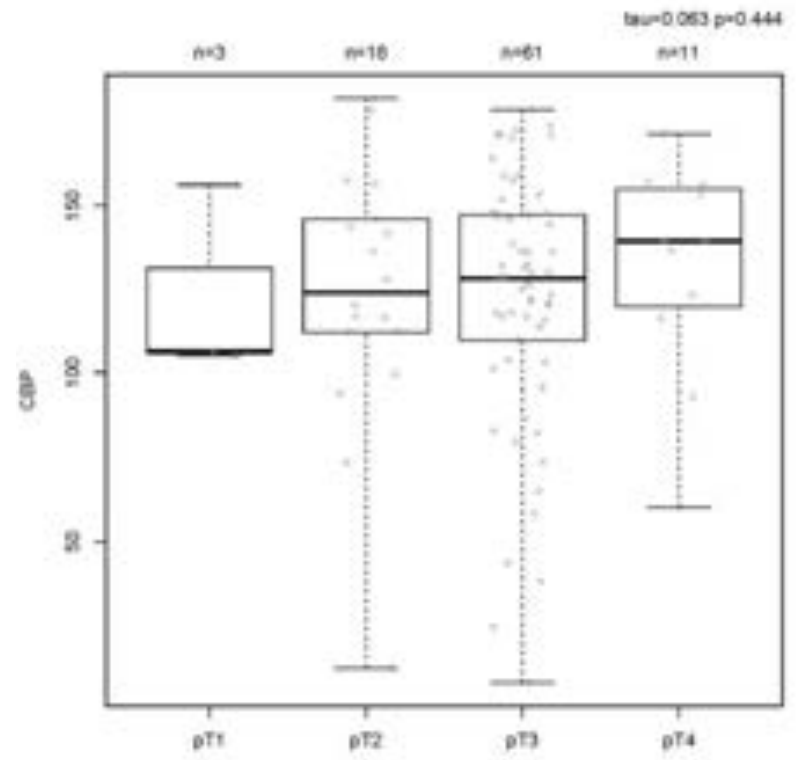

Abbildung 5: Korrelation von CBP mit T-Stadium

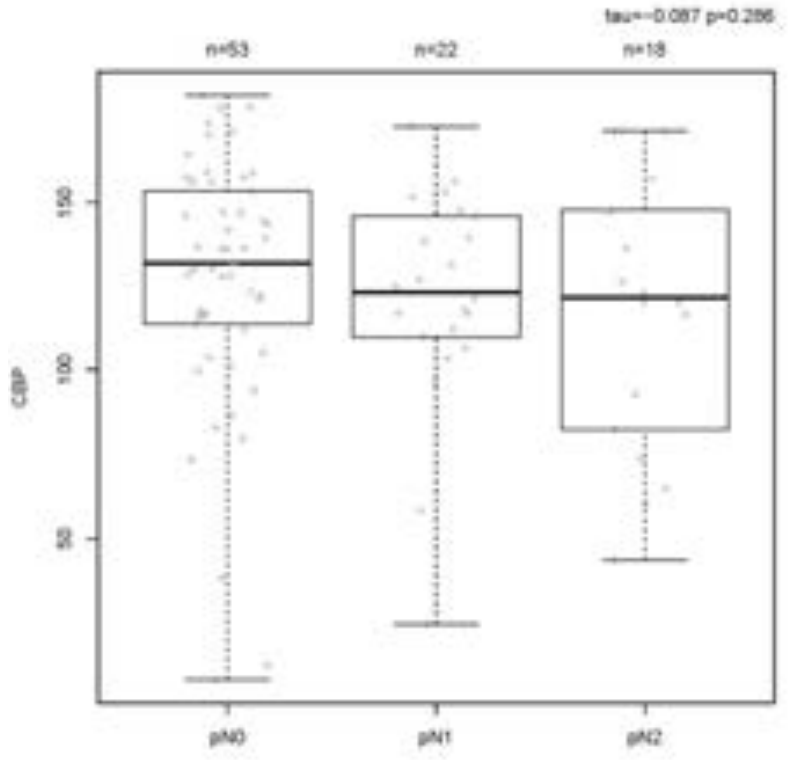

Abbildung 6: Korrelation von CBP mit N-Stadium 


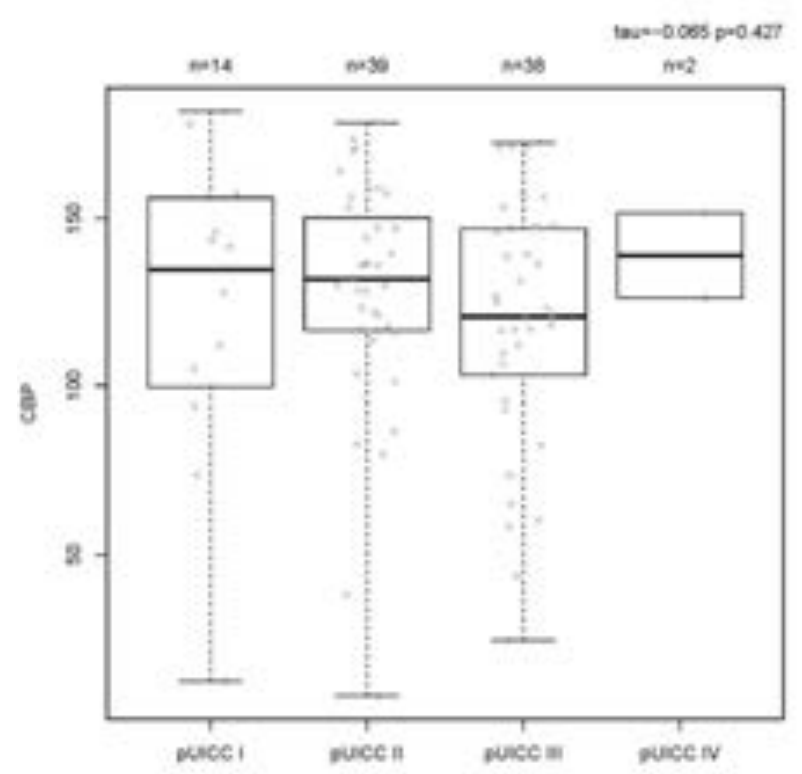

Abbildung 7: Korrelation von CBP mit UICC-Stadium

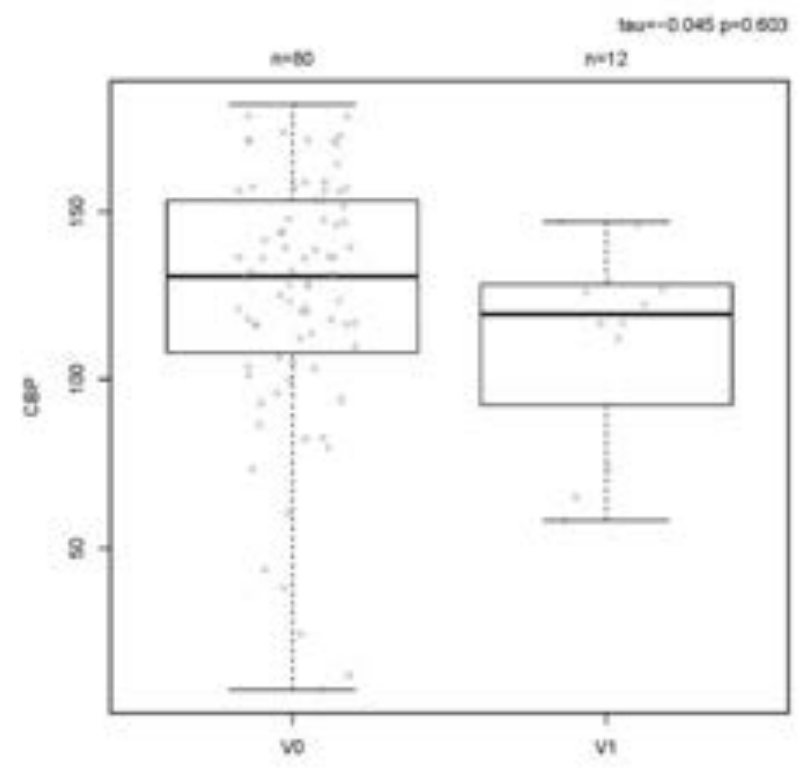

Abbildung 9: Korrelation von CBP mit Veneninfiltration

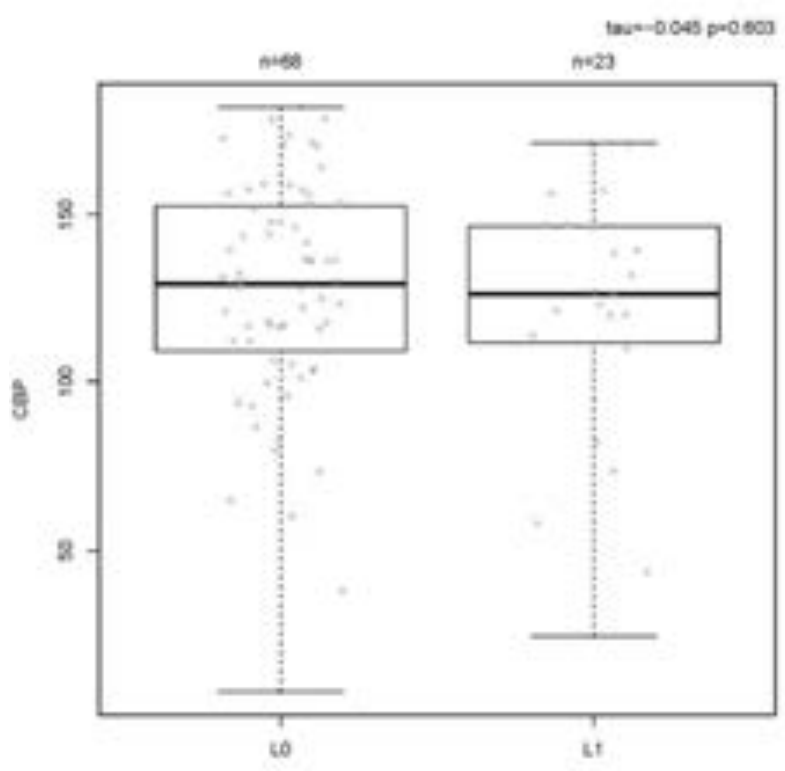

Abbildung 8:Korrelation von CBP mit Lymphgefäßinfiltration

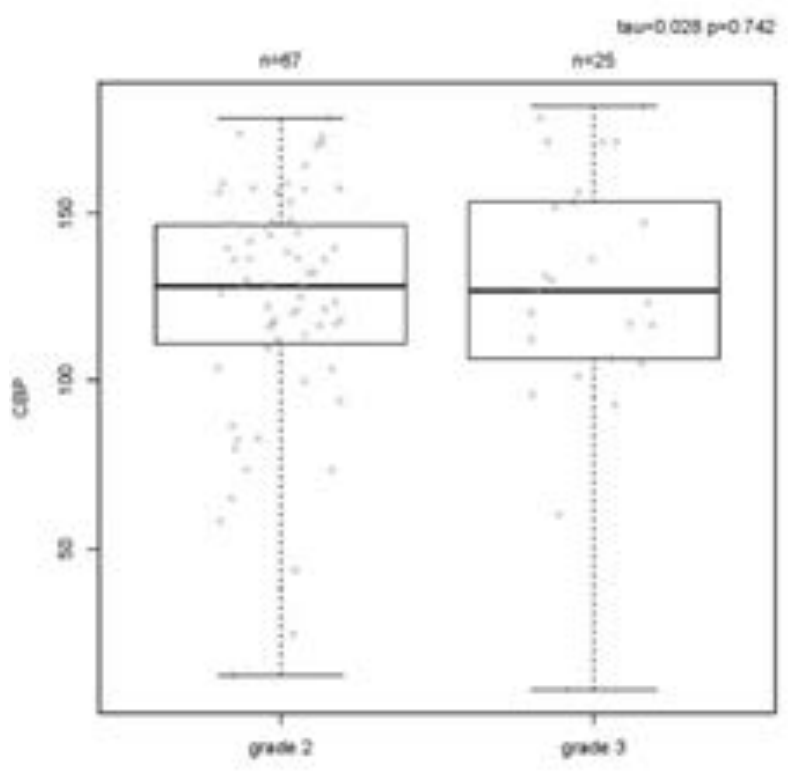

Abbildung 10: Korrelation von CBP mit Grading 


\subsubsection{Korrelation zwischen CBP-Expression und Tumorrezidivrate}

Neben den pathologischen Parametern wurden auch Faktoren wie beispielsweise die Rezidivraten und das Überleben überprüft. Bei diesen Analysen ist der Trend zu erkennen, dass sowohl bei der time to recurrence (TTR) als auch bei der time to local recurrence (TTLR) eine hohe Expression von CBP sich zeitlich positiv auf das Auftreten von Rezidiv und lokalem Rezidiv auswirkt (Abbildung 11).

Unter der TTR ist die Zeit zwischen der Operation und dem Auftreten eines Lokalrezidivs oder einer Metastase zu verstehen.
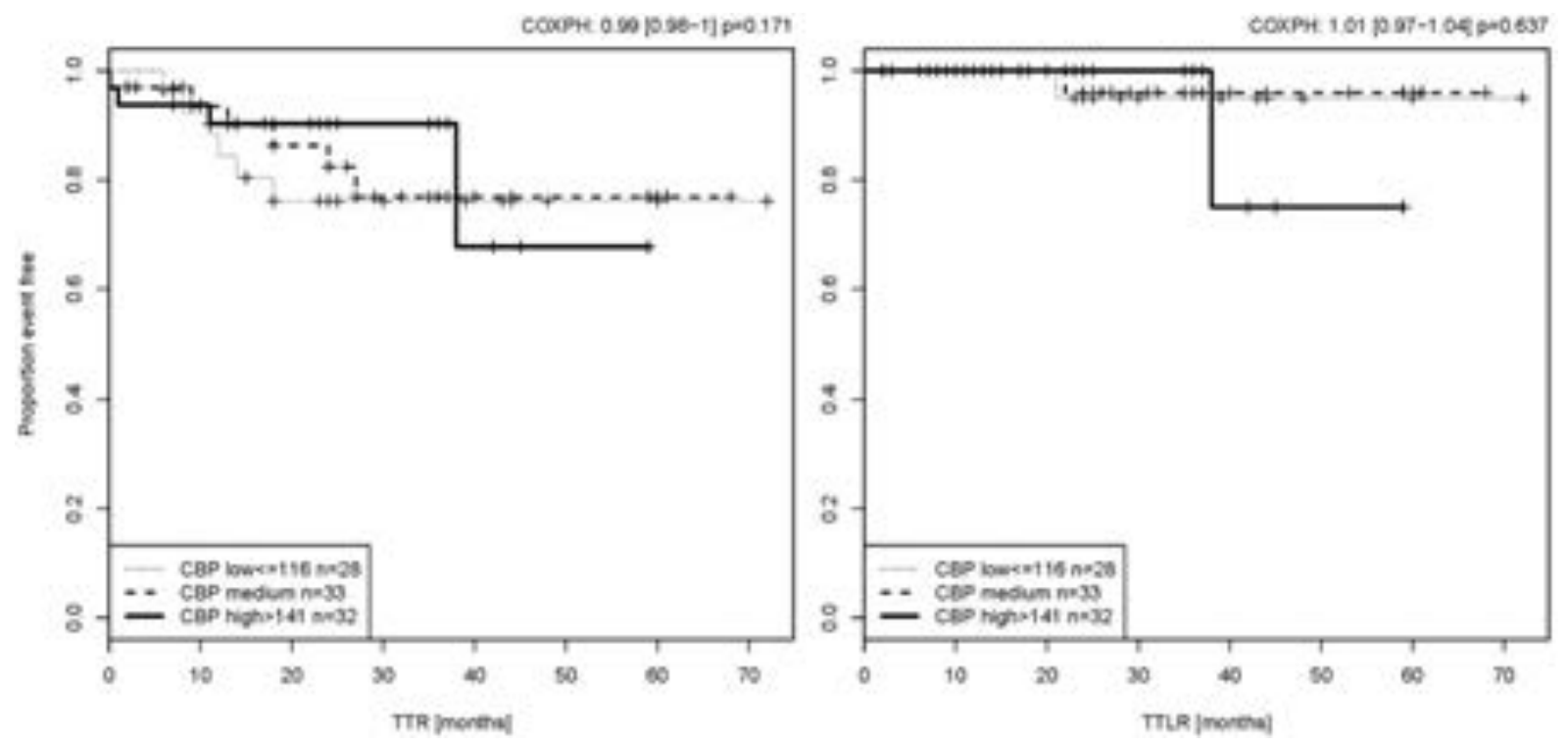

\section{Abbildung 11: CBP und TTR / TTLR}

Eine klare statistische Signifikanz ist nicht gegeben (TTR: $p=0,171$; TTLR: $p=0,637$ ).

\subsubsection{Korrelation zwischen CBP-Expression und tumorspezifischem Überleben}

Bei der Korrelation der CBP-Expression mit klinischen Daten konnte eine hohe statistische Signifikanz zwischen der Expressionsstärke von CBP und dem tumorspezifischen Überleben (CSS) festgestellt werden. Patienten, deren Tumoren eine hohe oder mittlere CBP-Expression aufweisen, zeigen ein verlängertes tumorbezogenes Überleben $(p=0,00278)$ (Abbildung 12). 


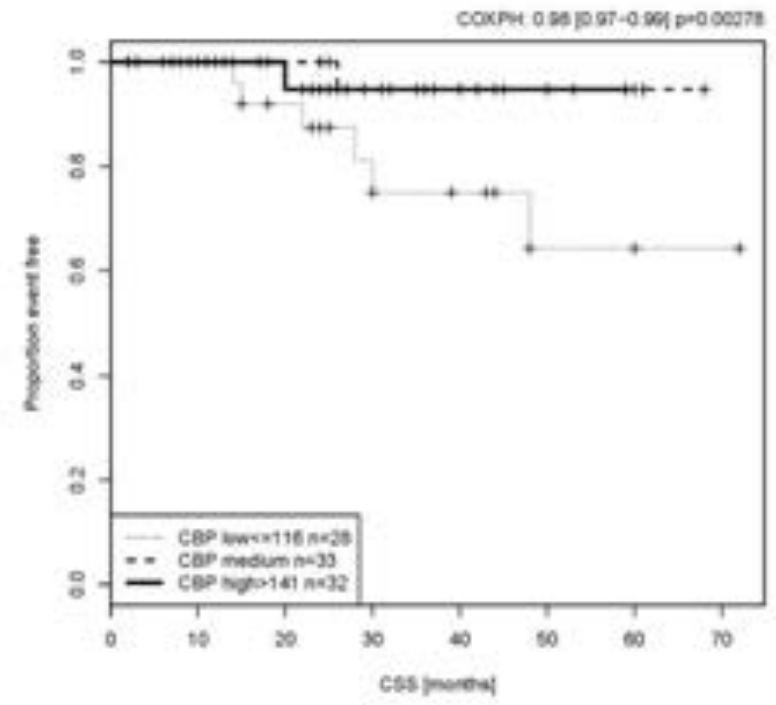

\section{Abbildung 12: Korrelation von CBP-Expression und CSS}

Das 5-Jahres-Überleben ist für Patienten mit niedriger CBP-Expression im Tumor über $30 \%$ geringer als für Patienten mit mittlerer bis hoher CBP-Expression. Die Einteilung der Patienten nach Tumoren mit niedriger, mittlerer und hoher CBPExpression wurde so gewählt, dass drei gleich große Gruppen zustande kommen.

\begin{tabular}{|c|c|c|c|c|c|}
\hline \multirow{2}{*}{ Variable } & \multirow{2}{*}{$\begin{array}{l}\text { Anzahl } \\
\text { Patienten }\end{array}$} & \multicolumn{3}{|c|}{ CBP-Expression } & \multirow{2}{*}{ p-Wert } \\
\hline & & Niedrig & Mittel & Hoch & \\
\hline Total & 93 & $28(30,1 \%)$ & $33(35,5 \%)$ & $32(34,4 \%)$ & \\
\hline \multicolumn{5}{|c|}{ Tumorausdehnung } & \multirow{5}{*}{0,444} \\
\hline pT1 & 3 & $2(66,7 \%)$ & $0(0 \%)$ & $1(33,3 \%)$ & \\
\hline pT2 & 18 & $6(33,3 \%)$ & $5(27,8 \%)$ & $7(38,9 \%)$ & \\
\hline pT3 & 61 & $18(29,5 \%)$ & $23(37,7 \%)$ & $20(32,8 \%)$ & \\
\hline pT4 & 11 & $2(18,2 \%)$ & $5(45,5 \%)$ & $4(36,3 \%)$ & \\
\hline \multicolumn{5}{|c|}{ Lymphknotenstatus } & \multirow{4}{*}{0,286} \\
\hline $\mathrm{pNO}$ & 53 & $15(28,3 \%)$ & $18(34 \%)$ & $20(37,7 \%)$ & \\
\hline $\mathrm{pN} 1$ & 22 & $7(31,8 \%)$ & $9(40,9 \%)$ & $6(27,3 \%)$ & \\
\hline $\mathrm{pN} 2$ & 18 & $6(33,3 \%)$ & $6(33,3 \%)$ & $6(33,3 \%)$ & \\
\hline \multicolumn{5}{|c|}{ Lymphgefäßstatus } & \multirow{3}{*}{0,603} \\
\hline LO & 68 & $20(29,4 \%)$ & $24(35,3 \%)$ & $24(35,3 \%)$ & \\
\hline L1 & 23 & $7(30,4 \%)$ & $9(39,1 \%)$ & $7(30,4)$ & \\
\hline
\end{tabular}




\begin{tabular}{|c|c|c|c|c|c|}
\hline \multicolumn{5}{|c|}{ Venenstatus } & \multirow{3}{*}{0,603} \\
\hline V0 & 80 & $24(30 \%)$ & $27(33,8 \%)$ & $29(36,2 \%)$ & \\
\hline V1 & 12 & $4(33,3 \%)$ & $6(50 \%)$ & $2(16,7 \%)$ & \\
\hline \multicolumn{5}{|c|}{ Grading } & \multirow{4}{*}{0,742} \\
\hline G1 & 0 & $0(0 \%)$ & $0(0 \%)$ & $0(0 \%)$ & \\
\hline G2 & 67 & $20(30 \%)$ & $25(37,2 \%)$ & $22(32,8 \%)$ & \\
\hline G3 & 25 & $8(32 \%)$ & $8(32 \%)$ & $9(36 \%)$ & \\
\hline \multicolumn{5}{|c|}{ UICC-Stadium } & \multirow{5}{*}{0,427} \\
\hline pUICC I & 14 & $6(42,9 \%)$ & $1(7,1 \%)$ & $7(50 \%)$ & \\
\hline pUICC II & 39 & $9(23 \%)$ & $17(43,7 \%)$ & $13(33,3 \%)$ & \\
\hline pUICC III & 38 & $13(34,2 \%)$ & $14(36,9 \%)$ & $11(28,9 \%)$ & \\
\hline pUICC IV & 2 & $0(0 \%)$ & $1(50 \%)$ & $1(50 \%)$ & \\
\hline
\end{tabular}

Tabelle 8: Zusammenfassung: Korrelation CBP-Expression und pathologische Parameter

\subsection{Molekularbiologische Auswertung}

\subsubsection{Einfluss von CBP-knockdown auf die Letalität}

Knockdown-Versuche mit shRNA in verschiedenen Konstellationen haben gezeigt, dass ein dauerhaftes Herunterregulieren des CBP für Zellen in vitro letal ist. Es wurden unterschiedliche Zeitreihen und Zelllinien getestet. $\mathrm{Zu}$ den getesteten Zelllinien gehören sowohl Rektum-, Colon-, Prostata als auch Nieren-Zelllinien: SW480, SW837, SW620, PC-3, HEK-293T.

Sowohl der Wildtyp als auch die mit dem Leervektor infizierten Zellen wachsen gleichermaßen zu einem dichten „Zellrasen“. Lediglich die Zellen mit einem CBPknockdown sterben (Abbildung 14). Um den knockdown nachzuweisen, wurde das Protein für den Western Blot aus dem Überstand, also den bereits toten Zellen gewonnen (Abbildung 13).

\section{WT $\operatorname{sh} 72 i$ \\ $265 \mathrm{kDa}--\mathrm{CBP}$ \\ $17 \mathrm{kDa}=\mathrm{H} 3$}

Abbildung 13: Western Blot sh-knockdown-Überstand (HEK-293T) 
O h

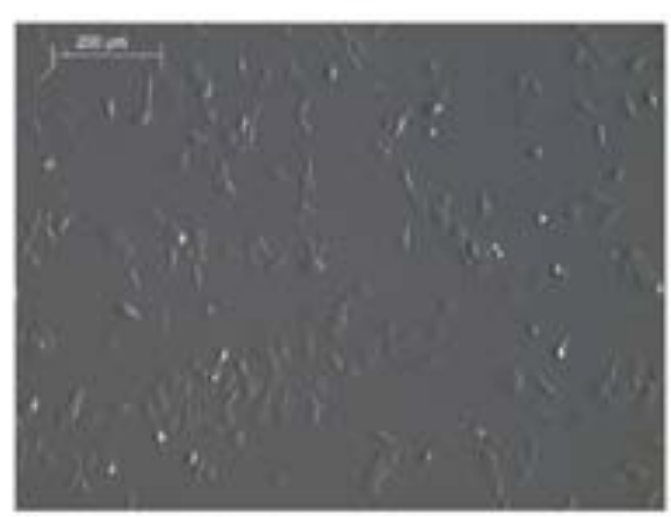

Widtyp

shEmpty

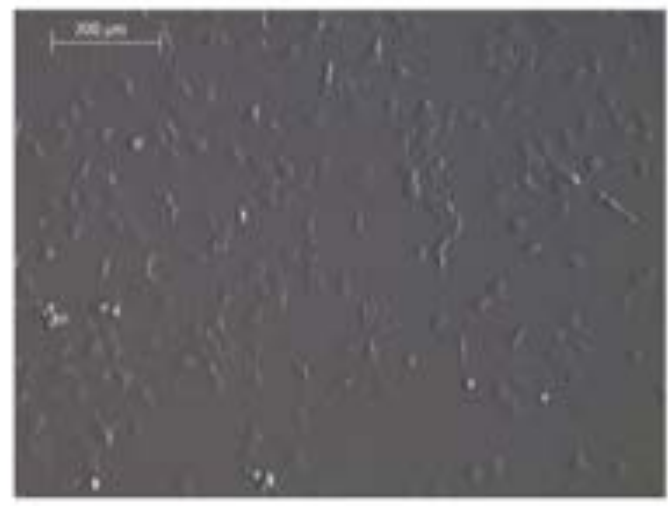

shCBP $\# 72$

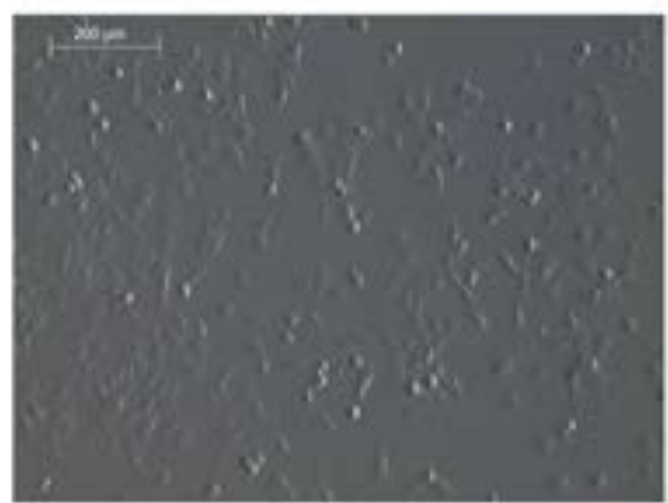

$60 \mathrm{~h}$
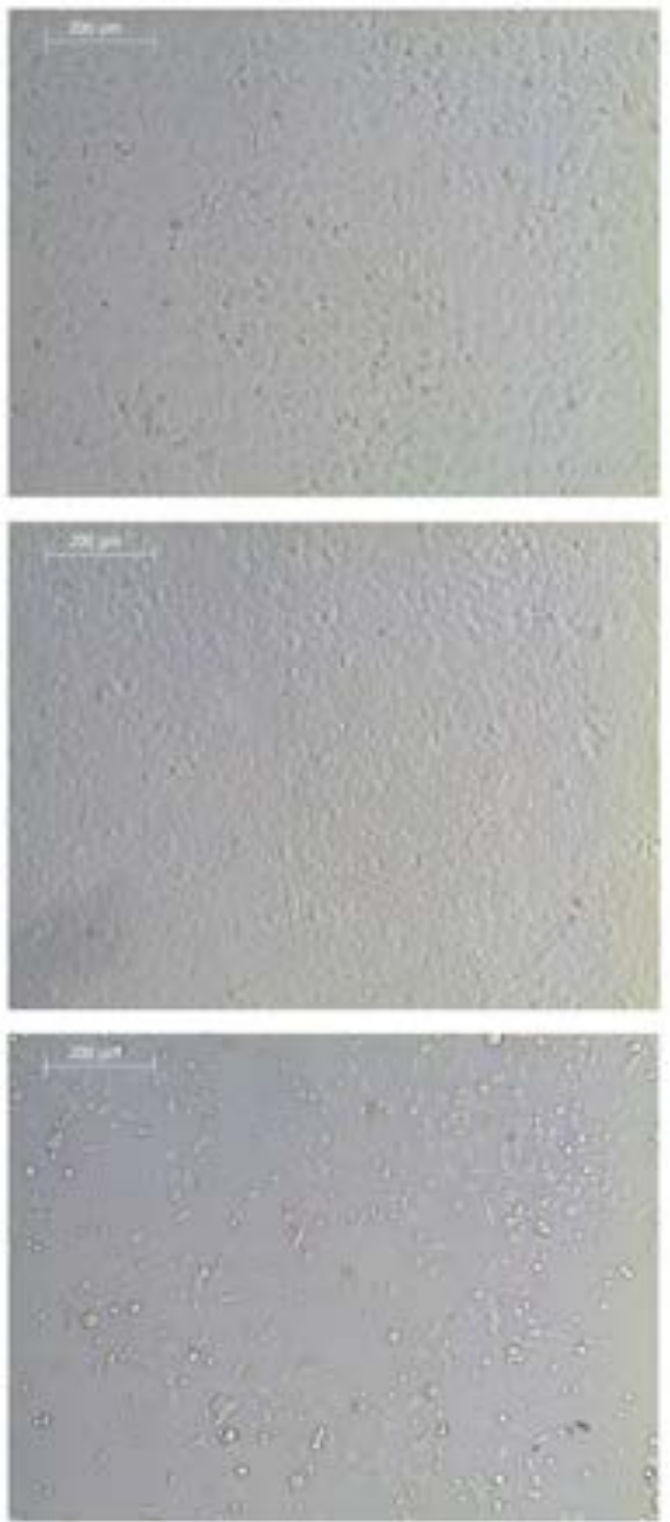

Abbildung 14: Zelluntergang nach CBP-knockdown mit shRNAi 


\subsubsection{Der knockdown von CBP induziert eine erhöhte Strahlensensibilität}

Bei dem folgenden Versuch wurde ein passagerer knockdown mittels siRNA erreicht. Für den Versuch wurden die Rektumzelllinie SW837 verwendet.

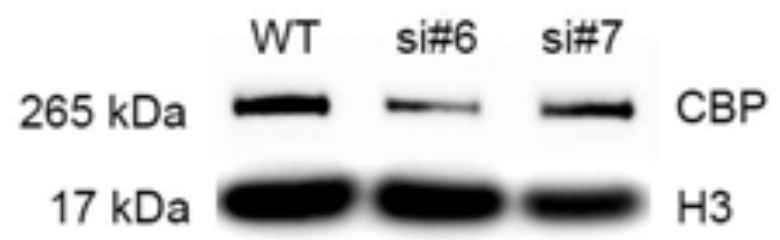

Abbildung 15: WB des CBP-KD der SW837 vom CFA

Anschließend wurde ein CFA durchgeführt. In Abbildung 16 ist die Tendenz erkennbar, dass sowohl bei der Radiotherapie als auch bei der kombinierten Radiochemotherapie durch den knockdown eine gesteigerte Strahlensensibilität erreicht werden konnte.
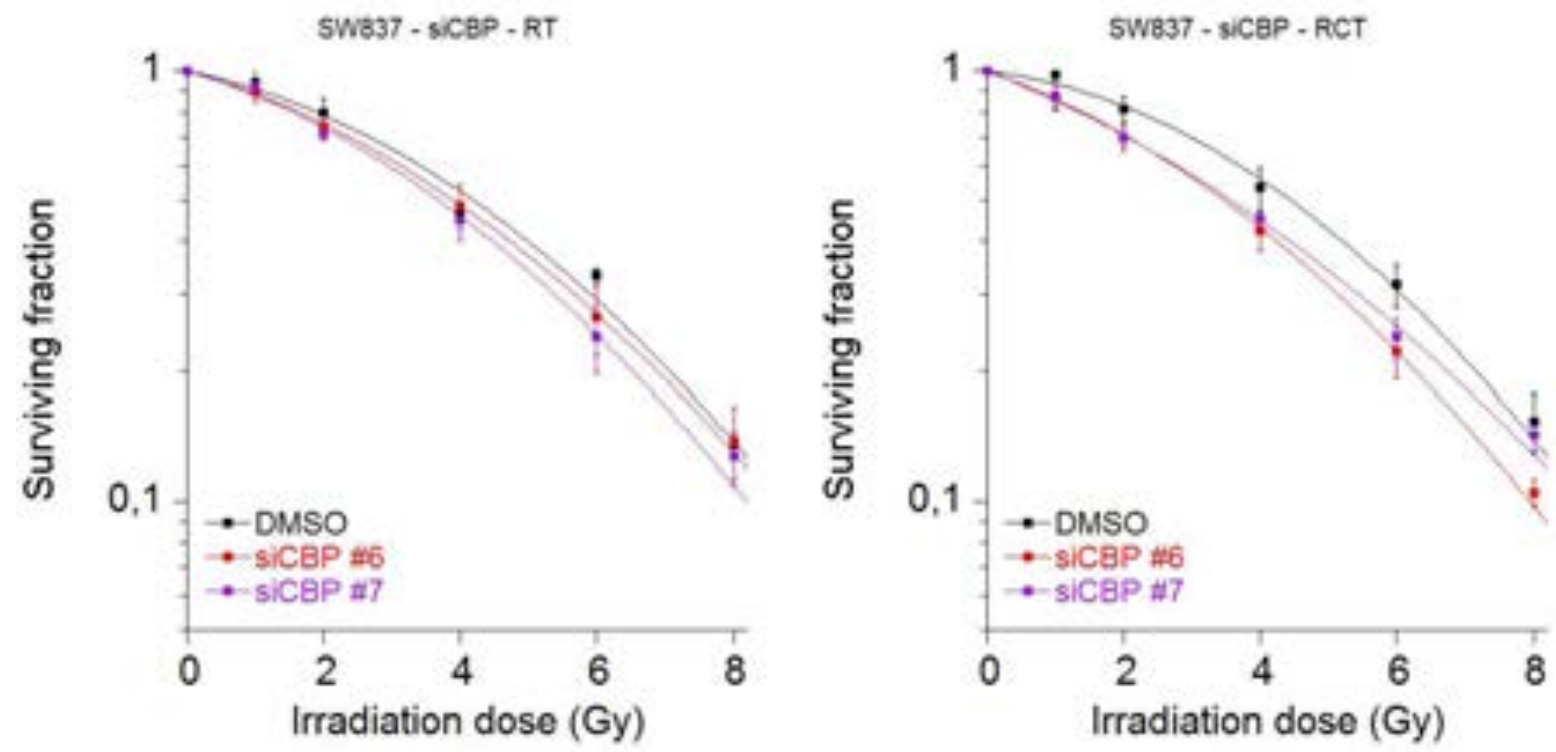

Abbildung 16: CFA mit RT (Radiotherapie) und RCT (Radiochemotherapie) von SW837 mit si-knockdown von CBP (3 Versuchsreihen)

Der Effekt des knockdown bei reiner Radiotherapie ist jedoch bei genauer Betrachtung des dose reduction factor nicht besonders ausgeprägt. Ein stärkerer Effekt kann bei der kombinierten Radiochemotherapie erzielt werden (Tabelle 9). Der größte DRF kann bei niedrigerer Strahlendosis beobachtet werden. So erzielt man 
mit dem CBP-knockdown sowohl bei der Radio- als auch bei der kombinierten Radiochemotherapie den stärksten Effekt bei einer LD (letalen Dosis) von $25 \%$.

\begin{tabular}{|c|c|c|c|c|c|c|}
\hline \multicolumn{7}{|c|}{ Dose reduction factor (DRF) } \\
\hline & \multicolumn{3}{|c|}{ Radiotherapie } & \multicolumn{3}{c|}{ Radiochemotherapie } \\
\hline & LD $_{25}$ & LD & LD $_{75}$ & LD $_{25}$ & LD $_{50}$ & LD $_{75}$ \\
\hline siCBP\#6 & 1,16 & 1,08 & 1,05 & 1,51 & 1,28 & 1,20 \\
\hline siCBP\#7 & 1,21 & 1,14 & 1,11 & 1,54 & 1,24 & 1,14 \\
\hline
\end{tabular}

Tabelle 9: DRF der SW837 mit CBP-KD bei LD25/50/75; DFR: Dose reduction factor; LD25/50/75: Letale Dosis mit Letalität bei 25/50/75\% der Zellen

\subsubsection{Der CBP-knockdown wirkt sich direkt auf Interaktionspartner aus}

Neben der Strahlen- und Chemosensibilität wurde überprüft, ob und inwieweit sich der knockdown des CBP auch auf Proteinebene auswirkt. Hierzu wurden Proteine von HEK-293T-Zellen mit einem shRNA-knockdown verwendet. Die ausgewählten Proteine spielen in der Onkogenese eine wichtige Rolle und sind direkte oder indirekte Interaktionspartner von CBP.

WT sh70i sh73i

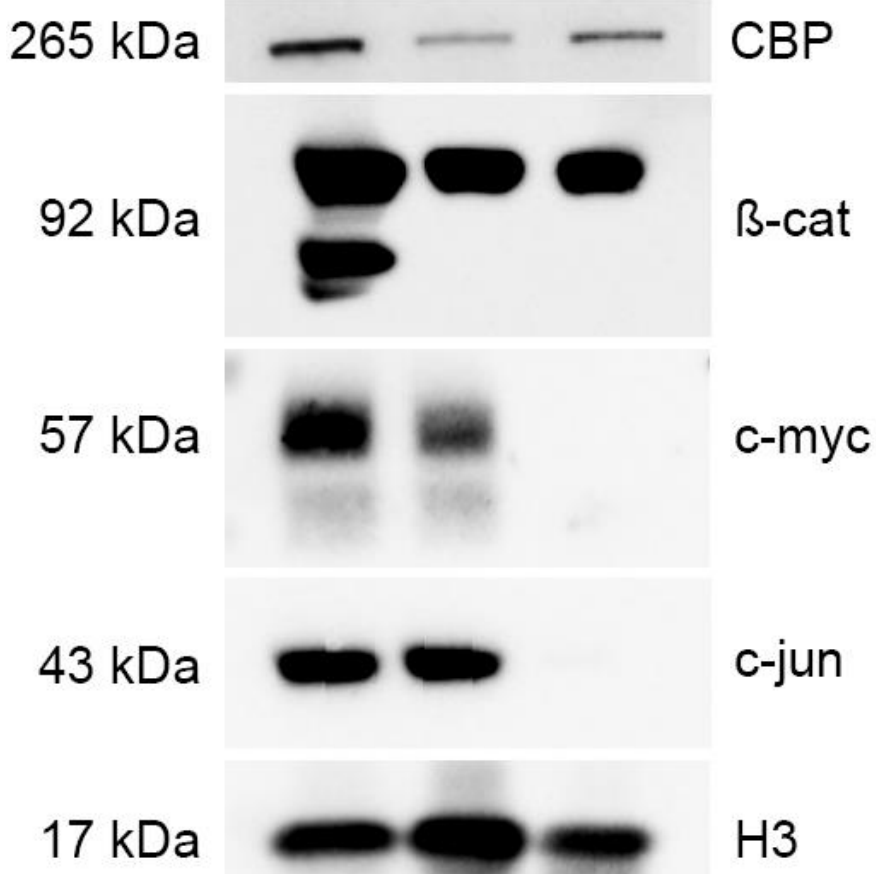

Abbildung 17: WB von Interaktionspartnern bei CBP-KD in HEK-293T 
Wie in Abbildung $17 \mathrm{zu}$ sehen ist, wurde bei dem CBP-knockdown mit sh73i ein gänzlicher knockout von ß-Catenin, c-myc und c-jun induziert. Bei dem knockdown mit sh70i wurde zumindest ein knockout von ß-Catenin und ein knockdown von cmyc erreicht. Diese Auswirkungen auf die Interaktionspartner konnten nicht reproduziert werden. Vermutlich ist es aufgrund der hohen Letalität bei einem effizienten und konstanten knockdown von CBP schwierig, den Versuch am richtigen Zeitpunkt abzustoppen. Ein passagerer knockdown mit siRNA ist nicht ausreichend, um die oben gezeigten Effekte hervorzurufen. 


\section{Diskussion}

\subsection{Auswirkung von CBP auf Tumorwachstum und Morphologie}

Wie in den Ergebnissen gezeigt, wirkt sich die CBP-Konzentration des Tumors nicht signifikant auf dessen Wachstumsverhalten und Morphologie aus. Alle klinikopathologischen Parameter (Absatz 3.1.2) wie Tumorausdehnung (T), der Lymphknotenstatus (N), Lymphgefäßinfiltration (L), Tumoreinbruch in Venen (V), das UICC-Stadium und das Grading (G) zeigen keinerlei Zusammenhang. Bezüglich der Tumormorphologie ist jedoch auffällig, wenn auch nicht signifikant $(p=0,541)$, dass in den apikalen Tumorbereichen tendenziell eine höhere CBP-Konzentration vorliegt als in den basalen Tumorbereichen (Abbildung 4). Eine mögliche Erklärung ist, dass die Zellschichten, die apikal und somit am weitesten entfernt von der Basis liegen, sich tumorbiologisch im Vergleich zu den ursprünglichen Tumorzellen an der Basis progredient entwickelt haben bzw. entartet sind. Das könnte ein Hinweis auf das Entwicklungsstadium des Tumors sein. Eigentlich wäre in diesem Fall zu erwarten, dass bei Tumoren, die CBP in einem besonders hohen Maße exprimieren, auch die Malignitätskriterien wie das Grading signifikant verändert wären.

\subsection{Korrelation von CBP Expression des Tumors und Überleben}

Mit hoher Signifikanz $(p=0,00278)$ besteht jedoch ein Zusammenhang zwischen der CBP-Expressionsstärke und dem cancer specific survival (Abbildung 12). Warum die Patienten, die an einem Tumor mit hoher CBP-Expression leiden, länger überleben, lässt sich unterschiedlich erklären. CBP spielt in vielen zellbiologischen Prozessen eine wichtige Rolle, sowohl bei pro-proliferativen (Bannister und Kouzarides 1995; Bannister et al. 1995; Chrivia et al. 1993; Dai et al. 1996; Vervoorts et al. 2003; Wang et al. 2013) als auch bei pro-apoptotischen (Ait-Si-Ali et al. 2000; Arany et al. 1996; Avantaggiati et al. 1997; Bhattacharya et al. 1996; Denis et al. 2012; Feng et al. 1998; Janknecht und Nordheim 1996; Kallio et al. 1998; Kitabayashi et al. 1998; Lill et al. 1997; Nasrin et al. 2000; Pao et al. 2000; So und Cleary 2002, 2003; Wang et al. 2013; Zhang et al. 1996) Signaltransduktionskaskaden. Exprimiert ein Tumor im hohen Maße CBP und ist auf dessen regulatorisches Potential angewiesen, könnte das für eine insgesamt sehr hohe molekularbiologische Aktivität in der Tumorzelle sprechen. Ein derart hyperaktives System ließe sich wesentlich schneller aus dem 
Gleichgewicht bringen als ein System mit vergleichsweise niedrigerer Aktivität. Ein möglicher Störfaktor für ein so fragiles System wäre beispielsweise eine adjuvante Chemotherapie. Dies könnte bedeuten, dass ein Tumor durch eine erhöhte CBPExpression eine größere Sensibilität bezüglich einer Strahlen- oder Chemotherapie aufweist.

Basierend auf diesen Überlegungen lassen sich auch die Zusammenhänge von CBP-Expression und Rezidivrate erklären (Abbildung 11). Zwar sind diese Beobachtungen nicht statistisch relevant, jedoch ist ein Trend dahingehend zu erkennen, dass Patienten mit einem Tumor, welcher eine starke CBP-Expression aufweist, tendenziell länger tumorrezidiv frei sind.

Um diese Zusammenhänge besser verstehen zu können, haben wir experimentell die Auswirkungen des CBP auf die Strahlen- und Chemosensibilität und den Zusammenhang zu den in der Onkogenese wichtigen Proteinen wie c-myc, c-jun und ß-Catenin untersucht. Einen Zusammenhang zwischen CBP-knockdown und Expression von MYC konnte in der Arbeit von $\mathrm{H}$. Ogiwara gezeigt werden. Eine Herunterregulierung von p300 in einem CBP-defizienten Tumor führte zu einer Supression von MYC (Ogiwara et al. 2016).

\subsection{CBP ist ein stark regulatorisches Protein}

Dass CBP eine regulatorische Funktion in vielen Signaltransduktionskaskaden innehat, konnte bereits in einigen Publikationen gezeigt werden. Nicht zuletzt aufgrund des direkten Bezuges zu pro-proliferativen und onkogenen Proteinen wie c_Myc, c-myb, CREB, c-jun und c-fos (Bannister und Kouzarides 1995; Chrivia et al. 1993; Dai et al. 1996; Vervoorts et al. 2003; Wang et al. 2013) und der Einflußnahme auf ß-Catenin und somit die wnt-Signaltransduktionskaskade (Teo und Kahn 2010) war es zu erwarten, dass sich der KD auf die Proliferation auswirkt. Das konnte besonders nach dem KD mit der shRNA beobachtet werden (Abbildung 14), der dauerhafte KD führt zum Zelltod. CBP besitzt offenbar eine enorme Regulationsfähigkeit und führt bei einigen der direkt interagierenden Proteine, in diesem Fall bei ß-Catenin, c-myc und c-jun gezeigt (Abbildung 17), nicht nur zu einer Aktivierung/Deaktivierung, sondern auch zu einer Beeinflussung der Transkription. Daher ist es nachvollziehbar, dass ein gelungener und dauerhafter KD, wie es bei der shRNA der Fall ist, zum Untergang der Zellen führt und sich eine Reproduktion 
der Ergebnisse als schwierig gestaltet. Dass ein gänzlicher knockout des CBP für die Zellen letal ist, wird durch die Tatsache gestützt, dass die Embryonen der Mäuse, bei denen ein homozygoter knockout für CBP besteht, nicht überlebensfähig sind (Kasper et al. 2006). Es erklärt auch, warum eine Zellreihe mit einem stabilen KD nicht möglich war, sodass die weiteren Arbeiten auf einem passageren KD mittels siRNA basieren.

\subsection{Der Resistenzverlust ist multifaktoriell bedingt}

Da es uns experimentell nicht gelungen ist, die Zellen am Leben zu erhalten, bei denen mittels shRNA ein dauerhafter KD des CBP durchgeführt wurde, musste die Methodik gewechselt werden. Für den Colony forming assay (Absatz 3.2.2) wurde ein passagerer KD mittels siRNA verwendet.

In dem CFA ist der Trend erkennbar, dass vor allem in einer kombinierten Radiochemotherapie die Zellen mit CBP-KD sensitiver auf die Behandlung reagieren (Abbildung 16). Eine Erklärung dafür ist eine Reduktion der Reparaturfähigkeit der durch die Strahlen- und Chemotherapie zugefügten DNA-Schäden, wie DNA-Einzelund Doppelstrangbrüche. Dieser Funktionsverlust könnte möglicherweise auf einer verminderten HAT-Aktivität des supprimierten CBP beruhen. Die direkte Wirkung der Acetylierung von Histonen auf die Reparatur von DNA-Strangbrüchen konnten (Bird et al. 2002) in ihren Arbeiten nachweisen. Robert et al. (Robert et al. 2016) zeigten im Zusammenhang mit Leukämien, dass es mit dem HDAC-Inhibitor Trichostatin A zu einer differenzierten Acetylierung von DNA-Reparatur-Faktoren wie Ku70/Ku80 und poly ADP-ribose polymerase-1 kommt. Ebendieser positive Reparatureffekt konnte durch die Inhibierung von p300/CBP mit dem Inhibitor C646 rückgängig gemacht werden.

Das wäre eine Erklärung für die erhöhte Strahlensensibilität von Zellen mit einem supprimierten CBP, verursacht durch die verminderten acetylierungsbedingten Reparaturmechanismen.

Da CBP neben der HAT-Aktivität über viele weitere in der Einleitung erläuterte funktionelle Domänen verfügt, ist ein monokausaler Rückschluss nicht möglich. Nicht zuletzt die Interaktionen mit den zahlreichen pro-proliferativen, onkogenen, proapoptotischen und Tumorsupressorproteinen (Ait-Si-Ali et al. 2000; Arany et al. 1996; Avantaggiati et al. 1997; Bannister und Kouzarides 1995; Bannister et al. 1995; 
Chrivia et al. 1993; Dai et al. 1996; Denis et al. 2012; Feng et al. 1998; Janknecht und Nordheim 1996; Kallio et al. 1998; Kitabayashi et al. 1998; Lill et al. 1997; Pao et al. 2000; Vervoorts et al. 2003; Wang et al. 2013; Zhang et al. 1996) lassen eine Vielzahl von Erklärungen zu. Beispielsweise konnten Cui, F. et al (Cui et al. 2015) in ihren Arbeiten nachweisen, dass HeLa-Zellen nach einem KD von c-Myc (Abbildung 17) einen starken Resistenzverlust gegenüber einer Radiotherapie erfahren, basierend auf einer verminderten Fähigkeit, DNA-Doppelstrangbrüche zu reparieren. Auch in Bezug auf die Sensibilisierung bezüglich einer Chemotherapie ließ sich ein Zusammenhang mit CBP und ß-Catenin herstellen (Zhao et al. 2015). Zhao, Y. et al konnten mit dem Inhibitor ICG-001, welcher die Interaktion zwischen CBP und ßCatenin hemmt, zeigen, dass bei resistenten CML-Zellen durch die Inhibition dieser Interaktion wieder eine Sensibilisierung gegenüber Tyrosinkinase-Inhibitoren erreicht werden konnte (Zhao et al. 2015).

Insgesamt lässt sich vermuten, dass hier ein Zusammenspiel mehrerer Faktoren zu einer verminderten Kompensationsfähigkeit des Strahlen- und Chemotherapieschadens nach CBP-KD eine Rolle spielt.

\subsection{Diskrepanz zwischen klinischen und molekularbiologischen} Ergebnissen?

Einerseits ließen die molekularbiologischen Ergebnisse erwarten, dass Tumoren mit einer hohen CBP-Expression widerstandsfähiger wären. Andererseits könnte bei einer antitumorösen Therapie erwartet werden, dass ein Tumor die Schäden effektiver kompensiert mit einer negativen Auswirkung auf die Prognose des Patienten.

Jedoch stellt es sich bei der Korrelation der CBP-Expression mit den klinischen Parametern entgegengesetzt dar. Patienten, die eine erhöhte CBP-Expression im Tumor aufwiesen, zeigten ein signifikant längeres Überleben. Auf die Gründe hierfür wurde in Absatz 4.2 eingegangen.

Bei diesen scheinbar diskrepanten Ergebnissen sollte kritisch hinterfragt werden, ob eine nachgewiesene erhöhte CBP-Expression zugleich auch eine erhöhte Aktivität bedeutet? Falls man davon ausgeht, dass es aufgrund der verstärkten Expression auch zu einer erhöhten Aktivität kommt, lässt dieses noch keinen Rückschluss darüber zu, ob alle funktionellen Domänen in gleichem Maße aktiv sind oder ob es 
aufgrund von anderen regulatorischen Mechanismen zu einer verstärkten Aktivität einzelner Domänen kommt. Sollte dies der Fall sein, ist es beispielsweise durchaus denkbar, dass ein Tumor mit erhöhter CBP-Expression ein Gleichgewicht der onkogenen pro-proliferativen und der anti-proliferativen apoptotischen Singaltransduktionskaskaden hergestellt hat. Führt man diesen Gedanken weiter, ist es sogar vorstellbar, dass es aufgrund eines Missverhältnisses zugunsten der antiproliferativen und apoptotischen Aktivität des CBP zu einer Stabilisierung des Tumorwachstums kommt und es sich somit durchaus positiv auf die Malignität und somit auf das Überleben der Patienten auswirken kann.

\subsection{Ausblick}

Diese Arbeit untersucht den Einfluss von CBP im kolorektalen Karzinom in vitro wie in vivo. Da CBP mit multiplen Interaktionspartnern agiert und offensichtlich auch im Hinblick auf das kolorektale Karzinom eine Rolle zu spielen scheint, sollte die Bedeutung von CBP im kolorektalen Karzinom weiter untersucht werden.

Bezüglich der klinischen Daten ist es zu überlegen, das Patientenkollektiv zu erweitern. Sicherlich wäre es auch interessant, Patienten, die eine neoadjuvante oder adjuvante Therapie erhalten haben, vermehrt in die Untersuchungen mit einzubeziehen. Hierdurch könnten vor allem weitere klinische Erkenntnisse über den Zusammenhang von CBP und Resistenzbildung gewonnen werden. Auch andere Karzinome könnten diesbezüglich untersucht werden.

Immunhistochemisch wäre es interessant zu wissen, ob die CBP-Expression bei Tumoren mit der Expression direkt interagierender pro-proliferativer und onkogener Proteine wie c-myc, c-jun und ß-Catenin korreliert.

Auf molekularbiologischer Ebene gibt es ebenfalls eine Vielzahl von Ansatzpunkten. Zum einen sollte weiterhin versucht werden, die von uns gezeigten Effekte eines CBP-knockdown auf die Interaktionspartner $\mathrm{zu}$ verifizieren. Ein weiterer interessanterer Ansatz ist die Möglichkeit, CBP mit Hilfe eines Überexpressionsvektors in den Zellen verstärkt exprimieren zu lassen und die Effekte auf Interaktionspartner und Strahlen-/Chemosensibilität zu überprüfen. Darüber hinaus könnte man bei Zellen mit hoher CBP-Expression mittels einer Co- 
Immunopräzipitation überprüfen, welche Proteine hier tatsächlich gebunden und somit tatsächlich mit dem CBP interagieren.

Die nächsten Schritte wären Analysen auf genomischer Ebene, beispielsweise mit einem DNA-Microarray. Hierdurch ließe sich ein direkter quantitativer Expressionsnachweis durchführten.

Sollten sich in weiteren Experimenten die Hinweise verdichten, dass CBP tatsächlich eine entscheidende Rolle in der Onkogenese spielt, wären auch Versuche in Tiermodellen denkbar. Da ein homozygoter knockout bei Mäusen letal endet (Kasper et al. 2006), wären andere knockout-Systeme vorstellbar. Zum Beispiel könnte ein Liganden-aktivierbares Cre/loxP-System zur Anwendung kommen, in dem ein knockout gezielt getriggert werden kann. 


\section{Zusammenfassung}

Die vorgelegte Arbeit befasst sich mit dem Protein CBP (CREB-binding protein) im kolorektalen Karzinom. CBP ist eine Histonacetyltransferaseaktivität mit 4 transactivation domains und acetyliert eine Vielzahl von Eiweißen. Biologischfunktionell ist CBP ein multifunktionales Protein, welches eine Vielzahl von proproliferativen onkogenen und pro-apoptotischen anti-proliferativen Signaltransduktionskaskaden beeinflusst, auch in Tumoren.

Ziel der Arbeit war es, die vermutete CBP-vermittelte Modulation der Tumorproliferation und den etwaigen Einfluss auf die Resistenzentwicklung am Beispiel des Rektumkarzinoms zu untersuchen.

Zunächst haben wir mit Hilfe immunhistochemischer Methoden untersucht, ob und inwieweit Zusammenhänge zwischen der CBP-Expression in Tumoren und den klinischen Parametern bei Patienten mit rektalen Karzinomen existieren. Wir konnten feststellen, dass sich eine hohe CBP-Expression in Tumoren positiv auf das Überleben von Patienten auswirkt. Das 5-Jahres-Überleben ist für Patienten mit niedriger CBP-Expression im Tumor über $30 \%$ geringer als für Patienten mit mittlerer bis hoher CBP-Expression. Darüber hinaus ist zumindest in der Tendenz ein positiver Einfluss von erhöhter CBP-Expression auf das Rezidiv-Verhalten von Tumoren erkennbar.

Als zweiter Schritt wurden molekularbiologische Aspekte eines CBP-knockdowns auf die Tumorproliferation anhand CBP-relevanter Signalkaskaden überprüft. Auf zellbiologischer Ebene konnten wir zeigen, dass CBP ein überlebensnotwendiges Protein für den Organismus darstellt und ein vollständiger knockdown sich letal auswirkt. Wir konnten zeigen, dass, wenn auch sehr dynamisch, CBP an der Regulation einiger Signalmoleküle, welche wichtig für die Tumorproliferation sind, beteiligt ist. Ein gänzlicher knockout von CBP hat außerdem einen Einfluss auf die Expression von Interaktionspartnern zur Folge. Es war begleitend ein knockout der onkogenen Proteinen c-myc, c-jun und ß-Catenin nachweisbar. Darüber hinaus haben wir die biologisch funktionelle Rolle von CBP bei der Resistenzentwicklung untersucht und konnten zeigen, dass eine Suppression tendenziell zu einer Sensibilisierung gegenüber einer Strahlen- und Chemotherapie in Rektumkarzinomen führt. 
Betrachtet man diese Ergebnisse in ihrer Gesamtheit, wird deutlich, dass das Protein CBP eine zentrale Schaltstelle im Organismus darstellt und eine wichtige Rolle bei der Tumorzellproliferation spielen kann. Die Folgen einer Dysregulation der CBPExpression können vielfältig sein. Um die tatsächliche Bedeutung dieses vielseitigen Proteins in der Entstehung und Progression maligner Erkrankungen abschätzen zu können, bedarf es jedoch noch weiterer funktioneller Analysen. 


\section{Literaturverzeichnis}

Ait-Si-Ali S, Polesskaya A, Filleur S, Ferreira R, Duquet A, Robin P, Vervish A, Trouche D, Cabon F, Harel-Bellan A (2000): CBP/p300 histone acetyl-transferase activity is important for the G1/S transition Oncogene. $\underline{19}$, 2430-2437

Al-Tassan N, Chmiel NH, Maynard J, Fleming N, Livingston AL, Williams GT, Hodges AK, Davies DR, David SS, Sampson JR, et al. (2002): Inherited variants of MYH associated with somatic G:C-->T:A mutations in colorectal tumors. Nat Genet 30, 227-232

Albanese C, D'Amico M, Reutens AT, Fu M, Watanabe G, Lee RJ, Kitsis RN, Henglein B, Avantaggiati M, Somasundaram K, et al. (1999): Activation of the cyclin D1 gene by the E1Aassociated protein p300 through AP-1 inhibits cellular apoptosis. J Biol Chem $\underline{274}$, 3418634195

Arany Z, Huang LE, Eckner R, Bhattacharya S, Jiang C, Goldberg MA, Bunn HF, Livingston DM (1996): An essential role for p300/CBP in the cellular response to hypoxia. Proc Natl Acad Sci U S A $\underline{93}, 12969-12973$

Avantaggiati ML, Ogryzko V, Gardner K, Giordano A, Levine AS, Kelly K (1997): Recruitment of p300/CBP in p53-dependent signal pathways. Cell $\underline{89}$, 1175-1184

Bader AG, Kang S, Vogt PK (2006): Cancer-specific mutations in PIK3CA are oncogenic in vivo. Proc Natl Acad Sci U S A $103,1475-1479$

Bagasra O, Prilliman KR (2004): RNA interference: the molecular immune system. J Mol Histol $\underline{35}, 545-553$

Baker SJ, Fearon ER, Nigro JM, Hamilton SR, Preisinger AC, Jessup JM, vanTuinen P, Ledbetter DH, Barker DF, Nakamura Y, et al. (1989): Chromosome 17 deletions and p53 gene mutations in colorectal carcinomas. Science $\underline{244}, 217-221$ 
Bannister AJ, Kouzarides T (1995): CBP-induced stimulation of c-Fos activity is abrogated by E1A. EMBO J $\underline{14}, 4758-4762$

Bannister AJ, Kouzarides T (1996): The CBP co-activator is a histone acetyltransferase. Nature $\underline{384}, 641-643$

Bannister AJ, Kouzarides T (2005): Reversing histone methylation. Nature $\underline{436}$, 1103-1106

Bannister AJ, Oehler T, Wilhelm D, Angel P, Kouzarides T (1995): Stimulation of c-Jun activity by CBP: c-Jun residues Ser63/73 are required for CBP induced stimulation in vivo and CBP binding in vitro. Oncogene $\underline{11}, 2509-2514$

Barber TD, McManus K, Yuen KW, Reis M, Parmigiani G, Shen D, Barrett I, Nouhi Y, Spencer F, Markowitz S, et al. (2008): Chromatid cohesion defects may underlie chromosome instability in human colorectal cancers. Proc Natl Acad Sci U S A $\underline{105}, 3443-3448$

Bhattacharya S, Eckner R, Grossman S, Oldread E, Arany Z, D'Andrea A, Livingston DM (1996): Cooperation of Stat2 and p300/CBP in signalling induced by interferon-alpha. Nature $\underline{383}, 344-347$

Bhattacharya S, Michels CL, Leung MK, Arany ZP, Kung AL, Livingston DM (1999): Functional role of p35srj, a novel p300/CBP binding protein, during transactivation by HIF-1. Genes Dev $\underline{13}, 64-75$

Bird AW, Yu DY, Pray-Grant MG, Qiu Q, Harmon KE, Megee PC, Grant PA, Smith MM, Christman MF (2002): Acetylation of histone H4 by Esa1 is required for DNA double-strand break repair. Nature $\underline{419}, 411-415$

Boland CR, Koi M, Chang DK, Carethers JM (2008): The biochemical basis of microsatellite instability and abnormal immunohistochemistry and clinical behavior in Lynch syndrome: from bench to bedside. Fam Cancer $\underline{7}, 41-52$ 
Bos JL, Fearon ER, Hamilton SR, Verlaan-de Vries M, van Boom JH, van der Eb AJ, Vogelstein B (1987): Prevalence of ras gene mutations in human colorectal cancers. Nature $\underline{327}, 293-$ 297

Bronner CE, Baker SM, Morrison PT, Warren G, Smith LG, Lescoe MK, Kane M, Earabino C, Lipford J, Lindblom A, et al. (1994): Mutation in the DNA mismatch repair gene homologue hMLH1 is associated with hereditary non-polyposis colon cancer. Nature $\underline{368}, 258-261$

Chakravarti D, LaMorte VJ, Nelson MC, Nakajima T, Schulman IG, Juguilon H, Montminy M, Evans RM (1996): Role of CBP/P300 in nuclear receptor signalling. Nature 383, 99-103

Chrivia JC, Kwok RP, Lamb N, Hagiwara M, Montminy MR, Goodman RH (1993): Phosphorylated CREB binds specifically to the nuclear protein CBP. Nature $\underline{365}, 855-859$

Conradi LC, Bleckmann A, Schirmer M, Sprenger T, Jo P, Homayounfar K, Wolff HA, Rothe H, Middel P, Becker H, et al. (2011): Thymidylate synthase as a prognostic biomarker for locally advanced rectal cancer after multimodal treatmen.t Ann Surg Oncol 18, 2442-2452

Cui F, Fan R, Chen Q, He Y, Song M, Shang Z, Zhang S, Zhu W, Cao J, Guan H, et al. (2015): The involvement of c-Myc in the DNA double-strand break repair via regulating radiation-induced phosphorylation of ATM and DNA-PKcs activity. Mol Cell Biochem 406, 43-51

Cuthbert GL, Daujat S, Snowden AW, Erdjument-Bromage H, Hagiwara T, Yamada M, Schneider R, Gregory PD, Tempst P, Bannister AJ, et al. (2004): Histone deimination antagonizes arginine methylation. Cell $\underline{118}$, 545-553

Dai P, Akimaru H, Tanaka Y, Hou DX, Yasukawa T, Kanei-Ishii C, Takahashi T, Ishii S (1996): CBP as a transcriptional coactivator of c-Myb. Genes Dev $\underline{10}, 528-540$ 
Davies H, Bignell GR, Cox C, Stephens P, Edkins S, Clegg S, Teague J, Woffendin H, Garnett MJ, Bottomley W, et al. (2002): Mutations of the BRAF gene in human cancer. Nature 417 949-954

De Guzman RN, Liu HY, Martinez-Yamout M, Dyson HJ, Wright PE (2000): Solution structure of the TAZ2 (CH3) domain of the transcriptional adaptor protein CBP. J Mol Biol $\underline{303}$, 243-253

Denis CM, Chitayat S, Plevin MJ, Wang F, Thompson P, Liu S, Spencer HL, Ikura M, LeBrun DP, Smith SP (2012): Structural basis of CBP/p300 recruitment in leukemia induction by E2APBX1. Blood 120, 3968-3977

Ding L, Chen S, Liu P, Pan Y, Zhong J, Regan KM, Wang L, Yu C, Rizzardi A, Cheng L, et al. (2014): CBP loss cooperates with PTEN haploinsufficiency to drive prostate cancer: implications for epigenetic therapy. Cancer Res $\underline{74}$, 2050-2061

Emre NC, Ingvarsdottir K, Wyce A, Wood A, Krogan NJ, Henry KW, Li K, Marmorstein R, Greenblatt JF, Shilatifard A, et al. (2005): Maintenance of low histone ubiquitylation by Ubp10 correlates with telomere-proximal Sir2 association and gene silencing. Mol Cell $\underline{17}$, $585-594$

Fearon ER, Bommer GT: Molecular Biology of Colorectal Cancer. In: DeVita, V.T., Lawrence, T.S., Rosenberg, S.A.(Hrgs.): DeVita, Hellman, and Rosenberg's Cancer: Principles \& Practice of Oncology. 8. Auflage. Auflage; Wolters Kluwer/Lippincott Williams \& Wilkins, Philadelphia 2008

Feng XH, Zhang Y, Wu RY, Derynck R (1998): The tumor suppressor Smad4/DPC4 and transcriptional adaptor $\mathrm{CBP} / \mathrm{p} 300$ are coactivators for smad3 in TGF-beta-induced transcriptional activation. Genes Dev $\underline{12}, 2153-2163$

Fishel R, Lescoe MK, Rao MR, Copeland NG, Jenkins NA, Garber J, Kane M, Kolodner R (1993): The human mutator gene homolog MSH2 and its association with hereditary nonpolyposis colon cancer. Cell $\underline{75}$, 1027-1038 
Friedenreich CM (2001): Physical activity and cancer prevention: from observational to intervention research. Cancer Epidemiol Biomarkers Prev 10, 287-301

Fronsdal K, Engedal N, Slagsvold T, Saatcioglu F (1998): CREB binding protein is a coactivator for the androgen receptor and mediates cross-talk with AP-1. J Biol Chem $\underline{273}$, 31853-31859

Fuchs R, Guggenberger D, Neumann U, Trautwein C: Kolorektale Karzinome / Kolonkarzinom / Rektumkarzinom. In: GI-Tumore 2011/2012. 13; hrsg. Nora-Verlag, Stolberg 2011

Ghadimi B, Becker H: Chirurgische Onkologie. In: Becker H, Enke A, Röher H-D (Hrsg.): Viszeralchirurgie. Elsevier, Urban und Fischer, München Jena 2006

Gorisch SM, Wachsmuth M, Toth KF, Lichter P, Rippe K (2005): Histone acetylation increases chromatin accessibility. J Cell Sci $\underline{118}$, 5825-5834

Goss KH, Groden J (2000): Biology of the adenomatous polyposis coli tumor suppressor. J Clin Oncol 18, 1967-1979

Goulding H, Pinder S, Cannon P, Pearson D, Nicholson R, Snead D, Bell J, Elston CW, Robertson JF, Blamey RW, et al. (1995): A new immunohistochemical antibody for the assessment of estrogen receptor status on routine formalin-fixed tissue samples. Hum Pathol 26, 291-294

Grady WM: Colorectal Cancer: Molecular Biology and Genetics. In: Kelsen D, Daly J, Kern S, Levin B, Tepper J (Hrsg.): Gastrointestinal oncology: principles and practice. 2. Auflage. Auflage; Wolters Kluwer/Lippincott Williams \& Wilkins, Philadelphia 2008

Grady WM, Rajput A, Myeroff L, Liu DF, Kwon K, Willis J, Markowitz S (1998): Mutation of the type II transforming growth factor-beta receptor is coincident with the transformation of human colon adenomas to malignant carcinomas. Cancer Res $\underline{58}, 3101-3104$ 
Gu W, Shi XL, Roeder RG (1997): Synergistic activation of transcription by CBP and p53. Nature $\underline{387}, 819-823$

Hamilton W, Sharp D (2004): Diagnosis of colorectal cancer in primary care: the evidence base for guidelines. Fam Pract 21, 99-106

Hanstein B, Eckner R, DiRenzo J, Halachmi S, Liu H, Searcy B, Kurokawa R, Brown M (1996): p300 is a component of an estrogen receptor coactivator complex. Proc Natl Acad Sci U S A 93, $11540-11545$

Hassa PO, Haenni SS, Elser M, Hottiger MO (2006): Nuclear ADP-ribosylation reactions in mammalian cells: where are we today and where are we going? Microbiol Mol Biol Rev $\underline{70}$, $789-829$

Henry RA, Kuo YM, Andrews AJ (2013): Differences in specificity and selectivity between CBP and p300 acetylation of histone $\mathrm{H} 3$ and $\mathrm{H} 3 / \mathrm{H} 4$. Biochemistry $\underline{52}, 5746-5759$

Herman JG, Umar A, Polyak K, Graff JR, Ahuja N, Issa JP, Markowitz S, Willson JK, Hamilton SR, Kinzler KW, et al. (1998): Incidence and functional consequences of hMLH1 promoter hypermethylation in colorectal carcinoma. Proc Natl Acad Sci U S A $\underline{95}$, 6870-6875

Issa JP (2004): CpG island methylator phenotype in cancer. Nat Rev Cancer 4 , 988-993

Janknecht R, Nordheim A (1996): MAP kinase-dependent transcriptional coactivation by Elk1 and its cofactor CBP. Biochem Biophys Res Commun 228, 831-837

Jarvinen HJ, Aarnio M, Mustonen H, Aktan-Collan K, Aaltonen LA, Peltomaki P, De La Chapelle A, Mecklin JP (2000): Controlled 15-year trial on screening for colorectal cancer in families with hereditary nonpolyposis colorectal cancer. Gastroenterology 118, 829-834

Jenuwein T, Allis CD (2001): Translating the histone code. Science $\underline{293}, 1074-1080$ 
Kaatsch P, Spix C, Katalinic A, Hentschel S, Baras N, Barnes B, Bertz J, Dahm S, Haberland J, Kraywinkel K, et al.: Krebs in Deutschland 2007/2008. hrsg. v.: Koch-Institut R. 2012

Kalkhoven E (2004): CBP and p300: HATs for different occasions. Biochem Pharmacol $\underline{68}$, $1145-1155$

Kallio PJ, Okamoto K, O'Brien S, Carrero P, Makino Y, Tanaka H, Poellinger L (1998): Signal transduction in hypoxic cells: inducible nuclear translocation and recruitment of the CBP/p300 coactivator by the hypoxia-inducible factor-1alpha. EMBO J $\underline{17}$, 6573-6586

Kane MF, Loda M, Gaida GM, Lipman J, Mishra R, Goldman H, Jessup JM, Kolodner R (1997): Methylation of the hMLH1 promoter correlates with lack of expression of hMLH1 in sporadic colon tumors and mismatch repair-defective human tumor cell lines. Cancer Res $\underline{57}, 808-811$

Kasper LH, Fukuyama T, Biesen MA, Boussouar F, Tong C, de Pauw A, Murray PJ, van Deursen JM, Brindle PK (2006): Conditional knockout mice reveal distinct functions for the global transcriptional coactivators CBP and p300 in T-cell development. Mol Cell Biol 26, 789-809

Kastrinos F, Syngal S (2007): Recently identified colon cancer predispositions: MYH and MSH6 mutations. Semin Oncol 34, 418-424

Kinzler W, Vogelstein B: Colorectal Tumors. In: Vogelstein B, Kinzler A, Kenneth W (Hrsg.): The Genetic Basis of Human Cancer. 2. Auflage; Mcgraw-Hill Professional, New York 2002

Kitabayashi I, Yokoyama A, Shimizu K, Ohki M (1998): Interaction and functional cooperation of the leukemia-associated factors AML1 and p300 in myeloid cell differentiation. EMBO J 17, 2994-3004

Kondo Y, Issa JP (2004): Epigenetic changes in colorectal cancer. Cancer Metastasis Rev $\underline{23}$, 29-39

Kouzarides T (2007): Chromatin modifications and their function. Cell $\underline{128}$, 693-705 
Kurreck J (2009): RNA interference: from basic research to therapeutic applications. Angew Chem Int Ed Engl 48, 1378-1398

Leach FS, Nicolaides NC, Papadopoulos N, Liu B, Jen J, Parsons R, Peltomaki P, Sistonen P, Aaltonen LA, Nystrom-Lahti M, et al. (1993): Mutations of a mutS homolog in hereditary nonpolyposis colorectal cancer. Cell $\underline{75}, 1215-1225$

Leary RJ, Lin JC, Cummins J, Boca S, Wood LD, Parsons DW, Jones S, Sjoblom T, Park BH, Parsons R, et al. (2008): Integrated analysis of homozygous deletions, focal amplifications, and sequence alterations in breast and colorectal cancers. Proc Natl Acad Sci U S A $\underline{105}$, 16224-16229

Lee DY, Teyssier C, Strahl BD, Stallcup MR (2005): Role of protein methylation in regulation of transcription. Endocr Rev $\underline{26}, 147-170$

Lengauer C, Kinzler KW, Vogelstein B (1997): Genetic instability in colorectal cancers. Nature 386, 623-627

Liersch T, Becker H, Langer C (2007): Rektumkarzinom Allgemein- und Viszeralchirurgie up2date, 41-69

Lill NL, Grossman SR, Ginsberg D, DeCaprio J, Livingston DM (1997): Binding and modulation of $p 53$ by $\mathrm{p} 300 / \mathrm{CBP}$ coactivators. Nature $\underline{387}, 823-827$

Lin CH, Hare BJ, Wagner G, Harrison SC, Maniatis T, Fraenkel E (2001): A small domain of $\mathrm{CBP} / \mathrm{p} 300$ binds diverse proteins: solution structure and functional studies. Mol Cell $\underline{8}, 581-$ 590

Liu J, Carmell MA, Rivas FV, Marsden CG, Thomson JM, Song JJ, Hammond SM, Joshua-Tor L, Hannon GJ (2004): Argonaute2 is the catalytic engine of mammalian RNAi. Science $\underline{305}$, 1437-1441 
Liu X, Wang L, Zhao K, Thompson PR, Hwang Y, Marmorstein R, Cole PA (2008): The structural basis of protein acetylation by the p300/CBP transcriptional coactivator. Nature $\underline{451}, 846-850$

Luger K (2003): Structure and dynamic behavior of nucleosomes. Curr Opin Genet Dev $\underline{13}$, $127-135$

Lynch HT, de la Chapelle A (2003): Hereditary colorectal cancer. N Engl J Med $\underline{348}$, 919-932

Lynch HT, Lynch JF, Lynch PM, Attard T (2008): Hereditary colorectal cancer syndromes: molecular genetics, genetic counseling, diagnosis and management. Fam Cancer $\underline{7}$, 27-39

Macdonald N, Welburn JP, Noble ME, Nguyen A, Yaffe MB, Clynes D, Moggs JG, Orphanides G, Thomson S, Edmunds JW, et al. (2005): Molecular basis for the recognition of phosphorylated and phosphoacetylated histone h3 by 14-3-3. Mol Cell 20, 199-211

Makinen MJ (2007): Colorectal serrated adenocarcinoma. Histopathology 50, 131-150

Miled N, Yan Y, Hon WC, Perisic O, Zvelebil M, Inbar Y, Schneidman-Duhovny D, Wolfson HJ, Backer JM, Williams RL (2007): Mechanism of two classes of cancer mutations in the phosphoinositide 3-kinase catalytic subunit. Science 317, 239-242

Moon RT (2005): Wnt/beta-catenin pathway. Sci STKE 2005, cm1

Naar AM, Lemon BD, Tjian R (2001): Transcriptional coactivator complexes. Annu Rev Biochem $\underline{70}$, 475-501

Nasrin N, Ogg S, Cahill CM, Biggs W, Nui S, Dore J, Calvo D, Shi Y, Ruvkun G, AlexanderBridges MC (2000): DAF-16 recruits the CREB-binding protein coactivator complex to the insulin-like growth factor binding protein 1 promoter in HepG2 cells. Proc Natl Acad Sci U S A 97, 10412-10417 
Nathan D, Ingvarsdottir K, Sterner DE, Bylebyl GR, Dokmanovic M, Dorsey JA, Whelan KA, Krsmanovic M, Lane WS, Meluh PB, et al. (2006): Histone sumoylation is a negative regulator in Saccharomyces cerevisiae and shows dynamic interplay with positive-acting histone modifications. Genes Dev 20, 966-976

Nelson CJ, Santos-Rosa H, Kouzarides T (2006): Proline isomerization of histone H3 regulates lysine methylation and gene expression. Cell $\underline{126}$, 905-916

Ogiwara H, Sasaki M, Mitachi T, Oike T, Higuchi S, Tominaga Y, Kohno T (2016): Targeting p300 Addiction in CBP-Deficient Cancers Causes Synthetic Lethality by Apoptotic Cell Death due to Abrogation of MYC Expression. Cancer Discov $\underline{6}, 430-445$

Ogryzko VV, Schiltz RL, Russanova V, Howard BH, Nakatani Y (1996): The transcriptional coactivators p300 and CBP are histone acetyltransferases. Cell 87, 953-959

Pao GM, Janknecht R, Ruffner H, Hunter T, Verma IM (2000): CBP/p300 interact with and function as transcriptional coactivators of BRCA1. Proc Natl Acad Sci U S A $\underline{97}, 1020-1025$

Papadopoulos N, Nicolaides NC, Wei YF, Ruben SM, Carter KC, Rosen CA, Haseltine WA, Fleischmann RD, Fraser CM, Adams MD, et al. (1994): Mutation of a mutL homolog in hereditary colon cancer. Science $\underline{263}, 1625-1629$

Parker D, Ferreri K, Nakajima T, LaMorte VJ, Evans R, Koerber SC, Hoeger C, Montminy MR (1996): Phosphorylation of CREB at Ser-133 induces complex formation with CREB-binding protein via a direct mechanism. Mol Cell Biol 16, 694-703

Pez F, Lopez A, Kim M, Wands JR, Caron de Fromentel C, Merle P (2013): Wnt signaling and hepatocarcinogenesis: molecular targets for the development of innovative anticancer drugs. J Hepatol $\underline{59}$, 1107-1117 
Pox SA, S. Bischoff, U. Graeven, M. Hass, P. Heußner, W. Hohenberger,, A. Holstege JH, F. Kolligs, M. Kreis, P. Lux, J. Ockenga, R. Porschen, S. Post,, N. Rahner AR-S, J.F. Riemann, R. Sauer, A. Sieg, W. Scheppach,, W. Schmitt H-JS, K. Schulmann, A. Tannapfel, W. Schmiegel (2014): S3-Leitlinie Kolorektales Karzinom. Leitlinien der AWMF (Arbeitsgemeinschaft der Wissenschaftlichen Medizinischen Fachgesellschaften e.V.)

Ptashne M, Gann A (1997): Transcriptional activation by recruitment. Nature $\underline{386}, 569-577$

R Core Team: R: A Language and Environment for Statistical Computing. 3.1.2; hrsg. [http://www.R-project.org/ 2013

Ragvin A, Valvatne H, Erdal S, Arskog V, Tufteland KR, Breen K, AM OY, Eberharter A, Gibson TJ, Becker PB, et al. (2004): Nucleosome binding by the bromodomain and PHD finger of the transcriptional cofactor p300. J Mol Biol $\underline{337}, 773-788$

Robert-Koch-Institut: Krebs in Deutschland 2011/2012. hrsg. 2015

Robert-Koch-Institut: Epidemiologie von Krebserkrankungen - Bericht zum Krebsgeschehen in Deutschland 2016. hrsg. 2016

Robert C, Nagaria PK, Pawar N, Adewuyi A, Gojo I, Meyers DJ, Cole PA, Rassool FV (2016): Histone deacetylase inhibitors decrease NHEJ both by acetylation of repair factors and trapping of PARP1 at DNA double-strand breaks in chromatin. Leuk Res $\underline{45}, 14-23$

Ruthenburg AJ, Li H, Patel DJ, Allis CD (2007): Multivalent engagement of chromatin modifications by linked binding modules. Nat Rev Mol Cell Biol $\underline{8}, 983-994$

Samuels Y, Wang Z, Bardelli A, Silliman N, Ptak J, Szabo S, Yan H, Gazdar A, Powell SM, Riggins GJ, et al. (2004): High frequency of mutations of the PIK3CA gene in human cancers. Science $\underline{304}, 554$ 
Schiltz RL, Mizzen CA, Vassilev A, Cook RG, Allis CD, Nakatani Y (1999): Overlapping but distinct patterns of histone acetylation by the human coactivators p300 and PCAF within nucleosomal substrates. J Biol Chem 274, 1189-1192

Schulmann K, Schmiegel W: Kolorektales Karzinom. In: Ganten, D., Ruckpaul, K. Hahn, S., Schmiegel, W. (Hrsg.): Molekularmedizinische Grundlagen von nicht-hereditären Tumorerkrankungen. 1. Auflage. Auflage; Springer, Berlin Heidelberg 2002

Selvi BR, Cassel JC, Kundu TK, Boutillier AL (2010): Tuning acetylation levels with HAT activators: therapeutic strategy in neurodegenerative diseases. Biochim Biophys Acta $\underline{1799}$, $840-853$

Shi X, Hong T, Walter KL, Ewalt M, Michishita E, Hung T, Carney D, Pena P, Lan F, Kaadige MR, et al. (2006): ING2 PHD domain links histone H3 lysine 4 methylation to active gene repression. Nature $\underline{442}, 96-99$

Shiama N (1997): The p300/CBP family: integrating signals with transcription factors and chromatin. Trends Cell Biol Z, 230-236

Siomi H, Siomi MC (2009): On the road to reading the RNA-interference code. Nature $\underline{457}$, 396-404

So CW, Cleary ML (2002): MLL-AFX requires the transcriptional effector domains of AFX to transform myeloid progenitors and transdominantly interfere with forkhead protein function. Mol Cell Biol 22, 6542-6552

So CW, Cleary ML (2003): Common mechanism for oncogenic activation of MLL by forkhead family proteins. Blood 101, 633-639

Sterner DE, Berger SL (2000): Acetylation of histones and transcription-related factors. Microbiol Mol Biol Rev $\underline{64}$, 435-459 
Storch M: Expression des epidermalen Wachstumsfaktorrezeptors Her2/neu in Rektumkarzinomen des lokal fortgeschrittenen Stadiums UICC II / III - Validierung an Patienten der Phase-III-Studien der German Rectal Cancer Study Group. 2016

Teo JL, Kahn M (2010): The Wnt signaling pathway in cellular proliferation and differentiation: A tale of two coactivators. Adv Drug Deliv Rev $\underline{62}$, 1149-1155

Teufel DP, Freund SM, Bycroft M, Fersht AR (2007): Four domains of p300 each bind tightly to a sequence spanning both transactivation subdomains of p53. Proc Natl Acad Sci U S A $\underline{104}, 7009-7014$

Thibodeau SN, Bren G, Schaid D (1993): Microsatellite instability in cancer of the proximal colon. Science $\underline{260}, 816-819$

Thomas MC, Chiang CM (2006): The general transcription machinery and general cofactors. Crit Rev Biochem Mol Biol 41, 105-178

Vakoc CR, Mandat SA, Olenchock BA, Blobel GA (2005): Histone H3 lysine 9 methylation and HP1gamma are associated with transcription elongation through mammalian chromatin. Mol Cell 19, 381-391

Vaquero A, Scher MB, Lee DH, Sutton A, Cheng HL, Alt FW, Serrano L, Sternglanz R, Reinberg D (2006): SirT2 is a histone deacetylase with preference for histone H4 Lys 16 during mitosis. Genes Dev 20, 1256-1261

Vazquez A, Bond EE, Levine AJ, Bond GL (2008): The genetics of the p53 pathway, apoptosis and cancer therapy. Nat Rev Drug Discov $\underline{7}, 979-987$

Veigl ML, Kasturi L, Olechnowicz J, Ma AH, Lutterbaugh JD, Periyasamy S, Li GM, Drummond J, Modrich PL, Sedwick WD, et al. (1998): Biallelic inactivation of hMLH1 by epigenetic gene silencing, a novel mechanism causing human MSI cancers. Proc Natl Acad Sci U S A $\underline{95}, 8698$ 8702 
Vervoorts J, Luscher-Firzlaff JM, Rottmann S, Lilischkis R, Walsemann G, Dohmann K, Austen M, Luscher B (2003): Stimulation of c-MYC transcriptional activity and acetylation by recruitment of the cofactor CBP. EMBO Rep $\underline{4}, 484-490$

Wang F, Marshall CB, Ikura M (2013): Transcriptional/epigenetic regulator CBP/p300 in tumorigenesis: structural and functional versatility in target recognition. Cell Mol Life Sci $\underline{70}$, $3989-4008$

Wang F, Marshall CB, Yamamoto K, Li GY, Gasmi-Seabrook GM, Okada H, Mak TW, Ikura M (2012): Structures of KIX domain of CBP in complex with two FOXO3a transactivation domains reveal promiscuity and plasticity in coactivator recruitment. Proc Natl Acad Sci U S A $\underline{109}, 6078-6083$

Wang $H$, Zhai L, Xu J, Joo HY, Jackson S, Erdjument-Bromage $H$, Tempst $P$, Xiong $Y$, Zhang $Y$ (2006): Histone H3 and H4 ubiquitylation by the CUL4-DDB-ROC1 ubiquitin ligase facilitates cellular response to DNA damage. Mol Cell 22, 383-394

Wang L, Tang Y, Cole PA, Marmorstein R (2008): Structure and chemistry of the p300/CBP and Rtt109 histone acetyltransferases: implications for histone acetyltransferase evolution and function. Curr Opin Struct Biol 18, 741-747

Wittekind C, Meyer HJ: TNM-Klassifikation Maligner Tumoren. 7. Auflage. Auflage; WileyVCH, Weinheim 2010

Yamamoto H, Imai K, Perucho M (2002): Gastrointestinal cancer of the microsatellite mutator phenotype pathway. J Gastroenterol 37, 153-163

Zhang JJ, Vinkemeier U, Gu W, Chakravarti D, Horvath CM, Darnell JE, Jr. (1996): Two contact regions between Stat1 and CBP/p300 in interferon gamma signaling. Proc Natl Acad Sci U S A $\underline{93}, 15092-15096$ 
Zhao Y, Masiello D, McMillian M, Nguyen C, Wu Y, Melendez E, Smbatyan G, Kida A, He Y, Teo JL, et al. (2015): CBP/catenin antagonist safely eliminates drug-resistant leukemiainitiating cells. Oncogene 


\section{Anhang}

\subsection{Material}

\subsubsection{Verbrauchsmaterialien}

\begin{tabular}{|c|c|}
\hline $0,2 \mu \mathrm{m}$ Filter, Rotilabo R-Spritzenfilter & $\begin{array}{l}\text { Carl Roth GmbH \& Co. KG, Karlsruhe, } \\
\text { Deutschland }\end{array}$ \\
\hline $4-12 \%$ NuPAGE Bis-Tris Gele $1.0 \mathrm{~mm}$ & $\begin{array}{l}\text { Gibco }{ }^{\circledR} \text { by life technologies }{ }^{\mathrm{TM}} \text {, Carlsbad, } \\
\text { CA, USA }\end{array}$ \\
\hline Auslaufpipetten, serologisch & STARLAB GmbH, Hamburg, Deutschland \\
\hline Einfrierröhrchen & TPP, Trasadingen, Schweiz \\
\hline Einmalreagenzreservoirs, steril & $\begin{array}{l}\text { Carl Roth GmbH \& Co. KG, Karlsruhe, } \\
\text { Deutschland }\end{array}$ \\
\hline $\begin{array}{l}\text { Filterpapier, Chromatography Paper } \\
\text { 3MM Chr. }\end{array}$ & $\begin{array}{l}\text { Whatman }{ }^{\mathrm{TM}} \text { GE Healthcare UK Limited, } \\
\text { Amersham, United Kingdom }\end{array}$ \\
\hline Flüssigkeitsreservoirs, Rotilabo® PVC & $\begin{array}{l}\text { Carl Roth GmbH \& Co. KG, Karlsruhe, } \\
\text { Deutschland }\end{array}$ \\
\hline Glasobjektträger & $\begin{array}{l}\text { Engelbrecht, Medizin und Labortechnik } \\
\text { GmbH, Edermünde, Deutschland }\end{array}$ \\
\hline Mini Trans-Blot Filter Papier & $\begin{array}{l}\text { Bio-Rad Laboratories } \mathrm{GmbH} \text {, München, } \\
\text { Germany }\end{array}$ \\
\hline Pasteurpipetten, Glas & $\begin{array}{l}\text { Brand GmbH \& Co. KG, Wertheim, } \\
\text { Deutschland }\end{array}$ \\
\hline Petrischalen (P10, P15) & $\begin{array}{l}\text { Sarstedt AG \& } \\
\text { Deutschland }\end{array}$ \\
\hline $\begin{array}{l}\text { Pipettenspitze }(10 \mathrm{ml}) \text {, für Multipette }{ }^{\circledR} \\
\text { Stream }\end{array}$ & Eppendorf AG, Hamburg, Deutschland \\
\hline $\begin{array}{lll}\text { Pipettenspitzen, } & \text { Safe } & \text { Seal-Tips } \AA \\
\text { professional } & & \\
\end{array}$ & $\begin{array}{l}\text { Biozym Scientific GmbH, Hessisch } \\
\text { Oldendorf, Deutschland }\end{array}$ \\
\hline Pipettenspitzen, Tip One ${ }^{\circledR}$ & STARLAB GmbH, Hamburg, Deutschland \\
\hline Pipettenspitzen, Tip One $®$, steril & STARLAB GmbH, Hamburg, Deutschland \\
\hline Platten, 6-Well, Cyto One $®$, steril & STARLAB GmbH, Hamburg, Deutschland \\
\hline Platten, 96-Well, Cyto One ${ }^{\circledR}$, steril & STARLAB GmbH, Hamburg, Deutschland \\
\hline
\end{tabular}




\begin{tabular}{|c|c|}
\hline $\begin{array}{l}\text { Reagiergefäße Biosphere } \circledast \text { Safe Seal } \\
(1,5 \mathrm{ml})\end{array}$ & $\begin{array}{l}\text { Sarstedt AG \& } \\
\text { Deutschland }\end{array}$ \\
\hline Reaktionsgefäße (1,5 ml) & $\begin{array}{l}\text { Carl Roth GmbH \& Co. KG, Karlsruhe, } \\
\text { Deutschland }\end{array}$ \\
\hline Reaktionsgefäße (2 ml) & Eppendorf AG, Hamburg, Deutschland \\
\hline Röhrchen, Falcon Tube (15 und 50 ml) & $\begin{array}{l}\text { Sarstedt AG \& } \\
\text { Deutschland }\end{array}$ \\
\hline $\begin{array}{l}\text { Transfermembran, Immobilon } ®-P \\
\text { Membran, Polyvinylidenfluorid (PVDF), } \\
\text { Filterporengröße } 0,45 \mu \mathrm{m}\end{array}$ & Merck Millipore, Billerica, MA, USA \\
\hline Transferpipetten (3,5 ml) & $\begin{array}{l}\text { Sarstedt AG \& } \\
\text { Deutschland }\end{array}$ \\
\hline $\begin{array}{l}\text { Zellkulturflaschen Cyto One }{ }^{\circledR}(25,75 \\
\text { und } 225 \mathrm{~cm} 2)\end{array}$ & STARLAB GmbH, Hamburg Deutschland \\
\hline Zellschaber, $300 \mathrm{~mm}$ & TPP, Trasadingen, Schweiz \\
\hline Zellspachtel, $195 \mathrm{~mm}$ & TPP, Trasadingen, Schweiz \\
\hline
\end{tabular}

\subsubsection{Geräte}

\begin{tabular}{|l|l|}
\hline Autoklav, HST 32/25 & $\begin{array}{l}\text { Zirbus technology GmbH, Bad Grund/ } \\
\text { Harz, Deutschland }\end{array}$ \\
\hline $\begin{array}{l}\text { Bestrahlungsgerät, Xstrahl RS225 X- } \\
\text { Ray irradiator }\end{array}$ & $\begin{array}{l}\text { Gulmay Medical Itd., Camberley (Surray), } \\
\text { United Kingdom }\end{array}$ \\
\hline $\begin{array}{l}\text { Charge-coupled device (CCD) Kamera, } \\
\text { ImageQuant LAS 4000 mini }\end{array}$ & $\begin{array}{l}\text { GE Healthcare Life Sciences, Uppsala, } \\
\text { Schweden }\end{array}$ \\
\hline $\begin{array}{l}\text { Freezing Container, 5100 Cryo } 1{ }^{\circ} \mathrm{C}, \\
\text { „Mr. Frosty" }\end{array}$ & $\begin{array}{l}\text { Thermo Fisher Scientific Inc., Waltham, } \\
\text { MA, USA }\end{array}$ \\
\hline $\begin{array}{l}\text { Gelelektrophoresekammer, Minigel- } \\
\text { Twin }\end{array}$ & Biometra GmbH, Göttingen, Deutschland \\
\hline $\begin{array}{l}\text { Glasplatte, ausgeschnitten, für Minigele } \\
\text { Glasplatte, fixe Spacer, 1,0 mm, für } \\
\text { Minigele }\end{array}$ & Biometra GmbH, Göttingen, Deutschland \\
\hline Heißluftsterilisator, Heraeus ST6060 & Thermo Fisher Scientific Inc., Waltham, \\
MA, USA
\end{tabular}




\begin{tabular}{|c|c|}
\hline Inkubator CO2, Incubator C200 & Labotect GmbH, Göttingen, Deutschland \\
\hline $\begin{array}{l}\text { Inkubator, Water-Jacketed Incubator } \\
3250\end{array}$ & Forma Scientific Inc., Marietta, OH, USA \\
\hline $\begin{array}{lccc}\text { Kämme } & (10-\text { und 16-zähnig), für } \\
\text { Minigele } & & & \end{array}$ & Biometra GmbH, Göttingen, Deutschland \\
\hline Magnetrührer & $\begin{array}{l}\text { IKA®-Werke GmbH \& Co. KG, Staufen, } \\
\text { Deutschland }\end{array}$ \\
\hline Membranpumpe, Miniport & $\begin{array}{lll}\text { KNF Neuberger } & \mathrm{GmbH}, & \text { Freiburg, } \\
\text { Deutschland } & & \end{array}$ \\
\hline Mikroskop, invers, Leica DM IL & Leica AG, Wetzlar, Deutschland \\
\hline Mikroskop, Leica S6 E & Leica AG, Wetzlar, Deutschland \\
\hline $\begin{array}{l}\text { Mikroskopkamera, High-speed Leica } \\
\text { EC3 }\end{array}$ & Leica AG, Wetzlar, Deutschland \\
\hline Mini Trans-Blot-Cell & $\begin{array}{l}\text { Bio-Rad Laboratories } \mathrm{GmbH} \text {, München, } \\
\text { Germany }\end{array}$ \\
\hline Multilabel Plate Reader, Victor ${ }^{\mathrm{TM}} \mathrm{X} 4$ & PerkinEImer, Waltham, MA, USA \\
\hline Netzgerät, PowerPac 3000 & $\begin{array}{l}\text { Bio-Rad Laboratories } \mathrm{GmbH} \text {, München, } \\
\text { Germany }\end{array}$ \\
\hline Netzgerät, Standard Power Pack P25 & Biometra GmbH, Göttingen, Deutschland \\
\hline pH-Meter, PB-11 & Sartorius AG, Göttingen, Deutschland \\
\hline $\begin{array}{l}\text { Pipette, elektrisch, 8-Kanal Research } \\
\text { pro 50-1200 } \mu \mathrm{l}\end{array}$ & Eppendorf AG, Hamburg, Deutschland \\
\hline Pipette, Multipette $®$ Stream & Eppendorf AG, Hamburg, Deutschland \\
\hline Pipetten, Eppendorf Reference & Eppendorf AG, Hamburg, Deutschland \\
\hline Pipettierhelfer, accu-jet $\circledast$ & $\begin{array}{l}\text { Brand } \mathrm{GmbH} \& \text { Co. KG, Wertheim, } \\
\text { Deutschland }\end{array}$ \\
\hline Präzisionswaage, BP 610 & Sartorius AG, Göttingen, Deutschland \\
\hline Präzisionswaage, ED224S & Sartorius AG, Göttingen, Deutschland \\
\hline Schlittenmikrotom, Microm HM 430 & $\begin{array}{l}\text { MICROM International, Walldorf, } \\
\text { Deutschland }\end{array}$ \\
\hline Schüttler, MS 3 digital & $\begin{array}{l}\text { IKA®-Werke GmbH \& Co. KG, Staufen, } \\
\text { Deutschland }\end{array}$ \\
\hline Silikonabdichtung, 1,0 mm, für Minigel & Biometra GmbH, Göttingen, Deutschland \\
\hline
\end{tabular}




\begin{tabular}{|c|c|}
\hline Spektrophotometer NanoDrop 1000 & $\begin{array}{l}\text { Thermo Fisher Scientific Inc., Waltham, } \\
\text { MA, USA }\end{array}$ \\
\hline $\begin{array}{l}\text { Sterilbank, SterilGARD Hood Class II } \\
\text { Typ A/B3 }\end{array}$ & The Baker Company, Sanford, ME, USA \\
\hline Thermomixer comfort & Eppendorf AG, Hamburg, Deutschland \\
\hline $\begin{array}{l}\text { Transfektionsgerät, Nucleofector }{ }^{\mathrm{TM}} 2 \mathrm{~b} \\
\text { Device }\end{array}$ & Lonza Cologne GmbH, Köln, Deutschland \\
\hline $\begin{array}{l}\text { Ultraschallhomogenisator SONOPULS } \\
\text { HD } 3100\end{array}$ & BANDELIN electronic $\mathrm{GmbH} \&$ Co. KG \\
\hline Vortexer, IKA® MS1 Shaker & $\begin{array}{l}\text { IKA®-Werke GmbH \& Co. KG, Staufen, } \\
\text { Deutschland }\end{array}$ \\
\hline Wasserbad, GFL 1003 & $\begin{array}{l}\text { Gesellschaft für Labortechnik } \mathrm{mbH} \text {, } \\
\text { Burgwedel, Deutschland }\end{array}$ \\
\hline $\begin{array}{l}\text { Water Purification System, Milli-Q } \\
\text { Reference Ultrapure }\end{array}$ & Merck Millipore, Billerica, MA, USA \\
\hline Wippschüttler, WS42 & $\begin{array}{l}\text { A. Hartenstein Gesellschaft für Labor- und } \\
\text { Medizintechnik mbH, Würzburg/ Versbach, } \\
\text { Deutschland }\end{array}$ \\
\hline Zählkammer, Neubauer improved & $\begin{array}{l}\text { Brand GmbH \& Co. KG, Wertheim, } \\
\text { Deutschland }\end{array}$ \\
\hline Zentrifuge, Heraeus Fresco 17 & $\begin{array}{l}\text { Thermo Fisher Scientific Inc., Waltham, } \\
\text { MA, USA }\end{array}$ \\
\hline Zentrifuge, Heraeus Labofuge $400 \mathrm{R}$ & $\begin{array}{l}\text { Thermo Fisher Scientific Inc., Waltham, } \\
\text { MA, USA }\end{array}$ \\
\hline Zentrifuge, Mini, Rotilabo® & $\begin{array}{l}\text { Carl Roth GmbH \& Co. KG, Karlsruhe, } \\
\text { Deutschland }\end{array}$ \\
\hline
\end{tabular}

\subsubsection{Chemikalien}

\begin{tabular}{|l|l|}
\hline 1,4-Dithio-DL-threit(ol) (DTT) & $\begin{array}{l}\text { AppliChem GmbH, Darmstadt, } \\
\text { Deutschland }\end{array}$ \\
\hline 2-Propanol & Merck KGaA, Darmstadt, Deutschland \\
\hline Bovines Serumalbumin (BSA) & AppliChem GmbH, Darmstadt, \\
\hline
\end{tabular}




\begin{tabular}{|c|c|}
\hline & Deutschland \\
\hline Brilliant Blau R250 Tabletten & Merck KGaA, Darmstadt, Deutschland \\
\hline Bromphenolblau-Lösung & $\begin{array}{lll}\text { AppliChem } & \mathrm{GmbH}, & \text { Darmstadt, } \\
\text { Deutschland } & & \end{array}$ \\
\hline Essigsäure $100 \% \mathrm{Ph}$. Eur., reinst & $\begin{array}{l}\text { Carl Roth GmbH \& Co. KG, Karlsruhe, } \\
\text { Deutschland }\end{array}$ \\
\hline Ethanol, ROTIPURAN $囚 \geq 99,8 \%$ & $\begin{array}{l}\text { Carl Roth GmbH \& Co. KG, Karlsruhe, } \\
\text { Deutschland }\end{array}$ \\
\hline $\begin{array}{l}\text { Ethylendiamintetraessigsäure (EDTA), } \\
0,5 \mathrm{M}, \mathrm{pH}=8,0\end{array}$ & $\begin{array}{l}\text { Quality Biological Inc., Gaithersburg, MD, } \\
\text { USA }\end{array}$ \\
\hline Glyzin & Sigma-Aldrich, St. Louis, MO, USA \\
\hline Hämalaun, Mayers & Merck KGaA, Darmstadt, Deutschland \\
\hline Hexadimethrine bromide (Polybrene) & Sigma-Aldrich, St. Louis, MO, USA \\
\hline Kaliumchlorid & Merck KGaA, Darmstadt, Deutschland \\
\hline $\begin{array}{l}\text { Luminata }^{\mathrm{TM}} \text { Forte, Western horse } \\
\text { raddish peroxidase }(\mathrm{HRP}) \text { Substrate }\end{array}$ & Merck Millipore, Billerica, MA, USA \\
\hline $\begin{array}{l}\text { Marker, Magic MarkTM XP Western } \\
\text { Standard }\end{array}$ & Invitrogen, Darmstadt, Deutschland \\
\hline $\begin{array}{l}\text { Marker, Spectra }{ }^{\mathrm{TM}} \text { Multicolour Broad } \\
\text { Range Protein Ladder }\end{array}$ & $\begin{array}{llll}\text { Fermentas } & \mathrm{GmbH}, & \text { St. Leon-Rot, } \\
\text { Deutschland } & & & \end{array}$ \\
\hline Methanol, ROTIPURAN $₫ \geq 99,9 \%$ & $\begin{array}{l}\text { Carl Roth GmbH \& Co. KG, Karlsruhe, } \\
\text { Deutschland }\end{array}$ \\
\hline $\begin{array}{l}\text { Milchpulver Blotting grade, pulver, } \\
\text { fettarm }\end{array}$ & $\begin{array}{l}\text { Carl Roth GmbH \& Co. KG, Karlsruhe, } \\
\text { Deutschland }\end{array}$ \\
\hline Natriumchlorid $(\mathrm{NaCl}) \geq 99,5 \%$ & $\begin{array}{l}\text { Carl Roth GmbH \& Co. KG, Karlsruhe, } \\
\text { Deutschland }\end{array}$ \\
\hline $\begin{array}{l}\text { Natriumdodecylsulfat (SDS)-Lösung } 10 \\
\% \text { für die Molekularbiologie }\end{array}$ & $\begin{array}{lll}\text { AppliChem } & \mathrm{GmbH}, & \text { Darmstadt, } \\
\text { Deutschland } & & \\
\end{array}$ \\
\hline Natriumhydroxid $(\mathrm{NaOH})$ Plätzchen & Merck KGaA, Darmstadt, Deutschland \\
\hline Nonidet $₫$ P40 (NP40) & $\begin{array}{l}\text { AppliChem } \quad \mathrm{GmbH} \text {, } \\
\text { Deutschland }\end{array}$ \\
\hline $\begin{array}{l}\text { Phosphatase-Inhibitor } \\
\text { Tabletten, PhosSTOP }\end{array}$ & $\begin{array}{l}\text { Roche Diagnostics } \mathrm{GmbH} \text {, Mannheim, } \\
\text { Deutschland }\end{array}$ \\
\hline
\end{tabular}




\begin{tabular}{|l|l|}
\hline $\begin{array}{l}\text { Protease-Inhibitor Cocktail, Protease } \\
\text { Block }^{\mathrm{TM}}\end{array}$ & $\begin{array}{l}\text { Fermentas GmbH, St. Leon-Rot, } \\
\text { Deutschland }\end{array}$ \\
\hline Roti® - Quant 5x Konzentrat & $\begin{array}{l}\text { Carl Roth GmbH \& Co. KG, Karlsruhe, } \\
\text { Deutschland }\end{array}$ \\
\hline Salzsäure $(\mathrm{HCl}) 5 \mathrm{M}$ & Merck KGaA, Darmstadt, Deutschland \\
\hline Tris ultrapure & $\begin{array}{l}\text { AppliChem Gor GmbH, Darmstadt, } \\
\text { Deutschland }\end{array}$ \\
\hline Tween ${ }^{2} 20$ & Sigma-Aldrich, St. Louis, MO, USA \\
\hline
\end{tabular}

\subsubsection{Puffer und Lösungen}

\begin{tabular}{|l|l|l|}
\hline PBS (Phosphat buffered saline) (10x) & $\mathrm{NaCl}$ & $80 \mathrm{~g}$ \\
\hline & $\mathrm{KCl}$ & $2 \mathrm{~g}$ \\
\hline & $\mathrm{Na}_{2} \mathrm{HPO}_{4}$ & $14,2 \mathrm{~g}$ \\
\hline & $\mathrm{Na}_{2} \mathrm{HPO}_{4} \cdot 2 \mathrm{H}_{2} \mathrm{O}$ & $17,8 \mathrm{~g}$ \\
\hline & $\mathrm{KH}_{2} \mathrm{PO}_{4}$ & $2,7 \mathrm{~g}$ \\
\hline & $\mathrm{H}_{2} \mathrm{O}$ & Ad $1000 \mathrm{ml}$ \\
\hline WB-Transferpuffer (10x) & & \\
\hline & Glycin & $29,3 \mathrm{~g}$ \\
\hline & Tris base & $58,1 \mathrm{~g}$ \\
\hline & SDS & $3,7 \mathrm{~g}$ \\
\hline & $\mathrm{H} O$ & Ad $1000 \mathrm{ml}$ \\
\hline
\end{tabular}

\subsubsection{Zellkultur und Bakterienkultur}

\begin{tabular}{|l|l|}
\hline $0,25 \%$ Trypsin -EDTA (1x) & $\begin{array}{l}\text { Gibco } \\
\text { CA, USA by life technologies }\end{array}$ \\
\hline Bad Stabil Konzentrat & $\begin{array}{l}\text { neoLab Migge Laborbedarf-Vertriebs } \\
\text { GmbH, Heidelberg, Deutschland }\end{array}$ \\
\hline Dimethylsulfoxid (DMSO) & Sigma-Aldrich, St. Louis, MO, USA \\
\hline Fetal Bovines Serum (FBS) & Biochrom AG, Berlin, Deutschland \\
\hline $\begin{array}{l}\text { L-Glutamine 200 mM in 0,85\% NaCl } \\
\text { Solution }\end{array}$ & $\begin{array}{l}\text { Boehringer Ingelheim GmbH \& Co.KG, } \\
\text { Ingelheim, Deutschland }\end{array}$ \\
\hline Nährmedium, (1:1) Dulbecco's Modified & Gibco $\circledast$ by life technologies ${ }^{\mathrm{TM}}$, Carlsbad, \\
\hline
\end{tabular}




\begin{tabular}{|c|c|}
\hline $\begin{array}{l}\text { Eagle Medium: F-12 Nutrient Mixture } \\
\text { (Ham) (DMEM/F-12) }\end{array}$ & CA, USA \\
\hline $\begin{array}{l}\text { Nährmedium, Dulbecco's } \text { Modified } \\
\text { Eagle Medium (DMEM) }\end{array}$ & $\begin{array}{l}\text { Gibco } \AA \text { by life technologies }{ }^{\mathrm{TM}} \text {, Carlsbad, } \\
\text { CA, USA }\end{array}$ \\
\hline Nährmedium, Leibovitz's L-15 Medium & $\begin{array}{l}\text { Gibco } \AA \text { by life technologies }{ }^{\mathrm{TM}} \text {, Carlsbad, } \\
\text { CA, USA }\end{array}$ \\
\hline Nährmedium, McCoy's 5A & $\begin{array}{l}\text { Gibco } \AA \text { by life technologies }{ }^{\mathrm{T}} \text {, Carlsbad, } \\
\text { CA, USA }\end{array}$ \\
\hline Nährmedium, RPMI-1640 Medium & $\begin{array}{l}\text { Gibco } \AA \text { by life technologies }{ }^{\mathrm{TM}} \text {, Carlsbad, } \\
\text { CA, USA }\end{array}$ \\
\hline Opti-MEM Reduced Serum Medium & $\begin{array}{l}\text { Gibco } \AA \text { by life technologies }{ }^{\mathrm{TM}} \text {, Carlsbad, } \\
\text { CA, USA }\end{array}$ \\
\hline $\begin{array}{l}\text { Phosphate Buffered Saline (PBS), } \mathrm{pH} \\
7,2\end{array}$ & $\begin{array}{l}\text { Gibco } \AA \text { by life technologies }{ }^{\mathrm{TM}} \text {, Carlsbad, } \\
\text { CA, USA }\end{array}$ \\
\hline Puromycin-Dihydrochlorid & life technologies ${ }^{\mathrm{TM}}$, Carlsbad, CA, USA \\
\hline TransIT®-293 Transfection Reagent & Mirus Bio LLC, Madison, WI, USA \\
\hline Trypan Blue Solution 0,4 \% & Sigma-Aldrich, St. Louis, MO, USA \\
\hline Trypsin-EDTA 0.05\% & $\begin{array}{l}\text { Gibco } \AA \text { by life technologies }{ }^{\mathrm{T} M} \text {, Carlsbad, } \\
\text { CA, USA }\end{array}$ \\
\hline
\end{tabular}

\subsubsection{Zelllinien}

\begin{tabular}{|l|l|l|}
\hline HEK-293T & Embryonale Nierenzellen & $\begin{array}{l}\text { American Type Culture Collection } \\
\text { (ATCC) Manassas, VA, USA }\end{array}$ \\
\hline HT29 & Adenokarzinom des Colons & $\begin{array}{l}\text { American Type Culture Collection } \\
\text { (ATCC) Manassas, VA, USA }\end{array}$ \\
\hline PC-3 & Adenokarzinom der Prostata & $\begin{array}{l}\text { American Type Culture Collection } \\
\text { (ATCC) Manassas, VA, USA }\end{array}$ \\
\hline SW680 & Adenokarzinom des Colons & $\begin{array}{l}\text { American Type Culture Collection } \\
\text { (ATCC) Manassas, VA, USA }\end{array}$ \\
\hline SW837 & $\begin{array}{l}\text { Aymphknotenmetastase eines } \\
\text { Colorektalen Karzinoms }\end{array}$ & $\begin{array}{l}\text { American Type Culture Collection } \\
\text { (ATCC) Manassas, VA, USA }\end{array}$ \\
\hline
\end{tabular}




\subsubsection{Kits}

\begin{tabular}{|l|l|}
\hline Fast Red Kit & $\begin{array}{l}\text { Ventana Medical Systems, Inc., } \\
\text { Tucson, AZ, USA }\end{array}$ \\
\hline Lonza Amaxa Cell line Nucleofector Kit V & $\begin{array}{l}\text { Lonza Cologne GmbH, Köln, } \\
\text { Deutschland }\end{array}$ \\
\hline QIAGEN DNeasy Blood and Tissue Kit & Qiagen N.V., Hilden, Deutschland \\
\hline
\end{tabular}

\subsubsection{Vektoren}

\begin{tabular}{|c|c|}
\hline Helper Vector pHDM-Hg-PM2 & $\begin{array}{l}\text { Yang Shi Lab, Harvard University, } \\
\text { Boston, USA }\end{array}$ \\
\hline Helper Vector pHDM-tat1b & $\begin{array}{l}\text { Yang Shi Lab, Harvard University, } \\
\text { Boston, USA }\end{array}$ \\
\hline Helper Vector pHDM-VSVG & $\begin{array}{l}\text { Yang Shi Lab, Harvard University, } \\
\text { Boston, USA }\end{array}$ \\
\hline Helper Vector pRC-CMV-Rall & $\begin{array}{l}\text { Yang Shi Lab, Harvard University, } \\
\text { Boston, USA }\end{array}$ \\
\hline $\begin{array}{llll}\text { TRC Lentiviral pLKO.1 Empty Vector } \\
\text { Control }\end{array}$ & $\begin{array}{l}\text { Whatman }^{\mathrm{TM}} \text { GE Healthcare } \text { UK } \\
\text { Limited, Amersham, UK }\end{array}$ \\
\hline
\end{tabular}

\subsection{9 shRNAis}

\begin{tabular}{|c|c|}
\hline $\begin{array}{l}\text { TRC Human PAG1 shRNA antiCBP \#69- } \\
\text { Clone ID: TRCN0000123269 }\end{array}$ & $\begin{array}{l}\text { Whatman }^{\mathrm{TM}} \text { GE Healthcare UK } \\
\text { Limited, Amersham, UK }\end{array}$ \\
\hline $\begin{array}{l}\text { TRC Human PAG1 shRNA antiCBP \#70 - } \\
\text { Clone ID: TRCN0000123270 }\end{array}$ & $\begin{array}{l}\text { Whatman }^{\mathrm{TM}} \text { GE Healthcare } \text { UK } \\
\text { Limited, Amersham, UK }\end{array}$ \\
\hline $\begin{array}{l}\text { TRC Human PAG1 shRNA antiCBP \#71 - } \\
\text { Clone ID: TRCN0000123271 }\end{array}$ & $\begin{array}{l}\text { Whatman }^{\mathrm{TM}} \text { GE Healthcare UK } \\
\text { Limited, Amersham, UK }\end{array}$ \\
\hline $\begin{array}{l}\text { TRC Human PAG1 shRNA antiCBP \#72 - } \\
\text { Clone ID: TRCN0000123272 }\end{array}$ & $\begin{array}{l}\text { Whatman }^{\mathrm{TM}} \text { GE Healthcare } \mathrm{UK} \\
\text { Limited, Amersham, UK }\end{array}$ \\
\hline $\begin{array}{l}\text { TRC Human PAG1 shRNA antiCBP \#73- } \\
\text { Clone ID: TRCN0000123273 }\end{array}$ & $\begin{array}{l}\text { Whatman }^{\mathrm{TM}} \text { GE Healthcare } \text { UK } \\
\text { Limited, Amersham, UK }\end{array}$ \\
\hline TRC Lentiviral eGFP shRNA positive control & $\begin{array}{l}\text { Whatman }{ }^{\mathrm{TM}} \text { GE Healthcare } \\
\text { Limited, Amersham, UK }\end{array}$ \\
\hline
\end{tabular}




\subsubsection{0 siRNAs}

\begin{tabular}{|l|l|}
\hline siAllStarsNEG & Qiagen N.V., Hilden, Deutschland \\
\hline Hs_CREBBP_2 FlexiTube siRNA (\#2) & Qiagen N.V., Hilden, Deutschland \\
\hline Hs_CREBBP_6 FlexiTube siRNA (\#6) & Qiagen N.V., Hilden, Deutschland \\
\hline Hs_CREBBP_7 FlexiTube siRNA (\#7) & Qiagen N.V., Hilden, Deutschland \\
\hline Hs_CREBBP_8 FlexiTube siRNA (\#8) & Qiagen N.V., Hilden, Deutschland \\
\hline
\end{tabular}

\subsubsection{Antikörper}

\begin{tabular}{|c|c|c|c|}
\hline Antikörper & Ursprung & $\begin{array}{l}\text { Katalog- } \\
\text { nummer }\end{array}$ & Hersteller \\
\hline $\begin{array}{l}\text { Polyclonal Antibody to } \\
\text { Mouse lgG (H\&L) - HRP }\end{array}$ & Kaninchen & R1253HRP & $\begin{array}{l}\text { Acris Antibodies } \mathrm{GmbH} \text {, } \\
\text { Herford, Deutschland }\end{array}$ \\
\hline $\begin{array}{l}\text { Polyclonal Antibody to } \\
\text { Rabbit lgG (H\&L) - HRP }\end{array}$ & Ziege & R1364HRP & $\begin{array}{l}\text { Acris Antibodies } \mathrm{GmbH} \text {, } \\
\text { Herford, Deutschland }\end{array}$ \\
\hline Anti-CBP (WB) & Kaninchen & ab2832 & $\begin{array}{l}\text { Abcam, Cambridge, MA, } \\
\text { USA }\end{array}$ \\
\hline Anti-CBP (IHC) & Kaninchen & $\mathrm{IHC}-00023$ & $\begin{array}{l}\text { Bethyl Laboratories Inc., } \\
\text { TX, } 77356\end{array}$ \\
\hline Anti-active-ß-Catenin & Maus & $05-665$ & $\begin{array}{l}\text { Merck Millipore, Billerica, } \\
\text { MA, USA }\end{array}$ \\
\hline $\begin{array}{l}\text { Anti- } \beta \text {-Catenin (Carboxy- } \\
\text { Terminal Antigen) }\end{array}$ & Kaninchen & \#9587 & $\begin{array}{l}\text { Cell Signaling Technology, } \\
\text { Inc., Danvers, MA, USA }\end{array}$ \\
\hline Anti-c-Myc & Kaninchen & \#5605S & $\begin{array}{l}\text { Cell Signaling Technology, } \\
\text { Inc., Danvers, MA, USA }\end{array}$ \\
\hline Anti-c-jun & Kaninchen & $\# 9165$ & $\begin{array}{l}\text { Cell Signaling Technology, } \\
\text { Inc., Danvers, MA, USA }\end{array}$ \\
\hline Anti-p21 & Maus & \#OP64 & $\begin{array}{l}\text { Merck Millipore, Billerica, } \\
\text { MA, USA }\end{array}$ \\
\hline Anti-p53 & HRP-Konj. & SC126HRP & $\begin{array}{l}\text { Santa Cruz Biotechnology, } \\
\text { Inc., Dallas, Texas, USA }\end{array}$ \\
\hline Anti-H3 & Kaninchen & ab1791 & Abcam, Cambridge, USA \\
\hline
\end{tabular}




\subsubsection{Programme}

\begin{tabular}{|l|l|}
\hline Adobe Acrobat XI Pro & Adobe, San Jose, CA, USA \\
\hline EndNote X7 & Thomson Reuters, New York, NY, USA \\
\hline KaleidaGraph V.4.1.0 & Synergy Software, Reading, PA, USA \\
\hline Microsoft Office 2016 & Microsoft Corporation, Redmond, WA, USA \\
\hline Program R V. 3.1.2 & R Foundation, Wien, Österreich \\
\hline
\end{tabular}

